\title{
Vita \& Froet: the development and evaluation of two interventions to promote fruit and vegetable intake among primary school children
}

Citation for published version (APA):

Reinaerts, E. B. M. (2008). Vita \& Froet: the development and evaluation of two interventions to promote fruit and vegetable intake among primary school children. [Doctoral Thesis, Maastricht University]. Maastricht University. https://doi.org/10.26481/dis.20080411er

Document status and date:

Published: 01/01/2008

DOI:

10.26481/dis.20080411er

Document Version:

Publisher's PDF, also known as Version of record

Please check the document version of this publication:

- A submitted manuscript is the version of the article upon submission and before peer-review. There can be important differences between the submitted version and the official published version of record.

People interested in the research are advised to contact the author for the final version of the publication, or visit the DOI to the publisher's website.

- The final author version and the galley proof are versions of the publication after peer review.

- The final published version features the final layout of the paper including the volume, issue and page numbers.

Link to publication

\footnotetext{
General rights rights.

- You may freely distribute the URL identifying the publication in the public portal. please follow below link for the End User Agreement:

www.umlib.nl/taverne-license

Take down policy

If you believe that this document breaches copyright please contact us at:

repository@maastrichtuniversity.nl

providing details and we will investigate your claim.
}

Copyright and moral rights for the publications made accessible in the public portal are retained by the authors and/or other copyright owners and it is a condition of accessing publications that users recognise and abide by the legal requirements associated with these

- Users may download and print one copy of any publication from the public portal for the purpose of private study or research.

- You may not further distribute the material or use it for any profit-making activity or commercial gain

If the publication is distributed under the terms of Article $25 \mathrm{fa}$ of the Dutch Copyright Act, indicated by the "Taverne" license above, 


\section{Vita \& Froet}

The development and evaluation of two interventions to promote fruit and vegetable intake among primary school children 



\title{
Vita \& Froet
}

\section{The development and evaluation of two interventions to promote fruit and vegetable intake among primary school children}

\author{
PROEFSCHRIFT \\ ter verkrijging van de graad van doctor aan de Universiteit Maastricht, \\ op gezag van de Rector Magnificus, Prof. mr. G.P.M.F. Mols, \\ volgens het besluit van het College van Decanen, \\ in het openbaar te verdedigen op vrijdag II april 2008 \\ om 16.00 uur \\ door
}

EVELINE B. M. REINAERTS

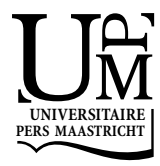




\section{Promotor}

Prof. dr. N.K. de Vries

\section{Copromotor}

Dr. J. de Nooijer

\section{Beoordelinscommissie}

Prof. dr. H. de Vries (voorzitter)

Prof. dr. L.K. Bartholomew (University of Texas, United States of America)

Prof. dr. ir. J. Brug (EMGO instituut VU Medisch Centrum)

Dr. ir. P.C. Dagnelie

Dr. R. Meertens

Printed by Datawyse / Universitaire Pers Maastricht

Cover design by Vivian Heijckers and Evelien Reinaerts

Copyright Evelien Reinaerts, Landgraaf 2008

ISBN 9789052787060

The study presented in this thesis was conducted at the Nutrition and Toxicology Research Institute Maastricht (NUTRIM), which participates in the Graduate School VLAG (Food Technology, Agrobiotechnology, Nutrition and Health Sciences) accredited by the Royal Netherlands Academy of Arts and Sciences.

The study was initiated by the department of Health Education \& Promotion (Universiteit Maastricht) in close collaboration with the Local Health Authority Noord \& Midden Limburg (GGD NML) and was funded by the Dutch Organisation for Health Research and Development (ZonMw): projectnumber 4010.0014. 


\section{Content}

General introduction

PART I: Development of Interventions I I

Chapter I The systematic development of two school-based interventions $\quad 13$

$\begin{array}{lll}\text { Chapter } 2 & \text { aimed at increasing children's fruit \& vegetable intake } \\ \text { Development of a school-based intervention to promote fruit \& } & 33\end{array}$ vegetable consumption: Exploring perceptions among 4-to- 12 year old children and their parents

Chapter 3 Explaining school children's fruit \& vegetable consumption: the contributions of availability, accessibility, exposure, parental consumption and habit in addition to psychosocial factors

Chapter 4 Parental versus child reporting of fruit \& vegetable consumption

PART 2: Impact and Process evaluation

Chapter 5 Increasing children's fruit \& vegetable consumption: distribution 91

Chapter 6 Increasing fruit \& vegetable intake among children: comparing long-term effects of a free distribution and a multi-component program

Chapter 7 Fruit \& vegetable distribution program versus a multi component program to increase F\&V consumption: which should be recommended for implementation?

General discussion

References

Summary \& Samenvatting 183

Dankwoord, Curriculum Vitae \& Publication list | 

"The spirit is there in everyone;

it has to be discovered and brought to the light."

Lord Baden Powell 



\section{General Introduction}




\section{Introduction}

It is well documented that consuming sufficient amounts of fruit and vegetables (F\&V) prevents the development of several chronic diseases (WHO, 2003). Nevertheless, most Dutch adults and children consume insufficient amounts of F\&V (Hollander, Hoeymans, Melse, van Oers, \& Polder, 2006). In 1998, Dutch children's average daily intake for vegetables was only 70 grams and, for fruit, children's intake was less than one serving a day (the equivalent of 80-100 grams) (Anonymous, 1998). Additionally, a recent study ranked Dutch II year olds children among the lowest consumers of F\&V when compared to other European children (Yngve et al., 2005).

Clearly, steps must be taken to increase the F\&V intake of Dutch children, especially since there is increasing evidence that the adoption of a healthy lifestyle in childhood is associated with health and well-being in adulthood (Licence, 2004; WHO, 2003). Research into dietary practices, such as F\&V consumption, has shown that the food habits of adults are acquired during childhood (Kelder, Perry, Klepp, \& Lytle, 1994; Lien, Lytle, \& Klepp, 200I). At the same time, children are more open to changes in their dietary patterns and food preferences (Birch, 1990) than adults, whose food habits are often firmly entrenched (Krebs-Smith et al., 1995).

Several initiatives have been undertaken to increase primary school children's F\&V intake (Burchett, 2003; French \& Stables, 2003; Knai, Pomerleau, Lock, \& McKee, 2006; Pomerleau, Lock, Knai, \& McKee, 2005). And more recently, several interventions that included a paid or free distribution of F\&V at primary schools were developed (Bere, Veierød, \& Klepp, 2005; Eriksen, Haraldsdóttir, Pederson, \& Flyer, 2003; Tak, te Velde, \& Brug, 2007; Wells \& Nelson, 2005; Wind, Te Velde et al., 2006). Most of these initiatives were combined with other interventions, such as curriculum activities. As a result, most initiatives were multi-component, classroom-based programs that focused on motivating children and parents to increase children's F\&V intake. The majority of these interventions resulted in limited to moderate short term effects. Long term effects are seldom reported.

This dissertation presents research findings on the F\&V intake of Dutch children and seeks to evaluate two interventions that aimed to promote this healthy behaviour. $A$ multi-component intervention and a daily F\&V distribution were compared to a 
control group receiving no intervention. The design of the study is represented in figure I. The studies described in this dissertation were initiated and conducted by the Universiteit Maastricht in close collaboration with the Local Health Authority Noord and Midden Limburg (GGD NML). The interventions were developed by the Department of Health Education and Promotion (HEP) at the Universiteit Maastricht also in close cooperation with the GGD NML. The GGD NML was primarily responsible for the implementation of the interventions, while the Department of HEP was primarily responsible for the studies described in this dissertation.

This chapter provides a short review of studies related to European children's F\&V consumption. This is followed by a description of the interventions that were developed and implemented and then reported in this dissertation. Lastly, an outline of the dissertation is provided.

\section{Recent programs promoting F\&V consumption in European countries}

Throughout Europe, several studies involving the promotion of F\&V consumption among children were initiated at the same time as our studies.

The National School Fruit Scheme (NSFS) was implemented in England in 2002. It provided children aged four to six with one free fruit serving daily. The effects of the intervention were tested in a pilot study among a sample of eight intervention and nine control schools. The study was cross-sectional and the consumption of children (four to six years old) taking part in the fruit scheme was compared to the consumption of children from schools not taking part in the scheme. The children who received free fruit ate about 50 grams more fruit per day than those who did not receive the fruit. Subsequently children of the elementary school (aged seven to ten years) who had received free fruit in pre-school and kindergarten were compared to children of the same age from non-participating schools. It became apparent that the fruit consumption did not differ between those who did and did not take part in the NSFS (Wells \& Nelson, 2005) and it appeared that no longer-term effects were established. 


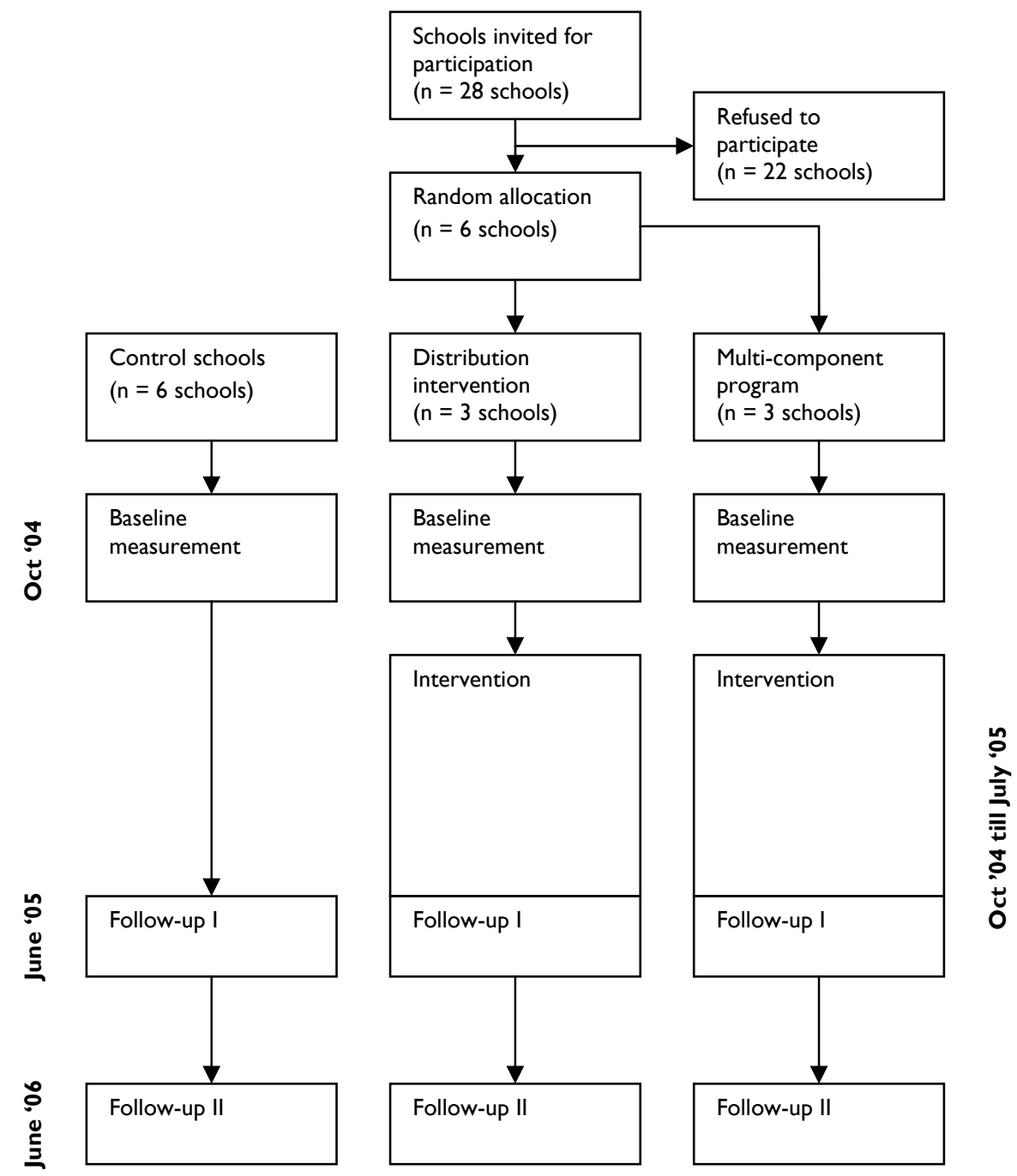

Figure I The design of the study

A fully subsidised F\&V distribution intervention in Denmark provided children aged six to ten years with one piece of F\&V per day. Four schools received F\&V and three schools served as controls. After five weeks, the intervention resulted in an increased fruit intake of 0.4 pieces during school hours for those children who had received free F\&V. Surprisingly non-subscribers also increased their consumption by 0.3 pieces. In 
spite of this apparent improvement, the subscribers did not increase their total daily F\&V intake, while the non-subscribers' total daily intake increased with 0.4 pieces per school day. This indicates that the subscribing children compensated for their school F\&V consumption by decreasing their consumption during the rest of the day (Eriksen et al., 2003).

A similar distribution program was implemented in Norwegian elementary schools and its effectiveness among 7th grade pupils was evaluated. This intervention consisted of three research conditions, namely a free F\&V subscription implemented in nine schools, a paid subscription implemented in nine other schools, and 20 schools that served as controls without fruit distribution. The results showed that the subscription programme resulted in variations between the free fruit group, the paid fruit group and the control group with respect to the participants' F\&V intake during the school day. After one year, the free fruit subscribers realised a net effect of 0.9 portions during school hours, while those that participated in the paid subscription realised a net effect of 0.2 portions. Additionally, improvements in the daily F\&V intake were found only in the free fruit group. This group increased its daily intake by 1.0 portion (net effect) (Bere et al., 2005). After three years, the researchers found a sustained effect in the free subscription group. The estimated long-term effects were 0.38 portions per day for boys and 0.44 for girls. Unfortunately, the free subscription programme ended after one year. Only very few children signed up for the paid scheme. Those children who subscribed to the pay for fruit programme continued to receive fruit at school after the end of the free programme. Although this partially mediated the long-term effects, the free subscription remained effective after correction for paid subscription (Bere, Veierød, Skare, \& Klepp, 2007).

Initiatives have also been undertaken in Dutch primary schools. The purpose of the Pro Children Study, a research project funded by the European Union that involves nine European countries including the Netherlands, was to develop effective strategies to promote adequate F\&V consumption levels among II tol 3 year old children. The project combined a free distribution of F\&V (twice a week) with other components such as curriculum activities and parental initiatives (Brug, Yngve, \& Klepp, 2005). Using a sample drawn from Norway, Spain and the Netherlands, researchers found that the intervention was effective in increasing children's F\&V intake and fruit 
consumption on the day prior to measurement (Wind, Te Velde et al., 2006). Programme effectiveness was also established one year after the completion of the curriculum and parental activities. Additionally, at this second follow-up, children reported eating fruit 0.24 times more often per day and the frequency of vegetable consumption was increased by $4.6 \%$ (Wind, Te Velde et al., 2006). However, the children were still receiving free F\&V twice weekly when the follow up studies were undertaken.

The national campaign 'Fruitables at School' ('SchoolGruiten') began in January 2003. This was an initiative of the Dutch Ministry of Health, Welfare and Sport (VWS), the Dutch Horticulture Marketing Board (Productschap Tuinbouw), the Netherlands Nutrition Centre (Voedingscentrum) and the Dutch Produce Promotion Group (AGF Promotie Nederland). The 'Fruitables at school' campaign sought to change children's attitudes towards F\&V and attempted to get children to perceive F\&V as tasty, healthy and 'cool'. In doing this, the programme endeavoured to make the healthy snack an accepted part of children's daily school routine. In total, nearly 75,000 pupils in seven cities received a serving of F\&V twice a week. Teaching materials were also made available in an effort to support the campaign (Voedingscentrum [Netherlands Nutrition Centre], 2004). Prior to initiating the national campaign, a pilot study was conducted among 4th grade students and their parents. About 50 schools participated and the results demonstrated a significant effect on the fruit intake of children of Dutch ethnicity (the difference between intervention and control group was 0.23 pieces per day at follow-up), and on the vegetable intake of children of non-Western ethnicity (a difference of 20.7 grams per day). However, the effects were only found in the analyses of the child-reported data and could not be replicated using data gathered from their parents (Tak et al., 2007).

In sum, numerous reports have demonstrated the potential of school-based interventions including F\&V distribution. However, the long term effectiveness of most initiatives remains unclear.

The interventions presented in this dissertation differ from initiatives mentioned above. Firstly, the interventions we developed attempted to make F\&V consumption habitual. Two different strategies were used to achieve this goal. The first strategy 
aimed to create a habit unintentionally through the frequent and consistent repetition of the same behaviour under the same circumstances (Bargh \& Chartrand, 1999). This strategy was operationalized as a F\&V distribution program in which children consumed a free portion of F\&V at the same time every day in the classroom. Only one of the other studies report on the effects of a daily distribution programme, despite the fact that the theory of habit formation stresses the importance of frequent and consistent repetition. The second strategy applied aimed to intentionally create a habit by encouraging respondents to purposefully engage in the desired behaviour, both frequently and consistently (Bargh \& Chartrand, 1999). A multi-component program that consisted of a curriculum and parental involvement was therefore developed. In this strategy, parents and children were motivated to bring F\&V to school every day (frequently and consistently) and, similarly to the distribution program, a special time was set aside for the children to eat the F\&V together in the classroom.

This study also differed from the initiatives mentioned earlier in that our interventions used a whole-school approach. The interventions were developed and tested for all grades of primary school. This was in contrast to most other interventions that focused on one particular grade or age group.

\section{Planning Health Promoting Interventions}

Two different approaches can be used when developing interventions to tackle health problems. In the 'reductionist' approach, the level of priority of a health problem is identified, while in the 'expansionist' approach, the health problem has already been chosen (Green \& Kreuter, 1999). In the present dissertation, the latter approach was taken. We identified the insufficient consumption of F\&V as the health behaviour under study. The purpose of this dissertation was to make a contribution to the systematic, evidence-based and theory-driven development, implementation and evaluation of interventions that aim to improve children's F\&V intake using a school-based approach. 
The Intervention Mapping (IM') protocol (Bartholomew, Parcel, \& Kok, 1998; Bartholomew et al., 200I) provides health education and promotion planners with a framework for effective decision making at each step in the process of intervention planning, implementation and evaluation. Its usefulness in the development of dietary interventions for children has been previously demonstrated (Pérez-Rodrigo et al., 2005; Weber Cullen, Bartholomew, Parcel, \& Kok, 1998). Therefore, it was used as the planning model in this research project. IM puts forth specific steps that can guide the problem-driven development, application and integration of theories that explain behaviour and theories that explain behavioural change (Bartholomew et al., 200I).

Prior to the first step of IM, program planners should conduct an extensive needs assessment, preferably in accordance with the PRECEDE/PROCEED model (Green \& Kreuter, 1999). The needs assessment provides insight into the target population's health and quality of life, as well as insight into the behavioural and environmental risk factors for the development of health problems. Additionally, determinants that underlie these risk behaviours are identified using several methods (Kok, Schaalma, Ruiter, \& van Empelen, 2004). For example, a theoretical framework can be created, previous research on determinants can be reviewed and/or new data can be collected.

Although IM is presented as a series of steps, the planning process is iterative rather than linear. Each step is based on previous steps, program planners must move back and forth between tasks and steps (Bartholomew et al., 200I). The development of our interventions also necessitated this moving back and forth in the mapping process. During the first step of IM, we discovered that the majority of determinant studies had been conducted in countries outside Europe and had focused on older children (aged 10-12 years) or adolescents (Rasmussen et al., 2006). To compensate for the lack of relevant literature, we were required to expand our needs assessment. Therefore, two additional determinant studies were conducted among Dutch children aged 4 to 12 and their parents.

\footnotetext{
I Although, recently a new edition of the IM protocol was published (Bartholomew, Parcel, Kok, \& Gottlieb, 2006), we based our development on the first edition (Bartholomew, Parcel, Kok, \& Gottlieb, 200I). The most important difference with the first edition is that in the second one the needs assessment is part of the IM protocol, instead of a separate step preceding the mapping process.
} 


\section{Theoretical framework}

An ecological perspective was used in the development of the interventions. According to this perspective, behaviour is influenced by intrapersonal (i.e. food preferences), social (i.e. family eating habits), and cultural factors (i.e. culture is often expressed through food), as well as factors in the physical environment (i.e. availability). Not only do these factors determine behaviour directly, they also interact. The ecological perspective therefore describes multiple levels of social, cultural and physical environment variables as relevant for understanding behaviour (Sallis \& Owen, 1997). From this perspective, children's $F \& V$ consumption can be explained by factors related to the family (micro level), school policy (meso level) or Dutch legislation and administrative measures (macro level). We assume that health promotion efforts may be more effective when efforts are coordinated across these levels of influence and, therefore, the ecological perspective was chosen as the main theoretical framework (see Chapter I).

However, it is also highly recommended that researchers maintain a broad and comprehensive theoretical scope when studying health behaviours (i.e. Rasmussen et al., 2006). By integrating concepts from multiple theoretical frameworks, the predictive power of the model can be increased (Achterberg \& Miller, 2004; Baranowski, Cullen Weber, \& Baranowski, 1999) and interventions can be tailored to the most important concepts related to these behaviours (Baranowski et al., 1999; Brug \& Oenema, 2005). Therefore, we used concepts from other theoretical models, such as the Theory of Planned Behaviour (Ajzen, 1991), Social Cognitive Theory (Bandura, 1986), the Elaboration Likelihood Model (Petty \& Cacioppo, 1986) and the Health Belief Model (Rosenstock, 1974)), to accommodate the intra- and interpersonal factors posited in the ecological perspective.

\section{Outline of the dissertation}

The first part of this dissertation describes the development of the interventions. The first chapter describes the needs assessment and the development, implementation and evaluation of the interventions according to the IM protocol. The development of the interventions was based on literature, theory and the results of two determinant studies. The results of the first determinant study, namely a qualitative study on the 
perceptions of Dutch children and their parents, are presented in Chapter 2. Chapter 3 presents the results of a quantitative cross-sectional survey among parents of 4 to 12 year old children and focuses on the determinants of F\&V consumption. Chapter 4 deals with issues related to the measurement of F\&V consumption using either reporting by the children themselves or reporting by parents whereby parents act as a proxy. The results of a study comparing parental and child perceptions of children's F\&V intake and family-related factors are also described in this chapter.

The second part of this dissertation focuses on the impact and process evaluation of the implementation of two programs, namely; (a) the free F\&V distribution program; and (b) the multi-component program, in which classroom curriculum and parental involvement were the main components. In Chapter 5, the short-term effects of the intervention are presented, while the long term effects that were measured one year after the termination of the interventions are described in Chapter 6. The process evaluation is described in Chapter 7. This chapter therefore deals with the extent to which teachers implemented the programs as originally planned, the teachers' subjective evaluation of the programs and also their intention to adopt the programs in the future.

The dissertation concludes with a summary and an integration of the main findings, as well as a discussion of the methodological issues and implications for future research and practice. 
Part I

\section{Development of Interventions}

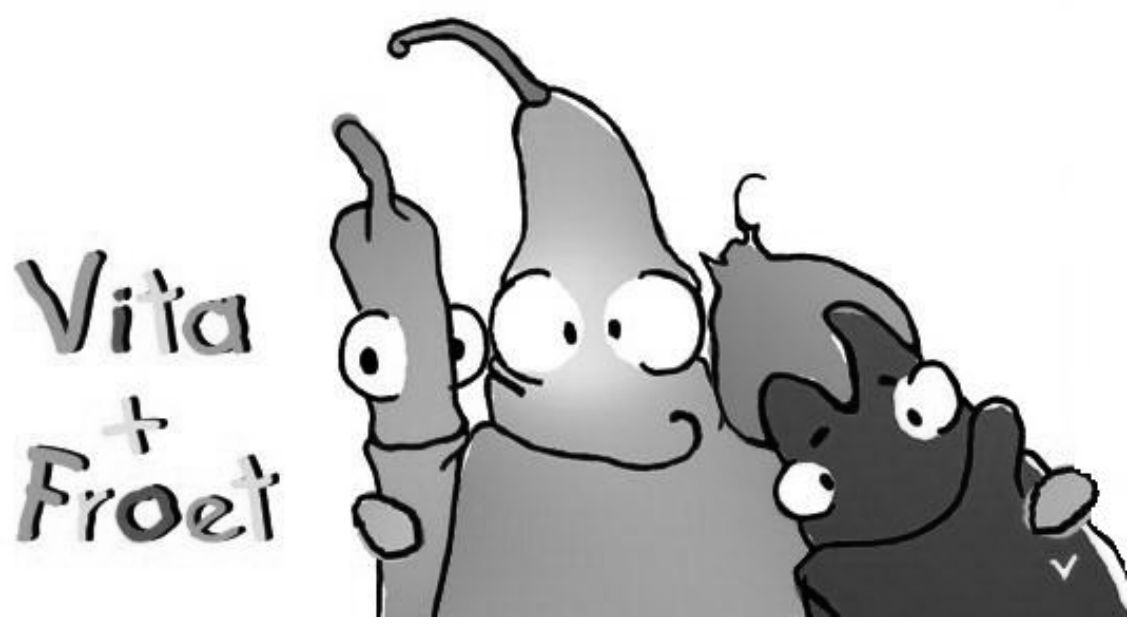




\section{Chapter I}

\section{The systematic development of two school-based interventions aimed at increasing children's fruit \& vegetable intake}




\section{ABSTRACT}

Purpose: The aim of the current study was to make the use of the Intervention Mapping (IM) protocol more transparent for health educators working in the field of health education and promotion by providing an extensive description of the development, implementation and evaluation of two interventions to increase the fruit and vegetable (F\&V) consumption of primary school children.

Design: This chapter describes how information drawn from relevant literature and theory, as well as additional data collected from the target group, were applied to the development, implementation and evaluation of the interventions. The IM protocol consists of five steps: (I) defining proximal program objectives; (2) applying methods and strategies for behavioural change; (3) creating a program plan; (4) preparing program implementation; and (5) evaluation. An extensive assessment of the perceived health problem was conducted prior to beginning step I of IM.

Findings: Application of the protocol resulted in two school-based interventions aimed at making F\&V consumption habitual: (I) a free F\&V distribution program; and (2) a multi-component, age-specific program consisting of a classroom curriculum and parental involvement.

Value: By providing a detailed description of the application of the IM, it was shown that the protocol can be used as a practical aid for the development of planned health promotion interventions. It proved to be an effective means for making wellconsidered choices in every step of program development and implementation. Furthermore, the matrices presented in the article can provide health educators with a foundation for the development of future dietary interventions for children. 


\section{Introduction}

Although it is well documented that consuming sufficient amounts of fruit and vegetables (F\&V) prevents disease (WHO, 2003), Dutch children consume, on average, only 70 grams of vegetables and less than one portion of fruit daily (Anonymous, 1998). This is significantly less than the recommended daily allowance of I50 grams of vegetables and two portions of fruit. Moreover, a recent survey of nine European countries showed that Dutch children rank among the lowest consumers of F\&V (Yngve et al., 2005). Clearly, effective interventions are needed. These interventions must target young children because dietary habits are formed during childhood (Kelder et al., 1994; Lien et al., 200I) and because children tend to be more open to changing their food patterns than adults (Birch, 1990), whose limited consumption of F\&V has often become habitual (Krebs-Smith et al., 1995).

The success of health promotion interventions is directly related to the quality of their development (Green \& Kreuter, 1999). Unfortunately, this process is rarely described in detail. As a result, program developers are forced to repeat the same process over and over again.

This chapter describes the systematic development of two school-based interventions to increase children's F\&V intake. Intervention Mapping (IM) (Bartholomew et al., 200I; Bartholomew et al., 2006) was the method chosen to develop the interventions because this approach had been successfully applied to the development of dietary interventions for children previously (Pérez-Rodrigo et al., 2005; Weber Cullen et al., 1998).

\section{Intervention Mapping}

The IM protocol can be considered a strategy to help program planners make balanced decisions during program development, implementation and evaluation. IM provides a systematic approach that is derived from knowledge about the behavioural determinants of specific behaviours. This knowledge subsequently informs intervention methods and strategies. The first version of IM developed by Bartholomew et al. in $200 \mathrm{I}$ was used to develop the interventions in this study. This version consists of five steps, each requiring the completion of specific processes (see figure I). Recently, a second version of IM was published by Bartholomew et al (2006). This recent version 
is similar to the previous one in content, but consists of six steps rather than five. The additional step is a needs assessment (NA), which, in the earlier version, preceded the first step of IM. In the second version, the NA is considered the first step. The remaining chapter will describe the planning process in accordance with the first version of IM.

IM is a cumulative process because, as each step is accomplished, it forms the foundation for the next step in the process. This eventually leads to the development of an intervention that is based on empirical data. IM is an iterative rather than a linear process, because new information may require a reassessment and adaptation of previous steps. Information from theoretical findings in addition to empirical evidence collected from the target group is used throughout the process.

IM offers an ecological perspective to health promotion interventions. According to this perspective, behaviour is influenced by intrapersonal (i.e. food preferences), social (i.e. family eating habits) and cultural factors (i.e. culture is often expressed through food), as well as factors in the physical environment (i.e. availability). The ecological perspective therefore generates multiple levels of social, cultural, and environmental variables for understanding behaviour (Sallis \& Owen, 1997). The IM protocol posits that for each selected ecological level, different objectives need to be determined. These objectives express not only the changes that must be made at each ecological level, but also the actor that must make the changes (Bartholomew et al., 200I).

Children are especially influenced by factors from ecological levels that include the family and school (Rasmussen et al., 2006). We believe that health promotion efforts may be more effective when efforts are coordinated to operate across these levels of influence. This further supports the selection of the IM protocol as the planning model. 


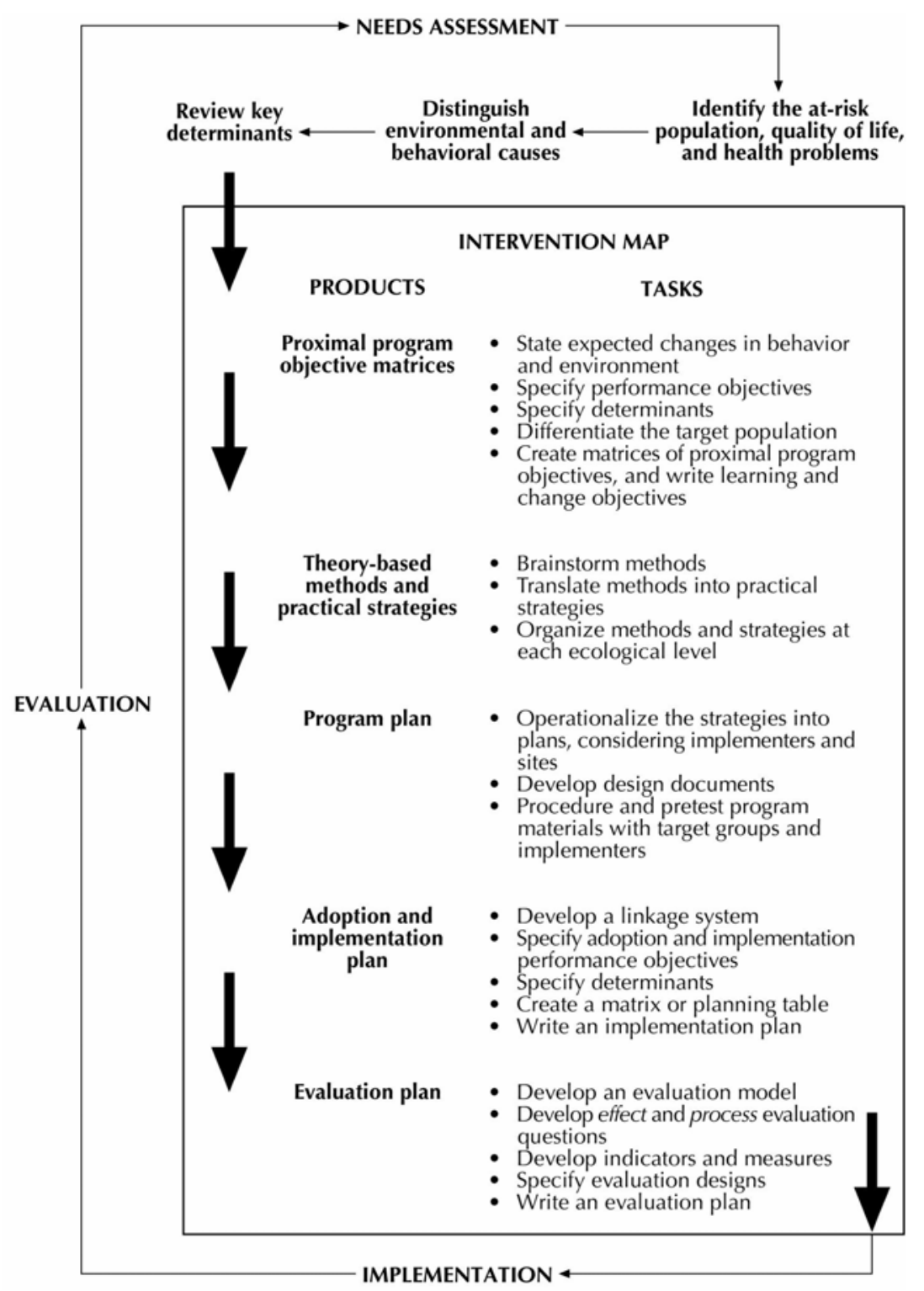

Figure I The Intervention mapping protocol (Bartholomew et al., 200I)

\section{Needs Assessment}

Prior to initiating in the IM protocol, an extensive Needs Assessment (NA) has to be conducted, preferably according to the PRECEDE/PROCEED model (Green \& Kreuter, 1999). A NA focuses on identifying and evaluating the potential health 
problems that may influence the target population's quality of life (QoL). Health problems that pose the greatest threat to QoL are normally prioritised. The behaviours and environmental conditions related to the prioritised threats are then assessed. This process is referred to as a 'reductionist' approach.

Another method of addressing health problems is the 'expansionist' approach. In the expansionist approach, the health problem has already been identified and its relationship with QoL has already been assessed (Green \& Kreuter, 1999). In the study reported here, the latter approach was used. F\&V consumption in children was identified as the health problem. Therefore, the main task in the NA was the identification of associated determinants for the population at risk, namely children.

During the NA, initial attempts were made to understand the target population, its members, its defining characteristics and its strengths (Bartholomew et al., 200I). To do this, an extensive study of the relevant literature was conducted. We sought out both the determinants of F\&V consumption and theories that could explain F\&V consumption in children. Furthermore, group interviews with primary schoolchildren and their parents were performed. The literature revealed that the Theory of Planned Behaviour (TPB) (Ajzen, 199I) and the Social Cognitive Theory (SCT) (Bandura, 1986) were the theories most commonly used to explain F\&V consumption. These theories were often complemented by social-ecological models (Sallis \& Owen, 1997). The most important determinants of F\&V consumption appeared to be individual taste preferences, the availability and accessibility of $F \& V$, and parental consumption (Blanchette \& Brug, 2005; Rasmussen et al., 2006). However, these factors only explained approximately $30 \%$ of the variance in F\&V consumption (Baranowski et al., 1999). This is probably due to the habitual nature of most eating behaviours (Ouelette \& Wood, 1998; Verplanken \& Faes, 1999), which tends to limit the importance of psychosocial factors. This was demonstrated in a recent study by Brug and colleagues (2006) where habit was included as a determinant of F\&V consumption alongside psychosocial factors. In this study, habit was identified as the most influential determinant of fruit consumption, which clearly illustrated the limited influence of the other psychosocial factors (Brug, de Vet, de Nooijer, \& Verplanken, 2006). Most eating behaviours do possess some characteristics of habitual behaviour in that they are frequently executed and repeated over time (Aarts, Paulussen, \& 
Schaalma, 1997; Verplanken \& Aarts, 1999; Verplanken \& Faes, 1999). When a habit is well established, conscious decision making processes no longer determine behaviour (Ouelette \& Wood, 1998). Consequently, psychosocial factors become less significant. Although a history of repetition is an important feature of habit (Verplanken \& Orbell, 2003), not all frequently repeated behaviour can be considered a habit. A major feature of habit is that it is a form of automaticity, which means that it is deliberate in its behavioural origin, controllable to a limited extent, executed without awareness, and efficient (Bargh, 1994). The second major feature of habit is that it is a reflection of someone's personal style. This, however, may not hold for all habits, but it is characteristic of some (Verplanken \& Orbell, 2003).

Since few studies on the determinants of F\&V consumption among children younger than ten years of age could be found, additional group interviews were conducted. Ten group interviews with children $(n=104)$, two interviews with parents $(n=28)$, and ten telephone interviews were conducted $(n=10)$ (see Chapter 2). In sum, the results of all these interviews showed that children preferred eating fruit over vegetables, but that they did not have a set time (i.e. upon returning from school) to do so. Parents indicated that motivating children to eat vegetables was frustrating. Additionally, while most parents had some rules about the amount of vegetables children had to eat during dinner, these rules often did not have the intended effect. Furthermore, parents said that they encouraged their children to eat fruit. However, the children did not report receiving encouragement nor did they report consuming fruit together with their parents. Most children were not familiar with the daily recommendations for F\&V consumption and also did not differentiate between fruit juice and soda. Some of the children reported bringing fruit to school. However, many did not eat the fruit brought to school consistently because it did not look appetizing, or because they did not want to spend time eating their fruit. Finally, many parents reported that they would not be willing to participate in school activities to promote F\&V intake. Tables I and 2 present an overview of the determinants that became apparent during the needs assessment. 
Table I Selected personal determinants of F\&V consumption in children

\begin{tabular}{|c|c|c|c|c|}
\hline $\begin{array}{l}\text { Personal } \\
\text { determinants }\end{array}$ & Literature & Interviews & Important ${ }^{a}$ & Changeable ${ }^{a}$ \\
\hline $\begin{array}{l}\text { Awareness of } \\
\text { low F\&V intake }\end{array}$ & & $x$ & ++ & $+/-$ \\
\hline Knowledge & $\begin{array}{c}\text { (Reynolds, Hinton, Shewchuk, \& Hickey, 1999; } \\
\text { van Zadellhoff \& Snel, 2003) }\end{array}$ & $x$ & + & ++ \\
\hline Attitude & (Resnicow et al., 1997; Reynolds et al., 1999) & $x$ & + & + \\
\hline $\begin{array}{l}\text { Taste } \\
\text { preferences }\end{array}$ & $\begin{array}{l}\text { (Baranowski et al., 1993; Birch, 1990, I999; } \\
\text { Domel Baxter \& Thompson, 2002; Domel Baxter } \\
\text { et al., I996; Gibson, Wardle, \& Watts, I998; } \\
\text { Resnicow et al., I997; van Assema, Brug, \& } \\
\text { Lechner, 200I) }\end{array}$ & $x$ & +++ & ++ \\
\hline $\begin{array}{l}\text { Self efficacy \& } \\
\text { skills }\end{array}$ & $\begin{array}{c}\text { (Domel Baxter et al., 1996; Resnicow et al., } \\
\text { 1997; Reynolds et al., 1999; van Zadellhoff \& } \\
\text { Snel, 2003) }\end{array}$ & $x$ & + & $+/-$ \\
\hline Habit & (Brug et al., 2006; Krebs-Smith et al., 1995) & & +++ & $+/-$ \\
\hline $\begin{array}{l}\text { Barrier } \\
\text { (forgetting) }\end{array}$ & $\begin{array}{c}\text { (van Zadellhoff \& Snel, 2003; Wind, Bobelijn, De } \\
\text { Bourdeaudhuij, Klepp, \& Brug, 2005) }\end{array}$ & $x$ & ++ & ++ \\
\hline
\end{tabular}

Table 2 External determinants of F\&V consumption in children

\begin{tabular}{|c|c|c|c|c|}
\hline $\begin{array}{l}\text { External } \\
\text { determinants }\end{array}$ & Literature & Interviews & Important $^{a}$ & Changeable ${ }^{a}$ \\
\hline Social support & $\begin{array}{l}\text { (Birch, I980; Gibson et al., I998; Hendy, 2002; } \\
\text { Hendy \& Raudenbush, 2000; Kratt, Reynolds, \& } \\
\text { Shewchuk, 2000; Reynolds et al., I999; Weber } \\
\text { Cullen et al., 200I; Weber Cullen, Baranowski, } \\
\text { Rittenberry, \& Olvera, 2000) }\end{array}$ & $x$ & & \\
\hline $\begin{array}{l}\text { - at school } \\
\text { (teachers, peers) }\end{array}$ & & & ++ & ++ \\
\hline $\begin{array}{l}\text { - at home } \\
\text { (parents) }\end{array}$ & & & +++ & $+/-$ \\
\hline $\begin{array}{l}\text { Parental F\&V } \\
\text { consumption }\end{array}$ & $\begin{array}{c}\text { (Gibson et al., 1998; Kratt et al., 2000; Reynolds } \\
\text { et al., I999; Weber Cullen et al., 200I; Weber } \\
\text { Cullen et al., 2000) }\end{array}$ & & +++ & + \\
\hline $\begin{array}{l}\text { Availability } \\
\& \text { accessibility }\end{array}$ & $\begin{array}{l}\text { (Baranowski et al., I993; Edmonds, Baranowski, } \\
\text { Baranowski, Cullen, \& Myres, 200 I; Hinton, } \\
\text { I998; Kratt et al., 2000; Reynolds et al., I999; } \\
\text { van Assema et al., 200I; van Zadellhoff \& Snel, } \\
\text { 2003; Weber Cullen et al., 200I; Weber Cullen } \\
\text { et al., 2000; Wind et al., 2005) }\end{array}$ & $x$ & & \\
\hline - at school & & & +++ & ++ \\
\hline - at home & & & +++ & + \\
\hline
\end{tabular}




\section{Step I Defining Proximal Program Objectives}

The first step of IM serves as the foundation for the intervention and determines who and what will change as a result of the intervention. The result of this first step is a set of matrices of selected ecological levels (i.e. children, parents, school) that combine performance objectives (POs) with selected determinants resulting in Proximal Program Objectives (PPOs). The PPOs are statements of what must change at each ecological level and who must make this change. PPOs are much more specific than traditional program goals (Bartholomew et al., 200I).

\section{Performance Objectives}

After an NA, the expected program outcome(s) are broken down into performance objectives (POs), which describe exactly who and what will change as a result of the intervention. The current study had two expected program outcomes, namely: (I) that children, aged 4 to 12 years, increase their daily F\&V consumption; and (2) the creation of environments (at home and at school) that facilitate children's F\&V intake. Because these expected program outcomes were not specific enough to serve as a starting point for intervention development, they were translated into POs (table 3). POs answer the questions: (a) what does the target group have to do in order to realise the health promoting behaviour?; (b) what must change in the environment as a result of the intervention?; and (c) who has to make these changes?

\section{Selection of Determinants}

Following the formulation of program objectives, internal and external determinants were selected by evaluating the determinants from the NA on their importance and changeability. Taste preferences, habit, forgetting to eat F\&V, social support at school, availability and accessibility at home and school were selected as the most important and changeable determinants. As a result, a decision was then made to place emphasis on these determinants (see Tables I and 2 for references). 
Table 3 General program outcomes specified into Performance Objectives

\begin{tabular}{|c|c|}
\hline $\begin{array}{l}\text { Children, aged } 4 \text { to } 12 \text { year, increase their } \\
\text { daily fruit consumption }\end{array}$ & $\begin{array}{l}\text { Creation of a home environment that } \\
\text { facilitates children's F\&V intake }\end{array}$ \\
\hline $\begin{array}{l}\text { I. Children bring a fruit (or vegetable) snack to } \\
\text { school daily } \\
\text { 2. Children increase their consumption of fruit at } \\
\text { school } \\
\text { 3. Children choose fruit if they feel hungry } \\
\text { 4. Children prepare their own fruit or mobilise } \\
\text { help for preparing fruit }\end{array}$ & $\begin{array}{l}\text { I. Parents provide their children with F\&V to bring to } \\
\text { school } \\
\text { 2. Parents encourage their children in eating F\&V } \\
\text { 3. Parents make F\&V available to their children } \\
\text { 4. Parents function as a role model for their children } \\
\text { 5. Parents make F\&V easily accessible (ready-to-eat) } \\
\text { for their children }\end{array}$ \\
\hline $\begin{array}{l}\text { Children, aged } 4 \text { to } 12 \text { year, increase their } \\
\text { daily vegetable consumption }\end{array}$ & $\begin{array}{l}\text { Creation of a school environment that } \\
\text { facilitates children's F\&V intake }\end{array}$ \\
\hline $\begin{array}{l}\text { I. Children bring a vegetable snack to school daily } \\
\text { 2. Children increase their consumption of } \\
\text { vegetables at school } \\
\text { 3. Children choose vegetables if they feel hungry } \\
\text { 4. Children prepare their own vegetable snack or } \\
\text { mobilise help for preparing vegetables } \\
\text { 6. Children consume at least I } 50 \text { grams of } \\
\text { vegetables at dinner each day }\end{array}$ & $\begin{array}{l}\text { I. The school facilitates the consumption of F\&V } \\
\text { 2. Teachers function as role models for the children } \\
\text { 3. Teachers encourage children in eating F\&V }\end{array}$ \\
\hline
\end{tabular}

\section{Matrix of Proximal Program Objectives}

At this point in the IM process, a matrix is created by combining performance objectives for each level with the personal and external determinants to produce Proximal Program Objectives (PPOs; see Table 4a). Then, the Learning Objectives (LOs) and Change Objectives (COs) are formulated. LOs, describe what the target group has to learn in order to attain the objective, while COs describe what has to be changed in the environment (see Table 4b). If a determinant is not necessary to reach a $\mathrm{PO}$, this specific cell remains empty.

Since parents and teachers were identified as important ecological levels regarding children's F\&V consumption, separate matrices were created for these groups' ${ }^{2}$. An example of a Learning Objective for parents was 'Parents know the recommended daily allowance for children's F\&V consumption.' A Learning Objective for schools was 'Teachers are aware of the effects of modelling on the F\&V consumption of their pupils.'

2 Matrices are not shown, but are available from the author upon request. 
Table 4a Matrix of Proximal Program Objectives (children)

\begin{tabular}{|c|c|c|c|c|c|c|}
\hline \multirow{2}{*}{$\begin{array}{l}\text { PERFORMANCE } \\
\text { OBJECTIVES }\end{array}$} & \multicolumn{3}{|c|}{ Personal determinants } & \multicolumn{3}{|c|}{ External determinants } \\
\hline & Barrier & Preferences & Habit & $\begin{array}{l}\text { Social } \\
\text { support }\end{array}$ & Availability & Accessibility \\
\hline $\begin{array}{l}\text { I. Children bring a } \\
\text { F\&V snack to school } \\
\text { daily }\end{array}$ & LOla & LO2a & LO3a & COla & $\mathrm{CO} 2 \mathrm{a}$ & $\mathrm{CO} a$ \\
\hline $\begin{array}{l}\text { 2. Children increase } \\
\text { their consumption } \\
\text { of } F \& V \text { at school }\end{array}$ & LOIb & LO2b & LO3b & $\mathrm{cOlb}$ & $\mathrm{CO} 2 \mathrm{~b}$ & $\mathrm{CO} b \mathrm{~b}$ \\
\hline $\begin{array}{l}\text { 3. Children choose } \\
\text { F\&V if they feel } \\
\text { hungry }\end{array}$ & LOIc & LO2c & LO3c & $\mathrm{COlc}$ & $\mathrm{CO} 2 \mathrm{c}$ & $\mathrm{CO} 3 \mathrm{c}$ \\
\hline $\begin{array}{l}\text { 4. Children prepare } \\
\text { their own F\&V } \\
\text { snack or mobilise } \\
\text { help for preparing } \\
\text { F\&V }\end{array}$ & LOId & LO2d & LO3d & cold & $\mathrm{CO} 2 \mathrm{~d}$ & $\cos d$ \\
\hline $\begin{array}{l}\text { 6. Children } \\
\text { consume at least } \\
150 \text { grams of } V \text { at } \\
\text { dinner each day }\end{array}$ & LOle & LO2e & LO3e & COle & $\mathrm{CO} 2 \mathrm{e}$ & $\mathrm{CO} e$ \\
\hline
\end{tabular}

Table 4b Proximal Program Objectives specified per determinant (children)

\begin{tabular}{|c|c|c|}
\hline \multirow[t]{2}{*}{ Barrier } & LOla & Children remind their parents daily to bring F\&V to school \\
\hline & LOIb & Children remember to eat their F\&V at school \\
\hline \multirow[t]{3}{*}{ Preferences } & $\mathrm{LO} 2 \mathrm{~b}$ & $\begin{array}{l}\text { Children expand their preferences for F\&V and therefore report an increased } \\
\text { liking for F\&V }\end{array}$ \\
\hline & LO2c & Children report an increased liking for F\&V as a snack \\
\hline & LO2e & Children report liking certain vegetables consumed at dinner more \\
\hline \multirow[t]{3}{*}{ Habit } & LO3a & Children bring F\&V to school without thinking about it (automatically) \\
\hline & LO3b & Children consume F\&V daily during the morning break at school \\
\hline & LO3c & Children choose F\&V automatically when the feel like snacking \\
\hline \multirow[t]{8}{*}{ Social support } & COla & $\begin{array}{l}\text { Children are encouraged by parents, teachers and peers to bring F\&V to school } \\
\text { Children report that teachers and peers are bringing F\&V to school }\end{array}$ \\
\hline & COIb & $\begin{array}{l}\text { Children are encouraged by parents, teachers and peers to consume F\&V at } \\
\text { school }\end{array}$ \\
\hline & & Children report that teachers and peers are consuming F\&V at school \\
\hline & $\mathrm{COIc}$ & Children are encouraged by their parents when they ask for F\&V \\
\hline & & Children watch their parents consuming F\&V daily \\
\hline & & Children are offered F\&V by their parents daily \\
\hline & COId & $\begin{array}{l}\text { Children are encouraged and supported by their parents in preparing F\&V } \\
\text { Children watch their parents preparing F\&V } \\
\text { Children watch teachers and peers preparing F\&V }\end{array}$ \\
\hline & COle & $\begin{array}{l}\text { Children are encouraged by their parents when they eat vegetables at dinner } \\
\text { Children watch their parents consume vegetables during dinner daily }\end{array}$ \\
\hline \multirow[t]{5}{*}{ Availability } & $\mathrm{CO} 2 \mathrm{a}$ & Parents increase the availability of F\&V suitable to bring to school \\
\hline & $\mathrm{CO} 2 \mathrm{~b}$ & At school, F\&V are available to consume during the morning break \\
\hline & $\mathrm{CO} 2 \mathrm{c}$ & $\begin{array}{l}\text { At home, a sufficient amount and variety of F\&V are readily apparent and } \\
\text { accessible (i.e. fruit bowl) }\end{array}$ \\
\hline & $\mathrm{CO} 2 \mathrm{~d}$ & Parents increase the availability of F\&V that children can prepare themselves \\
\hline & $\mathrm{CO} 2 \mathrm{e}$ & $\begin{array}{l}\text { Parents make at least I } 50 \text { grams of vegetables available for their child at dinner } \\
\text { daily }\end{array}$ \\
\hline \multirow[t]{2}{*}{ Accessibility } & $\mathrm{CO} 3 \mathrm{~b}$ & $\begin{array}{l}\text { At school F\&V is ready-to-eat available to consume during the morning break } \\
\text { Parents provide their children with ready-to-eat F\&V to bring to school }\end{array}$ \\
\hline & $\mathrm{CO} 3 \mathrm{c}$ & At home $F \& V$ is ready-to-eat available \\
\hline
\end{tabular}


Step 2 Selecting Methods and Strategies for Behavioural Change

In the second step, theory-informed methods are selected and translated into practical strategies for changing health behaviours and factors that influence the environment. In this process, one method might be translated into several strategies, but several methods can also be combined into one strategy. To verify if the practical strategies cover all objectives, the strategies are matched to the PPOs.

The methods used in the development of the interventions reported here were primarily adapted from the Social Cognitive Theory (Bandura, 1986), the Elaboration Likelihood Model (Petty \& Cacioppo, 1986), the Health Belief Model (Rosenstock, 1974) and theory of habit (Table 5). We chose to focus on the removal of barriers so that children do not forget to bring F\&V to school every day (Rosenstock, 1974). An example is creating a daily fruit break in the classroom that makes it possible for children to eat their fruit together. Additionally, methods related to peripheral information processing, like cues that can be used to remind children of the intended behaviour, were considered important. Although this method is less effective than central processing of information, which focuses more on persuasion and relevant argumentation (Petty \& Cacioppo, 1986), it is advantageous in that it is less timeconsuming and easier to implement. To extend children's preferences for F\&V, 'mere exposure' (smelling, seeing, touching, tasting) was the method selected (Birch, 1990, 1999; Birch \& Fisher, 1998) as experiences with F\&V, like repeated tasting sessions, can lead to an increased appreciation of F\&V (Wardle et al., 2003; Wardle, Herrera, Cooke, \& Gibson, 2003).

One important objective of our study was to make F\&V consumption habitual. According to Bargh (1999), a habit can be created by acquiring automaticity. This can be done intentionally or unintentionally. When creating a habit intentionally, people purposefully engage in certain behaviour, frequently and consistently, in order to sublimate the different components of the behaviour. After a certain amount of time, the level of deliberation needed to perform the behaviour decreases and automatic behaviour is generated. This strategy was used as part of the multi-component program and aimed to motivate parents and children to bring F\&V to school daily. We tried to intentionally create a habit by teaching children and parents to fill a specially designed lunch box with F\&V every day so that children would eat their F\&V at school. 
To boost children's motivation, they were rewarded for filling their lunch box with F\&V during the first two weeks of the intervention.

We also tried to create automatic behaviour unintentionally. Like intentional habit formation, the necessary and sufficient ingredients for unintentional automation are frequent and consistent repetition of the same behaviour under the same circumstances. However, in the unintentional method, the individual does not deliberately intend to make certain behaviour habitual. In essence, the person is not aware that automatic behaviour is being created or has been created. Instead of making a conscious choice, situational features become responsible for the activation of a desired goal and subsequent performance of the behaviour (Bargh \& Chartrand, 1999). This unintentional method was translated into a second intervention strategy, namely daily F\&V distribution at school, including a daily fruit break in the classroom. In this manner, the same routine for consuming F\&V was repeated every day.

The influence of modelling can be important when it comes to the determinant social support. Modelling can be an effective method if the target population sees a model being rewarded for performing a positive behaviour (Flanders, 1968). To increase the effectiveness of modelling, the person observing the model should identify with the model (Brody \& Stoneman, 198I) as would be the case with a peer model. Alternatively, this person should admire the model (Bandura, 1986) as would be the case with some elementary school teachers. Popular TV cartoons (Harris \& Baudin, 1972), peers (Hendy, 2002; Lowe, Horne, Tapper, Bowdery, \& Egerton, 2004), parents (Jansen \& Tenney, 200I), and teachers (Hendy \& Raudenbush, 2000) have demonstrated their effectiveness as models. Positive reinforcement of the desired behaviour and facilitation of F\&V consumption are also important methods that can be used to influence social support.

By distributing free, ready-to-eat F\&V at school, we aimed to remove barriers like limited availability and accessibility. Another strategy defined in our study was motivating parents to provide their children with F\&V by pointing out the importance of availability and accessibility (providing ready-to-eat F\&V). We determined that this could be accomplished by stimulating central processing of information through newsletters or homework assignments that parents had to complete with their 
child(ren). Strategies using the peripheral route such as cues or reminders like refrigerator magnets were also adopted.

\section{Step 3 Designing and Pre-testing the Program}

In this step, strategies are operationalized into intervention components. This demands careful reconsideration of the program context. Moreover, this step includes a pre-test of the program materials prior to the final production (Bartholomew et al., 200I).

Two different interventions were developed: (I) a free F\&V distribution program; and (2) a multi-component program. The first intervention consisted of distributing free fruit to the children and allowing them to consume the distributed F\&V every day at the same time in the classroom with the other students. In doing this, we endeavoured to create a daily routine among the children. Additionally, by exposing children to different kinds of F\&V daily, they were able to learn to appreciate the taste of F\&V and, consequently, serve as each other's peer models. The children received a serving of fruit twice a week, a serving of raw vegetables such as a piece of cucumber or a carrot twice a week, and pure fruit juice once a week. The local distributor made sure that a large variety of F\&V was provided during the intervention year and that the same F\&V was not handed out twice during the same week. The F\&V were delivered to the school twice a week in a ready-to-eat form and distributed among the classes by pupils or school employees. The F\&V were consumed together in the classroom just before the morning break.

The second intervention, namely the multi-component program, encouraged both parents and children to have children bring their own F\&V to school. To do this, various curricular activities (see table 6) were developed for children in age group I (grade I and 2), II (grade 3, 4 and 5) and III (grade 6, 7 and 8). Due to limited time and resources, existing materials were used if these corresponded to the selected strategies and objectives formulated in the previous steps of IM. New materials were developed for the remaining strategies. As described in step 2, the children also received a specially designed lunch box with a F\&V compartment. This lunchbox not only made it possible for children to bring F\&V to school undamaged, it also served as a reminder for both children and parents that children should bring F\&V to school. 


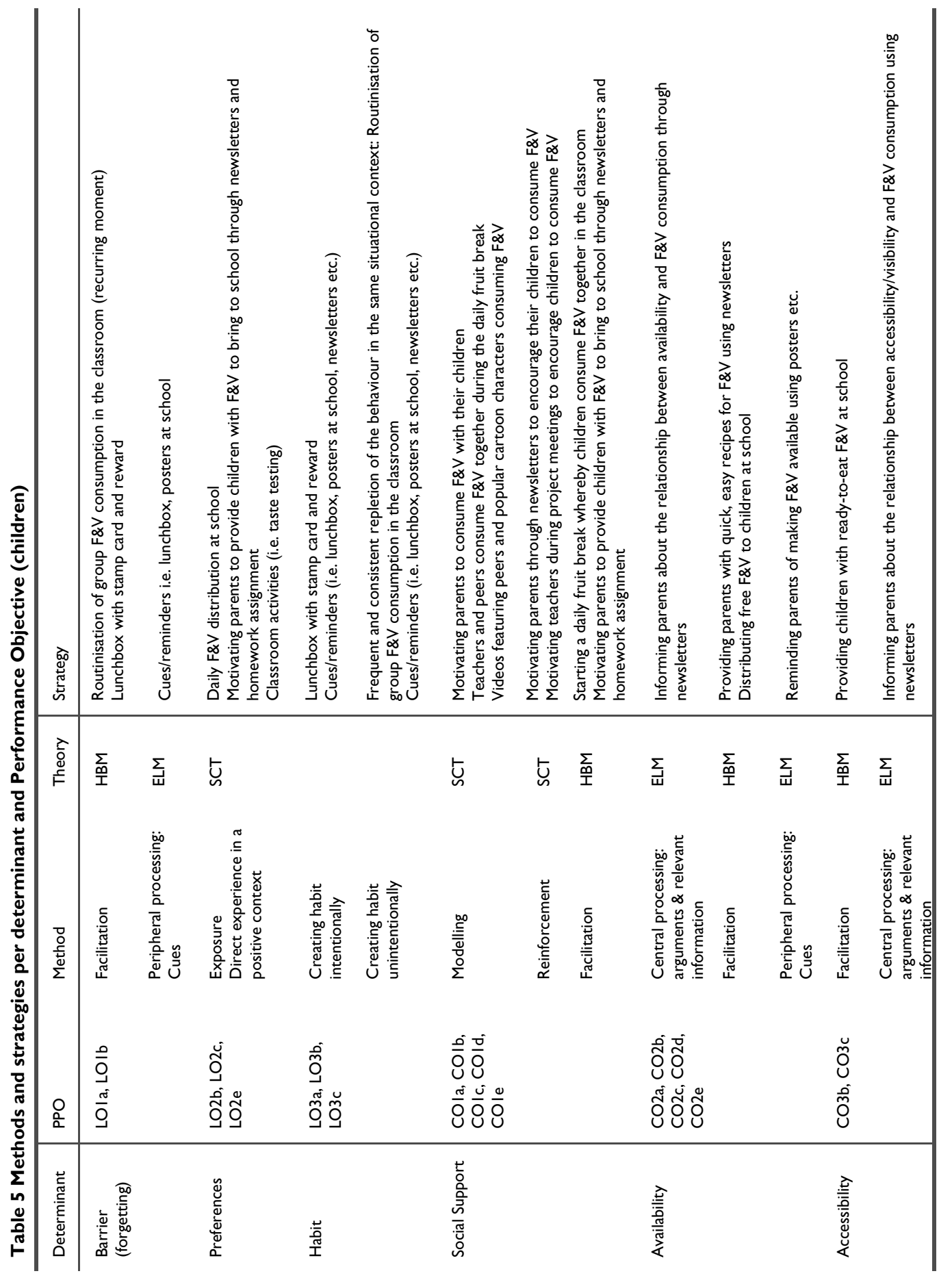


The lunch box was developed in cooperation with the national project 'Fruitables at school' (Tak et al., 2007) and was based on a consumer survey. In this intervention, a specific time was set aside for the students to eat the F\&V together in the classroom. By developing several newsletters for parents and homework activities that children had to complete together with their parents, we attempted to create a home environment that facilitated F\&V consumption.

Table 6 Classroom activities of the multi-component program

\begin{tabular}{|c|c|c|c|}
\hline & Lesson & Activities \& goals \\
\hline \multirow{14}{*}{ 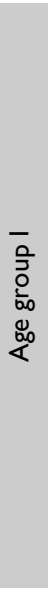 } & \multirow{5}{*}{$\begin{array}{l}\overline{\bar{O}} \\
\frac{\mathrm{o}}{\bar{\alpha}} \\
\overline{0}\end{array}$} & I & $\begin{array}{l}\text { - Posters with mascots to introduce the project } \\
\text { - F\&V Lunchbox \& conversation about F\&V }\end{array}$ \\
\hline & & 2 & - Learning a song about F\&V to make the project fun \\
\hline & & 3 & - Smelling \& feeling F\&V with teacher to experience different kinds of F\&V \\
\hline & & 4 & - Learning new kinds of F\&V using pictures of whole F\&V and crosscuts \\
\hline & & 5 & - Video with Sesame Street role models \\
\hline & \multirow{5}{*}{$\begin{array}{l}= \\
\overline{0} \\
\frac{0}{2} \\
0 \\
0\end{array}$} & 6 & - Colouring pictures of F\&V \\
\hline & & 7 & - Artwork with F\&V \\
\hline & & 8 & - CD with stories about F\&V \\
\hline & & 9 & - Preparing and tasting a F\&V snack to experience that F\&V can taste good \\
\hline & & 10 & - F\&V dominoes to learn different kinds of F\&V \\
\hline & \multirow{4}{*}{$\begin{array}{l}\equiv \\
\overline{0} \\
\frac{0}{\overline{0}} \\
0\end{array}$} & $\mathrm{II}$ & - Artwork with F\&V \\
\hline & & 12 & - Preparing and tasting a F\&V snack to experience that F\&V can taste good \\
\hline & & 13 & - Playing name games with F\&V \\
\hline & & 14 & - Growing your own beans \\
\hline \multirow{12}{*}{$\begin{array}{l}= \\
\overline{0} \\
\overline{0} \\
\frac{0}{60} \\
0 \\
0 \\
0\end{array}$} & \multirow{4}{*}{$\begin{array}{l}\overline{0} \\
\frac{0}{2} \\
\frac{0}{0} \\
0\end{array}$} & I & $\begin{array}{l}\text { - Posters with mascots to introduce the project and teach recommended intake } \\
\text { - F\&V Lunchbox \& two-week eating contest to facilitate use of F\&V lunchbox }\end{array}$ \\
\hline & & 2 & - Memory game with pictures of whole F\&V and crosscuts to learn new kinds of F\&V \\
\hline & & 3 & - Feeling, smelling and taste testing of F\&V to experience that F\&V can taste good \\
\hline & & 4 & - Quiz to assess knowledge about F\&V \\
\hline & \multirow{4}{*}{$\begin{array}{l}= \\
\frac{0}{0} \\
\frac{0}{0} \\
0\end{array}$} & 5 & - Question form to assess F\&V intake during all day \\
\hline & & 6 & - Stories with question form to learn recommended intake of F\&V \\
\hline & & 7 & $\begin{array}{l}\text { - Action from to interview people about their F\&V preferences so children realise } \\
\text { preferences differ }\end{array}$ \\
\hline & & 8 & - Creative activity to experience that F\&V can taste good and is easy to prepare \\
\hline & \multirow{4}{*}{$\begin{array}{l}\equiv \\
\equiv \\
\frac{0}{2} \\
\frac{0}{0} \\
0\end{array}$} & 9 & - Homework assignment with action form to assess availability of F\&V at home \\
\hline & & 10 & - Homework assignment including setting a goal to eat recommended amount of F\&V \\
\hline & & II & $\begin{array}{l}\text { - Action form on how to make a banana-shake so that children experience that } F \text { tastes } \\
\text { good and is easy to prepare }\end{array}$ \\
\hline & & 12 & - Action form to make a poster to motivate children to eat F\&V \\
\hline
\end{tabular}


Table 6 (Continued) Classroom activities of the multi-component program

\begin{tabular}{|c|c|c|c|}
\hline & & Lesson & Activities \& goals \\
\hline \multirow{12}{*}{$\begin{array}{l}\equiv \\
\equiv \\
\frac{0}{3} \\
\frac{0}{60} \\
\frac{10}{80} \\
\stackrel{0}{<}\end{array}$} & \multirow{4}{*}{$\frac{\overline{0}}{\overline{0}}$} & 1 & $\begin{array}{l}\text { - Posters with mascots to introduce the project and teach recommended intake } \\
\text { - F\&V Lunchbox and two-week eating competition to facilitate use of F\&V lunchbox }\end{array}$ \\
\hline & & 2 & - Video with peer models eating F\&V and preparing quick and easy F\&V recipes \\
\hline & & 3 & - Feeling, smelling and taste testing of F\&V to experience that F\&V can taste good \\
\hline & & 4 & - Question form to assess knowledge about F\&V \\
\hline & \multirow{4}{*}{$\begin{array}{l}= \\
\frac{0}{0} \\
\frac{0}{0}\end{array}$} & 5 & - Homework assignment with food diary to assess own F\&V intake \\
\hline & & 6 & - Question form to compare own intake with recommended F\&V intake \\
\hline & & 7 & $\begin{array}{l}\text { - Action form to measure and weigh different kinds of F\&V so that recommended intake } \\
\text { can be learned }\end{array}$ \\
\hline & & 8 & $\begin{array}{l}\text { - Creative activity including preparing and tasting of F\&V to experience that F\&V can taste } \\
\text { good and is easy to prepare }\end{array}$ \\
\hline & \multirow{4}{*}{$\begin{array}{l}\equiv \\
0 \\
\frac{0}{10} \\
0\end{array}$} & 9 & $\begin{array}{l}\text { - Action form to compare daily consumption of different people with recommended } \\
\text { intake of F\&V }\end{array}$ \\
\hline & & 10 & $\begin{array}{l}\text { - Action form to assess who influences the availability of F\&V at home } \\
\text { - Reflection on ways to influence availability of F\&V at home }\end{array}$ \\
\hline & & II & - Action form to make a commercial to motivate children to eat F\&V \\
\hline & & 12 & $\begin{array}{l}\text { - Action form on how to make a banana-shake so that children experience that } F \text { tastes } \\
\text { good and is easy to prepare } \\
\text { - Homework assignment including quick and easy F\&V recipes to try at home }\end{array}$ \\
\hline
\end{tabular}

Furthermore, project mascots were developed and pre-tested among the target group. During the first pre-test, children $(n=36)$ were questioned about their perceptions of the mascots and the associations they made when they saw the pictures of the mascot for the first time. Based on the results, the mascots were modified and presented to a new group of children $(n=208)$ in a second pre-test. Posters with the final mascots, 'Vita \& Froet', were posted at school and in local supermarkets, where they served as a reminder for parents to buy F\&V.

\section{Step 4 Planning Adoption and Implementation}

In this step, preparation for the implementation of the interventions is conducted. The process described in step I is repeated but now the final program adopters - in this case, the teachers - are the target group. The program objectives for the teachers were: (I) teachers adopt the F\&V project; and (2) teachers implement the interventions as described in the program plan. These general objectives were linked with determinants to produce learning objectives to promote program adoption and use. A brief questionnaire was administered to the teachers $(n=48)$ to identify 
determinants. The results showed that about $90 \%$ of the teachers thought it was important to pay more attention to $F \& V$ consumption at school. We also surveyed the literature and found some important factors regarding the adoption of new interventions. For example, it is important that teachers see the benefits of the new intervention, the intervention must fit easily into the daily school routine, the intervention must not be too complicated, and it must be possible to try out the interventions on a trial basis (Rogers, 2003). These factors were addressed when schools were invited to participate in the project.

To optimise the implementation of the interventions, a planning group was formed prior to the development of the interventions (December, 2003). The planning group remained active until the end of the intervention period (July, 2005) and consisted of health educators from the Local Health Authority, program developers from the Universiteit Maastricht and school directors and teachers from the target population. The group met once every two to three months and worked towards developing user-friendly intervention components. This group also aimed to optimise implementation, communicate the interventions at school, and distribute activities and teachers' manuals among program users. Due to financial restrictions, pre-testing all program components was impossible. Therefore, the teachers in the planning group evaluated the activities.

Step 5 Planning the Evaluation

To identify which of the two interventions was most effective in increasing children's F\&V intake, a pre-test/post-test design including two intervention groups and one control group was used. Effects were studied at the end of the intervention period (June, 2005) and one year after the interventions were terminated (June, 2006). Each intervention group consisted of three primary schools and the control group consisted of six schools. To measure the F\&V intake of the children, we used self-reports among the oldest children (grades 7 and 8 ) and we asked all parents to fill out a questionnaire concerning their child's F\&V consumption. Effectiveness of the interventions will be reported in Chapter 5 and 6, respectively.

The process evaluation is equally important as the effect evaluation of interventions. Data on the implementation and perception of health promoting 
interventions are essential for numerous reasons. Firstly, information on how the program was implemented and received by those involved is required so that we can distinguish between the consequences of poor program delivery and those of intrinsically ineffective interventions. In this sense, a process evaluation enables an appropriate interpretation of the findings yielded in the effect evaluation (Bartholomew et al., 200I; Green \& Kreuter, 1999; Potvin, Haddad, \& Frohlich, 200I; Rossi, Freeman, \& Lipsey, 1999). Secondly, process evaluation data can be used to identify key facilitating and inhibiting factors for future program implementation and dissemination (Klepp et al., 2005). In the current study, the implementation of interventions was monitored using questionnaires that were completed by the teachers during the intervention period. Additionally, oral feedback was acquired from the planning group. After each intervention was completed, both interventions were compared to each other on their respective facilitating and hindering factors for implementation (Rogers, 2003; Zaltman \& Duncan, 1977). Results are described in Chapter 7. Finally, parents, teachers, children and school directors were asked for their assessment of the interventions.

\section{In conclusion}

This chapter has described the application of the IM protocol in the development of interventions to promote F\&V intake among children. We successfully demonstrated that, by adopting several behavioural change strategies, two different interventions that are based on the same program objectives could be developed. Recently, similar initiatives have been developed in the Netherlands, namely the national project 'Fruitables at school' and the European Pro Children project (Wind, Zadellhoff, Snel, Ham, \& Brug, 2004). Our project diverges from these two projects in that we aimed to compare two interventions while the other two projects endeavoured to test the effectiveness of a F\&V distribution at school in combination with a curriculum.

In addition to providing an extensive description of the development of the interventions, this chapter aimed to make the use of the IM protocol more transparent for health educators working in the field of health education and promotion. We intended to show that IM can be used as a practical aid for the development of planned health promotion interventions. The presented matrices can provide health educators 
with a foundation for the development of future dietary interventions for children. Although IM is a time-consuming process, it proved to be an effective means for making well-considered choices in every step of program development and implementation.

Unfortunately, this form of planned development can hinder the acquisition of funding for health promoting interventions because, at the start of the process, it is unclear what the final intervention will look like. By making the planning process more transparent, we hope to convince funding agencies of the added value of planned development, implementation and evaluation of health promoting interventions. 


\title{
Chapter 2
}

\author{
Development of a school-based \\ intervention to promote fruit and \\ vegetable consumption: \\ Exploring perceptions among four-to- \\ twelve year old children and their parents
}

Published as: Reinaerts, E., de Nooijer, J., van de Kar, A. \& de Vries, N.K. (2006). Development of a school-based intervention to promote fruit and vegetable consumption: Exploring perceptions among four-to-twelve year old children and their parents. Health Education, 106(5), 345-356. 


\section{ABSTRACT}

Purpose: The aim of this study was to explore individual and social factors that are associated with children's F\&V intake in order to develop a school-based intervention to increase their F\&V consumption.

Methodology: Group interviews were conducted with ten groups of children $(n=104)$, aged four to twelve years, and two groups of parents $(n=28)$. Additionally, a total of ten parents participated in an interview by telephone. Opinions about the actual F\&V consumption, awareness of consumption patterns, attitudes towards F\&V, promotion of F\&V consumption by parents and F\&V intake at school were explored. Transcripts were analysed using Nvivo 2.0.

Findings: Several factors that are likely to increase F\&V consumption of the participants were identified, such as preferences, modelling of F\&V consumption by teachers and parents and availability of F\&V in ready-to-eat form at home and school. Although both children and parents favoured activities to promote F\&V at school, most parents were not willing to participate in these activities.

Practical implications: This article is a useful source for health promotion planners that are developing food-related interventions for children.

Originality/value: Information on factors that influence children's F\&V consumption is usually acquired through parents. It is questionable if parents are aware of the factors that influence their children's food choice. Therefore this study combined information gathered among parents with information gathered directly among children. 


\section{INTRODUCTION}

This chapter explores factors that are associated with fruit and vegetable (F\&V) consumption among children aged four to twelve years, with a view to developing a school-based intervention in the Netherlands.

Over the last decade, the consumption of F\&V has attracted considerable attention in health promotion research, since there is evidence that such consumption decreases the risk of chronic diseases, such as cancer, coronary heart disease and asthma (WHO, 2003). Dutch nutritional guidelines (Gezondheidsraad [Health Council of the Netherlands], 2006) as well as the World Health Organization (WHO, 2003) recommend a daily intake of at least 150-200 grams of vegetables and two servings of fruit or fruit juice for children up to twelve years. However, Dutch children aged four to twelve years consume only $7 \mathrm{I}$ grams of vegetables and less than one portion of fruit a day (Anonymous, 1998).

Children's low intake of F\&V is particularly troubling since many food preferences and behaviours, including dietary habits, are established during childhood (Birch, 1990; Domel Baxter \& Thompson, 2002; Sandeno, Wolf, Drake, \& Reicks, 2000) and appear to persist into adolescence and adulthood (Kelder et al., 1994; Krebs-Smith et al., 1995; Lien et al., 200I). Therefore, childhood is an important period for developing dietary habits and behaviours in order to maximize health benefits (Wardle et al., 2003).

Recently, several initiatives to promote F\&V consumption among children have been started in the Netherlands (Wind et al., 2004). The Regional Health Service GGD Noord- and Midden Limburg, in collaboration with Maastricht University, also intended to develop an intervention, within a primary school setting, to increase the daily intake of F\&V among four-to-twelve-year old children. Prior to the development of this intervention, it is necessary to explore factors that encourage or hamper F\&V consumption among the target group and its social environment. An extensive literature search identified several potential determinants of F\&V consumption among children, such as knowledge (Reynolds et al., 1999; van Zadellhoff \& Snel, 2003), outcome expectations (Resnicow et al., 1997; Reynolds et al., 1999), preferences (Baranowski et al., 1993; Birch, 1990, 1999; Domel Baxter \& Thompson, 2002; Domel Baxter et al., 1996; Gibson et al., 1998; Resnicow et al., 1997; van Assema et al., 200I), 
peer influences (Weber Cullen et al., 200I), habit strength (Brug et al., 2006; KrebsSmith et al., 1995), self-efficacy (Domel Baxter et al., 1996 ; Resnicow et al., 1997; Reynolds et al., 1999; van Zadellhoff \& Snel, 2003), and availability and accessibility (Baranowski et al., ; Edmonds et al., 200I; Kratt et al., 2000; Reynolds et al., 1999; van Assema et al., 200I; van Zadellhoff \& Snel, 2003; Weber Cullen et al., 200I; Weber Cullen et al., 2000). In addition, the influence of parents on children's consumption patterns, either by making certain food products available or by their own consumption, was repeatedly shown in several studies (Gibson et al., 1998; Kratt et al., 2000; Reynolds et al., 1999; Weber Cullen et al., 200I; Weber Cullen et al., 2000) and needs to be considered when developing interventions to change children's consumption patterns.

Unfortunately, most studies had been conducted among American parents or children older than ten years, so data applicable to the Dutch situation was limited. Therefore, the aim of the present study was to obtain a better understanding of the factors that are associated with young Dutch children's F\&V consumption, with a view to developing a school-based intervention to promote F\&V consumption. Since it is difficult to get reliable information about eating habits from very young children, both children and their parents were interviewed, so as to combine information.

\section{METHODS}

\section{Participants \& procedures}

A convenience sample of schools in the middle region of the province of Limburg, which had at least 200 pupils $(n=28)$, were invited by the local Health Authority to participate in the current study. It was aimed to include schools with a majority of native pupils and schools with a majority of non-native pupils. A total of five primary schools were willing to take part. Of the five schools that were willing to participate in the study two schools had more than $50 \%$ of non-native pupils. Of the children $40 \%$ had at least one parent that was born in a foreign country. Furthermore, none of the schools had a specific policy regarding fruit or vegetable consumption or healthy eating in general and had no restrictions regarding snacks that children brought to school.

The group interviews were conducted at two schools during the so-called 'coffee talks' (meetings during which parents talked with each other and teachers about 
specific topics). Parents from the remaining schools were invited to take part in a telephone interview by means of participation forms, which could be handed in at school. Furthermore, ten interviews were conducted with a total of 104 schoolchildren (50 girls and 54 boys). Children who participated were randomly selected and were therefore not necessarily the children of the interviewed parents. For all children parental consent was acquired.

Four different procedures were used to gather information from the children and their parents (Table I). In view of the age differences among the children, two different kinds of semi-structured interviews were conducted. The interviews with the children of age group I were conducted in the classroom in the presence of the teacher to create a more familiar atmosphere. The children sat in a large circle and talked about F\&V. Real F\&V were used to support the questions. Because these children have a fairly short attention span, these interviews lasted only 20 minutes and were less structured than the interviews that were conducted among the older children. Contrary to the interviews with the children of age group II and III who were very willing to engage in a conversation with each other, the children of age group I hesitated to answer somewhat more. In several occasions children answered by putting their hand up and had to be invited by the interviewer or the teacher to answer the question more extensive. This yielded other reactions of the children but answers were always given to the interviewer and spontaneous reactions on each other stayed out. The more silent children were invited to participate by the interviewer. The interviews with children aged six to twelve years (age groups II and III) were conducted in small groups of classmates, because of the potential sensitivity to social pressure from other, unfamiliar children. To allow the children to get used to the interview situation and the interviewer, all children were invited to tell each other about their favourite kinds of F\&V. 
Table I Procedures for data collection

\begin{tabular}{llllll}
\hline Respondents & Data collection method & $\begin{array}{l}\text { No of } \\
\text { interviews }\end{array}$ & $\begin{array}{l}\text { Duration } \\
\text { (minutes) }\end{array}$ & $\begin{array}{l}\text { No of } \\
\text { participants }\end{array}$ & Age \\
\hline Age group I & Group interview in classroom & 3 & 20 & 56 & $3-5$ \\
Age group II & Group interview & 3 & 45 & 24 & $6-9$ \\
Age group III & Group interview & 4 & 45 & 24 & $10-14$ \\
Parents & Group interview during 'coffee talk' & 2 & $45-60$ & 28 & 10 \\
Parents & Telephone interview & 10 & $15-20$ & 10 & \\
\hline
\end{tabular}

An interviewer that was very experienced in communicating with young children conducted all interviews. During all group interviews, the interviewer asked the questions and an assistant observed the participants and took notes about their nonverbal reactions. Interviews were tape-recorded, with the participants' consent, to enable transcription.

Interviews

The structure of the interviews was based on the literature but due to practical reasons (such as duration of the interviews) not every determinant could be covered in the interview route. The group interviews and the individual interviews started with general questions and subsequently focused on more specific topics. Key questions for the children addressed issues like actual F\&V consumption and attitude towards $F \& V$, awareness of F\&V consumption, perceived attitude and behaviour of parents towards F\&V and F\&V at school (Table 2). For the parents, questions focused on their children's consumption of F\&V, availability and accessibility of $F \& V$, promotion of F\&V consumption by parents and F\&V at school (Table 3). Children and parents were invited to come up with any kind of issues they thought important to discuss regarding F\&V consumption at the end of the interview, to enable them to raise issues not covered by the interview route. 
Table 2 Interview route for the children

\begin{tabular}{ll}
\hline Main topics & Key questions* \\
\hline Actual F\&V consumption & When, where and with who do you eat F\&V? \\
& How much F\&V do you eat? \\
Attitude towards F\&V & Do you like F\&V? What kinds of F\&V are your favourites? \\
& Why do you eat F\&V? \\
& Why do you sometimes not eat F\&V? \\
Awareness of F\&V consumption & How much F\&V should children eat in order to stay healthy? \\
& Do you think you are eating enough F\&V? \\
Promotion of F\&V consumption by & Do your parents stimulate you to eat F\&V? How? \\
parents & Are there rules at home about eating F\&V? \\
& Do you have any say in what kinds of F\&V you can eat? \\
& Who prepares the F\&V? \\
F\&V at school & Do you take F\&V to school? Do you eat the F\&V you take to school? \\
& How could your parents you to bring an F\&V snack to school \\
& every day? \\
& Are there activities at school that have to do with F\&V? \\
& What kind of activities would you like to do that have to do \\
& with F\&V? \\
\hline
\end{tabular}

* The questions in italics were used in the interview route for the children of age group I

Table 3 Interview route for the parents

\begin{tabular}{ll}
\hline Main topics & Important questions \\
\hline Availability and accessibility of F\&V & How many days of the week do you have F\&V available at \\
& home? \\
& Can you identify situations in which no F\&V is available at \\
& home? \\
& Who prepares the F\&V at home? \\
Promotion of F\&V consumption by & Do you stimulate your children to eat F\&V? \\
parents & Do you have rules about F\&V consumption? \\
F\&V at school & Do you think it would be a good idea to pay more attention to \\
& F\&V consumption in primary schools? \\
& Would you want to participate in these kinds of activities at \\
& school? \\
& Would you be prepared to pay for an F\&V distribution scheme \\
& at school?
\end{tabular}

\section{Data analysis}

After each interview the interviewer and the assistant discussed the interview and relevant non-verbal behaviour. When all interviews were conducted the tape-recorded interviews were transcribed and analyzed using the qualitative data analysis package Nvivo 2.0. Two researchers read the transcripts several times to familiarize themselves with the data. Because the interview route was developed based on literature on determinants of children's F\&V consumption, broad coding of the data took place based on the interview route. Subsequently, detailed coding using a thematic approach was conducted as advocated by Kidd and Parshall (Kidd \& Parshall, 2000). Segments of the data were identified and coded by both researchers separately. If the researchers 
had coded segments differently, the interpretation was discussed until consensus was reached. The interviews with the children were analyzed separately for each age group. Key concepts are discussed below.

\section{RESULTS}

\section{Consumption and attitude towards F\&V}

Children - All interviewed children preferred certain kinds of fruit, most often apples, bananas and strawberries. The types of fruit they reported eating most were those that are most commonly available at Dutch supermarkets, like apples, bananas, tangerines and oranges. The children mentioned several reasons for eating fruit, such as tastiness and healthfulness. The children in age groups II and III said that they also drank fruit juice, but the children in age group II could not distinguish fruit juice from soft drinks. The children in age group III did not think that a glass of fruit juice was the same as a serving of fruit.

Most children said they did not eat fruit every day. On the days when they did, they consumed about two servings. They reported that they did not eat fruit every day because sometimes there was no fruit available or they were not hungry. Most of them did not eat fruit at regular moments. The older children (groups II and III) said they just ate fruit when they felt like it. According to the children, they consumed more fruit on schooldays than on weekend days, because in the weekend they tended to forget to eat fruit.

Although the interviewed children reported that they liked eating fruit in the company of other people, they said that they seldom ate fruit with their parents. The children in age groups II and III were expected to take and prepare their own fruit, but sometimes they did not feel like it and chose another snack. Washing and peeling of fruit was mentioned as a barrier to fruit consumption. Other reasons not to eat fruit included the presence of seeds and fruit being overly ripe or dented.

With respect to vegetables, children said they liked them, but not as much as fruit. Children named several vegetables they disliked, such as Brussels sprouts. Most children said that they ate vegetables mainly during dinner, but they also said that this did not imply that they ate vegetables every day. On weekend days in particular, dinner often consisted of dishes low in vegetables. Of the vegetables they liked, they reported 
eating about two or three tablespoons, of the other vegetables one or two, because their parents wanted them to do so. Unlike the children of Dutch origin, some of the children of foreign origin reported consuming vegetables during the day, for instance on sandwiches or as a snack.

Although preschool children appeared to be familiar with different kinds of $\mathrm{F} \& \mathrm{~V}$, they sometimes had trouble naming different varieties.

Parents - In almost all of the interviews, parents said that their children liked eating fruit, but getting them to eat vegetables was a major problem. They did mention, however, that children liked vegetables more as they grew older. According to the parents, the consumption of raw or uncooked vegetables, like salads, was less of a problem than consumption that of cooked or baked vegetables.

\section{Children's awareness of F\&V consumption}

Children - Children in age group II said they did not know the national recommendations for fruit consumption, but children in age group III did. However, the children in age group III did not think that it was necessary to consume two servings of fruit every day. According to them, doing so on four days a week should be sufficient. None of the interviewed children knew the recommendations for vegetable consumption. Most of them thought that they were consuming enough fruit, but thought they were not eating enough vegetables.

The children in age groups II and III found it difficult to understand the term 'average consumption per day', but said they could report the number of days on which they ate F\&V and how much they ate on such days.

Parents - Whereas most of the interviewed parents were able to reproduce the recommendation for fruit correctly, few reported knowing that their children were recommended to eat at least three to four serving (spoonfuls) of vegetables a day.

\section{Promotion of F\&V consumption by parents}

Children - Only a few children reported that their parents actively encouraged them to eat more F\&V (i.e., by offering some fruit or preparing sliced fruit for their children). Children in the age groups II and III explained that they were expected to take, wash and peel their own fruit. If they needed help they had to ask their parents. Except for 
the children in age group I, who reported they were obliged by their parents to eat some fruit every day, most children reported that there were no rules at home about the consumption of fruit. However, almost all children explained that there were rules about the consumption of vegetables during dinner, like eating a certain amount or at least tasting the vegetables they did not like. According to the children, there was always some F\&V available at home, but this was not always ready for consumption. Parents - Almost all of the interviewed parents said they encouraged their children to eat F\&V, especially to finish their vegetables. The parents who stimulated their children to eat more fruit used verbal encouragement or offered their children fruit or a bowl of sliced fruit. Otherwise, their children would not eat any fruit at all.

Parents mentioned various techniques to encourage their children's vegetable consumption, such as letting them choose the vegetables once or twice a week or preparing two vegetables to choose from at dinner. Other parents stated clearly that they chose not to do this, because they thought their child had to learn to eat all kinds of vegetables. Some parents reported rewarding their children for finishing their vegetables, or punishing them for not doing so. Furthermore, most of the interviewed parents reported that they had rules for vegetable consumption, like eating a certain amount or tasting a bite of a vegetable that the child does not like. Some parents said that they had the rule that their children had to stay at the dinner table until they had finished their vegetables. Although most parents reported having such rules, some of them also reported dropping them because they had no effect. Parents reported being frustrated by their children's consumption pattern and were eager to learn more effective methods to encourage their children's vegetable consumption.

Parents said that they sometimes allowed their children to help with the preparation of vegetables. This happened mostly during the weekend, because then there was more time.

According to most interviewed parents, there were always F\&V available at their homes. Some parents said that F\&V were always available on weekend days, but not always on weekdays, due to lack of time. Most parents said they had fruit available for their children on a fruit bowl. According to the parents, children aged five years are unable to take their own fruit, but children aged nine years or older should be able to take and prepare their own fruit. 


\section{F\&V consumption at school}

Children - At preschool, some children said they frequently brought fruit or fruit juice to school, but the older children at primary school admitted they hardly ever brought fruit to school. Preschool children all reported having a daily 'fruit break' in the classroom. During this 'fruit break', the teacher divided the fruit that children had brought from home among all classmates, even among the children who had not brought any fruit, so that all children ate fruit together. The older children reported that they brought biscuits, candy bars and soft drinks to school instead of F\&V.

Children who stayed at school during the lunch break reported bringing fruit to school to consume during their lunch break. Some children explained that bringing fruit to school did not automatically lead to consumption, because they often were just not hungry enough or did not take the time to eat fruit, and preferred to play outside instead.

Parents - Not all of the interviewed parents said they gave their children fruit to take to school. Some parents left this up to their children. Parents recognized the problem that children do not eat their fruit at school. The fruit was often returned and forgotten by the children. Parents reported that sometimes the fruit was eaten at home after all, but only when the parent reminded the child.

\section{Promoting F\&V consumption at school}

Children - According to the children in age groups II and III, there were not many teachers who modelled F\&V consumption. Children also reported that hardly any attention was paid to F\&V consumption at school. If activities at school to promote F\&V consumption were to be initiated, children said they preferred creative activities, like preparing F\&V and eating it afterwards. Those in age group III particularly wanted to know more about how F\&V are grown and to visit a market gardener. Parents - Parents reported that they were very much in favour of activities to promote F\&V consumption at school. They were also positive about schools distributing fruit, but were afraid that some parents would see distribution by schools as a replacement for fruit consumption at home. Most of the interviewed parents were willing to pay for F\&V at school, although they could not say how much. Parents reported that they would appreciate to be informed about such activities at school, but they did not want 
to participate. However, parents also said that promoting F\&V consumption is not the school's responsibility, but the parents'.

\section{DISCUSSION}

The aim of the present study was to obtain a better understanding of factors that are associated with young Dutch children's F\&V consumption, with a view to developing a school-based intervention. Therefore, the results will be discussed especially from the point of view of implications for interventions. In interpreting the results, it should be remembered that the aim of the present study was to obtain information from a broad perspective, and not from a representative sample.

The results showed that F\&V consumption among the interviewed children did not meet the national recommendations. This is consistent with national data indicating that Dutch children (aged four to twelve years) consume too little F\&V (Anonymous, 1998). In agreement with the results of a study by Domel Baxter (2002), preference for certain kinds of F\&V was reported to be an important factor associated with consumption. Since food preferences are learned through experience with food and eating (Birch, 1990, 1999; Birch \& Fisher, 1998), an intervention to promote F\&V consumption should incorporate strategies to increase children's preference for F\&V. This was successfully done by Wardle et al. (2003), who showed that daily exposure to vegetables could be an effective intervention to increase preference and consumption.

The children in our study reported that they hardly ever brought fruit or vegetables to school. This might be explained by the fact that parents said they did not provide their children with daily F\&V to take to school. Only the children in age group I sometimes brought fruit, probably because the preschool teachers encouraged this by implementing a fruit break, which is a common practice at most preschools in The Netherlands.

Eriksen (2003) conducted a study on the effects of an F\&V subscription scheme in Denmark. In this intervention parents were offered a F\&V subscription comprising one piece per day. It was concluded that the social implications of a fruit break could motivate those children who did not take part in the subscription to bring F\&V to school. In addition, observing peers who consume F\&V can favourably affect the consumption of and preferences for F\&V (Birch, 1980). Our data suggest that 
bringing F\&V to school does not necessarily imply consumption. For this reason, a daily F\&V break in the classroom could have a positive effect on F\&V consumption, because it reminds children to eat their fruit. Additionally, measures should be taken to make sure that F\&V arrive at school undamaged, because children saw dented fruit as a barrier for consumption.

Children reported that few teachers modelled F\&V consumption or taught about the importance of F\&V. Since a study by Hendy et al. (2000) showed that enthusiastic teacher modelling affects food acceptance by children, motivating teachers to model F\&V in an enthusiastic way should be considered when developing a schoolbased intervention.

Although both children and parents were in favour of activities to promote F\&V at school and would also appreciate F\&V distribution, parents do not tend to participate in activities to promote F\&V consumption at school. Therefore other ways to get through to parents have to be considered. For example, according to the family reciprocal determinism model (Baranowski, 1997) parents not only influence their children, but children can also influence their parents' behaviour, skills and cognition by providing information, rewards and punishment. Furthermore, it must be considered that F\&V distribution at school could lead to a decrease in the corresponding behaviour at home (Eriksen et al., 2003).

Surprisingly, the children reported that their parents did not encourage them to eat F\&V, while their parents reported the opposite. Furthermore, most of the children as well as the parents reported that there were rules about F\&V consumption at home. Several studies have shown that parental F\&V consumption (Fisher, Mitcell, Smicilas-Wright, \& Birch, 2002; Young, Fors, \& Hayes, 2004) and parenting style (Kremers, Brug, de Vries, \& Engels, 2003) are related to children's F\&V consumption. This is especially important considering that parents influence their children's behaviour, including their eating habits (Ferme \& McManamon, 2003). This implies that interventions to promote F\&V consumption should also include activities aimed at parents.

Another factor that was mentioned in the interviews was the accessibility of F\&V. Cullen Weber (2000) showed that when F\&V are not readily available to eat at home, this inhibits the children from eating F\&V and makes them more likely to turn to 
more convenient snack foods. For interventions to promote F\&V consumption, this means that activities should be considered to support parents in making F\&V more accessible for their children. Moreover, the children said they liked activities in which they could prepare their own F\&V. Providing parents with easy-to-fix recipes for preparing F\&V snacks together with their children or teaching children at school to make their own F\&V snacks could be useful activities. Moreover, the important role of accessibility implies that if F\&V distribution at school is considered, the F\&V should be provided in ready-to-eat form.

Some limitations of the study need to be discussed. Since we used two different methods to collect data among parents, results have to be interpreted with caution. Although the group interviews and telephone interviews both used the same interview route, it is likely that the interviewer used somewhat different techniques to invite parents to elaborate on the previous question. Moreover, maybe discussion in group interviews yielded more information than individual telephonic interviews could ever do. When interpreting the results it is therefore important to recognize that despite the differences mentioned, all interviews were treated as of equal richness. Parents who participated in the 'coffee talk' did not know on forehand what the subject of discussion was; we therefore do not expect a selective group that was more involved in health related issues. Regarding telephone interviews, participating parents were self-selected. Therefore, it is likely that parents more interested in health related issues were involved in the interviews. However, this is the case in all voluntary health promotion activities.

Although studies involving children yield valuable information, especially when developing a child-based intervention, there are always some ethical considerations that have to be taken into account. Is it ethical to use children as a source of information? In our opinion the answer to this question depends on the kind of subject under study and the methods used to gather information from children. The current study looked at F\&V consumption, which is not an emotionally charged subject. Furthermore, to minimize a potential burden on the children we chose interview methods that connected to the children's class routine as much as possible. The interview held with the youngest children was conducted with their teacher and 
resembled the recurring opening of the day; moreover working on assignments in small groups is also a common school activity for the older children.

Finally, it can be concluded that this study has yielded a number of practical implications for designing school-based interventions aimed at promoting F\&V consumption among children aged four to twelve years and making this healthy behaviour habitual. Although the children's and parents' perspectives are important, further study is required into teachers' willingness to implement an intervention and the conditions under which schools are ready to promote F\&V at school. 


\section{Chapter 3}

Explaining school children's fruit \& vegetable consumption: the contributions of availability, accessibility, exposure, parental consumption and habit in addition to psychosocial factors

Published as: Reinaerts, E., de Nooijer, J., Candel, M. \& de Vries, N.K. (2007). Explaining school children's fruit \& vegetable consumption: the contributions of availability, accessibility, exposure, parental consumption and habit in addition to psychosocial factors. Appetite, 48, 248-258. 


\section{ABSTRACT}

We studied the contributions of parental fruit and vegetable (F\&V) consumption, availability and accessibility of F\&V in the home, exposure to F\&V, and habit, in addition to psychosocial factors, in explaining F\&V consumption in 4 tol2-year-old children. Furthermore, we looked for effect modification of ethnicity and gender. Children's parents $(n=1739)$ completed a questionnaire assessing psychosocial and additional factors regarding their children's F\&V consumption. Consumption was assessed by a food-frequency questionnaire. The model explained the children's F\&V consumption better when the additional factors were included $\left(R^{2}=.49\right.$ and $R^{2}=.50$ for fruit consumption, and $\mathrm{R}^{2}=.33$ and $\mathrm{R}^{2}=.33$ for vegetable consumption). Habit was the most influential correlate of F\&V consumption. It is concluded that nutrition education interventions aimed at stimulating F\&V consumption among children should take into account that the consumption of fruit and that of vegetables are clearly different behaviours, with different influencing factors for boys and girls and children of native or non-native background. Furthermore, interventions to increase F\&V consumption should include strategies aimed at making these behaviours habitual. 


\section{INTRODUCTION}

The Dutch National Food Council recommends that children eat at least I50g of vegetables and two portions of fruit daily (Gezondheidsraad [Health Council of the Netherlands], 2002). Unfortunately, Dutch children aged 4 to 12 years only eat an average of $7 \mathrm{I} g$ of vegetables and less than one portion of fruit a day (Anonymous, 1998). Considering that the pattern of F\&V consumption persists into adulthood (Kelder et al., 1994; Krebs-Smith et al., 1995; Lien et al., 200I), it is important to develop F\&V promoting interventions aimed at children and their social environment, especially their parents.

According to the Intervention Mapping framework for the design of health promoting interventions (Bartholomew et al., 200I), the first step in developing effective interventions is the assessment of key variables that influence the behaviour of interest.

When explaining behaviour such as F\&V intake, it is important to start from theory. Theories like the Theory of Planned Behaviour (TPB) (Ajzen, I99I) are used to explain F\&V intake (Montano, Kasprzyk, \& Taplin, 1997), and provide an initial but somewhat limited set of psychosocial factors that can influence F\&V consumption. The ecological perspective is somewhat more extensive, and posits that eating behaviour is influenced by intrapersonal (i.e. food preferences), social (i.e. family eating habits) and cultural factors (i.e. culture is often expressed through food), and factors in the physical environment (i.e. availability). These factors are likely to interact and influence behaviour through different levels (Sallis \& Owen, 1997). From this perspective and because children's behaviour is not fully under their own control but is regulated by their social environment, we suggest that children's F\&V consumption is also influenced by additional factors, which are of less importance in adults. Therefore, the main objective of this study was to examine whether factors other than psychosocial ones contribute to the explanation of children's F\&V consumption.

The psychosocial concepts of attitude, subjective norm, and perceived behavioural control (or self-efficacy) determine a person's intention to engage in certain behaviour. Positive outcome expectations (attitudes) have been found to be related to children's F\&V consumption (Resnicow et al., 1997; Reynolds et al., 1999). The same has been found for children's preferences (Domel Baxter \& Thompson, 
2002; Gibson et al., 1998 ; Vereecken, van Damme, \& Maes, 2005; Wind, de Bourdeaudhuij et al., 2006), which can also be regarded as (results of) outcome expectations (Birch \& Sullivan, 199I). Blanchette et al (2005) even conclude in their review that taste preference is probably the most important personal determinant for F\&V-consumption. Previous studies have found several types of social influence to be associated with children's F\&V intake, namely social support (encouragement by others) towards eating F\&V (Corwin, Sargent, Rheaume, \& Saunders, 1999), peer normative beliefs (Weber Cullen et al., 200I) and modelling by parents (Vereecken et al., 2005; Weber Cullen et al., 200I; Wind, de Bourdeaudhuij et al., 2006), peers (Vereecken et al., 2005) and teachers (Hendy \& Raudenbush, 2000). Another factor that has been shown to be related to children's F\&V consumption is self-efficacy (Corwin et al., 1999; Reynolds et al., 1999; Wind, de Bourdeaudhuij et al., 2006), although conflicting results about the influence of self-efficacy have been reported (Blanchette \& Brug, 2005). This concept has been operationalized as self-efficacy in difficult situations (Vereecken et al., 2005), self-efficacy towards choosing F\&V as opposed to less healthy choices, and self-efficacy towards asking family members to buy or prepare F\&V (Resnicow et al., 1997). According to a review by Baranowski and colleagues (1999), these psychosocial constructs explain only approximately $30 \%$ of the behaviour. Therefore, several authors have recommended integrating constructs from other theories to increase the predictive power of the model (Achterberg \& Miller, 2004; Baranowski et al., 1999).

Parental consumption is considered a relevant determinant for F\&Vconsumption (Blanchette \& Brug, 2005). A study by Gibson (1998) especially showed that parental consumption of fruit was associated with children's fruit consumption. Furthermore, a study by Kratt and colleagues (2000) showed that this is conditional on medium to high availability of F\&V in the home. Although parental consumption is often used as a 'modelling' measure we argue that parental consumption could be more than just an example (model) for children.

Availability of F\&V is believed to be one of the most important environmental factors for F\&V consumption by children (Blanchette \& Brug, 2005; Weber Cullen et al., 200I). Vereecken (2005) reported an association between availability and the consumption of fruit and Wind (2006) between availability at home and vegetable 
consumption, whereas other studies found a relationship between availability and total F\&V consumption (Corwin et al., 1999; Reynolds et al., 1999; Weber Cullen et al., 200I).

A relatively new but important concept related to children's F\&V consumption is accessibility or facilitation (i.e. whether foods are available in a form and at a location and time that facilitate their consumption, for example ready-to-eat pieces of apple or cucumber in the refrigerator) (Blanchette \& Brug, 2005; Wind, de Bourdeaudhuij et al., 2006). A study showed that accessibility of F\&V at home was especially important in explaining intake when children had a low preference for F\&V (Weber Cullen et al., 2003). Children who liked F\&V only needed them to be available, whereas children who disliked F\&V also needed easy access in order to eat them. Children's exposure to F\&V is defined as the number of different kinds of F\&V children have ever tasted (Resnicow et al., 1997). Although effects of exposure to one specific vegetable on children's consumption have been reported (Jane Wardle et al., 2003) only the study by Resnicow and colleagues (1997) focused on exposure to a variety of $\mathrm{F} \& \mathrm{~V}$, and found a positive relation with $\mathrm{F} \& \mathrm{~V}$ consumption.

Recently, Brug and colleagues studied the role of habit regarding fruit consumption. Their study found habit and intention to be significant predictors of consumption of two or more daily servings of fruit, identifying habit as the most influential predictor (Brug et al., 2006).

Although the above-mentioned factors regarding F\&V consumption have been studied previously, no efforts have been made to look into the contribution of each factor in combination with the others. The current study aimed to combine traditional psychosocial factors (attitude, social influence and self-efficacy) with additional factors (parents' F\&V consumption, availability and accessibility of F\&V in the home, exposure to $F \& V$ and habit) to explain the F\&V consumption of children aged 4 to 12 years.

\section{METHODS}

\section{Subjects and procedures}

Data were used from a convenience sample consisting of parents of children participating in a larger longitudinal study, which focused on the F\&V intake of children at primary school. 
A total of 49 primary schools from the southern part of the Netherlands were selected. School boards were approached by mail and telephone and invited to take part in the study. This procedure resulted in the participation of 12 schools (a response of 25\%) with a total of 2506 pupils (aged 4 to 12 years). The parents of these children were invited to participate in the study through an information sheet that the children took home. Questionnaires were distributed and collected by the teachers. A total of 1739 parents completed the questionnaire and handed it in at the school (a response of $69 \%)$.

\section{Questionnaire}

A written questionnaire was developed based on social cognitive theories, recent literature on factors that influence children's F\&V consumption and qualitative interviews with children and parents (Chapter 2).

Background characteristics of the children included age, sex, and ethnicity. Ethnicity of the children was assessed by asking for the country of birth of both parents. Children were classified as 'of Dutch origin' when both parents had been born in the Netherlands and as 'non-native' when one or both parents had been born outside the Netherlands, based on the definition used by Statistics Netherlands (Centraal Bureau voor de Statistiek (CBS), 2005). In addition, the questionnaire included questions about family composition (marital status and number of siblings), educational level of the parent(s) and the weight and height of the children.

F\&V Intake. Both fruit- and vegetable consumption were measured with frequency methods that were used in a similar Dutch national project (www.schoolgruiten.nl) and based on the Pro-children questionnaire (Haraldsdóttir et al., 2005). Children's consumption of whole fruit was assessed by two questions: 'On how many days a week does your child eat fruit?' (I-7days) and 'How many portions of fruit does your child eat on a day on which he or she consumes fruit?', ranging from ' $1 / 2$ portion a day' to ' 3 portions a day or more' on a six-point scale. The average consumption of whole fruit (in portions per day) was calculated by multiplying the scores for both questions and dividing the outcome by 7 .

Children's vegetable consumption frequency was measured by three questions: 'How many times a week does the child eat (I) cooked or baked vegetables for dinner 
(including mixed dishes), (2) mixed dishes like pasta and (3) extra salad, like lettuce, tomato or other raw vegetables?'. Portion size was assessed by means of photographs of plates filled with different amounts of cooked vegetables (25-50-100-150 g) or mixed dishes (75-150-300-450 g). Parents had to select the photograph that best represented the amount of the food that their children usually consumed. According to the Netherlands Nutrition Centre, the average share of vegetables in a mixed dish is one third. The amount of extra salad or raw vegetables was calculated by multiplying frequency per week by $35 \mathrm{~g}$ (the weight of a small bowl of salad). Finally, the average consumption of vegetables in grams per day was computed as ((number of days on which the children consumed cooked or baked vegetables * portion size) plus (number of days on which the children ate mixed dishes* .33 portion size) plus (number of days on which the children ate extra salad or raw vegetables *35 gram)) / 7 days.

Psychosocial factors. All psychosocial factors were assessed separately for fruit consumption and for vegetable consumption, using the same format. Table I presents the psychosocial concepts, numbers of items, range, Cronbach's alpha and mean scores.

Attitude. Separate confirmatory principal component analysis (PCA) with oblique rotation was used to extract one factor for attitude towards fruit consumption, with factor loadings ranging from .83 to .52 , and one factor for attitude towards vegetable consumption, with factor loadings ranging from .87 to .66 . The PCA for Preference for fruit extracted two factors: preference for tropical or exotic fruit (litchis, mangoes, passion fruits, pineapples, melons, kiwi fruits, and peaches), with factor loadings ranging from .87 to .52 , and preferences for traditional Dutch fruit (including apples, bananas, tangerines, oranges, pears, grapes, and strawberries), with factor loadings ranging from .7I to .39. The PCA for preference for vegetables revealed three factors: preference for Dutch cooked vegetables (cauliflower, broccoli, carrots, beans, cabbage, Brussels sprouts, and spinach), with factor loadings ranging from .77 to .45 , preference for raw vegetables (cucumber, lettuce, and tomato), with factor loadings varying from .79 to .72 , and preferences for vegetables children generally dislike (egg plant, zucchini, leek, sweet pepper, and radish), with factor loadings ranging from -.77 to -.40 . 
Social influence was assessed with two concepts: modelling by important others (mother, father, classmates, teacher, and peers) and subjective norm. The PCA revealed two factors for modelling of fruit consumption: modelling outside the home (teachers, friends, and classmates), with factor loadings ranging from .96 to .69 , and modelling by parents, with factor loadings .9I and .66. The PCA for vegetable consumption revealed the same factors (factor loadings from .98 to .73 and from .90 and .89 for modelling outside the home and modelling by parents, respectively). Due to the low internal consistency of the items included in the modelling by parents factor $(\alpha<.48)$, these were treated as separate variables in further analyses.

Table I Description of psychosocial variables, numbers of items, mean (SD), internal consistency, sample items and range

\begin{tabular}{|c|c|c|c|c|}
\hline & $\begin{array}{l}\text { No. of } \\
\text { items }\end{array}$ & Mean (SD) & $\begin{array}{l}\text { Internal } \\
\text { Consistency } \\
(\alpha)\end{array}$ & $\begin{array}{l}\text { Examples of questions, answering options } \\
\text { and ranges }\end{array}$ \\
\hline \multicolumn{5}{|l|}{ Fruit consumption } \\
\hline Attitude & 7 & $.92(.78)$ & .85 & $\begin{array}{l}\text { My child thinks that eating more fruit will } \\
\text { make him/her more healthy; totally } \\
\text { disagree }(-2) \text { to totally agree }(+2)\end{array}$ \\
\hline $\begin{array}{l}\text { Preferences for } \\
\text { Dutch fruits }\end{array}$ & 7 & I.II (.63) & .76 & $\begin{array}{l}\text { How much does your child like: apples, } \\
\text { oranges, mandarins etc.; likes them a lot } \\
(+2) \text { to does not like them at all }(-2)\end{array}$ \\
\hline $\begin{array}{l}\text { Preferences for } \\
\text { tropical fruits }\end{array}$ & 7 & $.70(.85)$ & .88 & $\begin{array}{l}\text { How much does your child like: } \\
\text { pineapples, melons, kiwi fruits, passion } \\
\text { fruits etc.; likes them a lot }(+2) \text { to does } \\
\text { not like them at all }(-2)\end{array}$ \\
\hline $\begin{array}{l}\text { Modeling outside } \\
\text { the home }\end{array}$ & 3 & $.29(.65)$ & .86 & $\begin{array}{l}\text { My child's teacher eats fruit everyday; } \\
\text { totally disagree }(-2) \text { to totally agree }(+2)\end{array}$ \\
\hline $\begin{array}{l}\text { Modeling by } \\
\text { mother }\end{array}$ & I & $.83(1.26)$ & - & $\begin{array}{l}\text { My child's mother eats fruit everyday; } \\
\text { totally disagree }(-2) \text { to totally agree }(+2)\end{array}$ \\
\hline Modelling by father & 1 & $.56(1.44)$ & - & $\begin{array}{l}\text { My child's father eats fruit everyday; } \\
\text { totally disagree }(-2) \text { to totally agree }(+2)\end{array}$ \\
\hline $\begin{array}{l}\text { Subjective norm } \\
(\mathrm{nb} * \mathrm{mc})\end{array}$ & 2 & $2.11(5.10)$ & - & - \\
\hline Self-efficacy & 2 & $.82(.89)$ & .77 & $\begin{array}{l}\text { Do you think you child is able to increase } \\
\text { her/his fruit consumption? Definitely not (- } \\
\text { 2) to definitely so }(+2)\end{array}$ \\
\hline $\begin{array}{l}\text { Intention to eat } \\
\text { more fruit }\end{array}$ & 1 & $.20(.93)$ & - & $\begin{array}{l}\text { Does your child intend to eat more fruit? } \\
\text { Definitely not }(-2) \text { to definitely so }(+2)\end{array}$ \\
\hline
\end{tabular}


Table I (continued) Description of psychosocial variables, numbers of items, mean (SD), internal consistency, sample items and range

\begin{tabular}{|c|c|c|c|c|}
\hline & & No. of items & Mean (SD) & $\begin{array}{l}\text { Internal } \\
\text { Consistency } \\
(\alpha)\end{array}$ \\
\hline \multicolumn{5}{|c|}{ Vegetable consumption } \\
\hline Attitude & 7 & $.93(.83)$ & .89 & $\begin{array}{l}\text { My child thinks that eating more } \\
\text { vegetables will make her/him more } \\
\text { healthy; totally disagree }(-2) \text { to totally } \\
\text { agree }(+2)\end{array}$ \\
\hline $\begin{array}{l}\text { Preference for } \\
\text { traditional Dutch } \\
\text { vegetables }\end{array}$ & 7 & $.55(.74)$ & .76 & $\begin{array}{l}\text { How much does your child like the } \\
\text { following vegetables: carrots, beans, } \\
\text { cauliflower etc; likes them a lot }(-2) \text { to } \\
\text { does not like them at all }(+2)\end{array}$ \\
\hline $\begin{array}{l}\text { Preference for raw } \\
\text { vegetables }\end{array}$ & 3 & $.78(1.00)$ & .73 & $\begin{array}{l}\text { How much does your child like the } \\
\text { following vegetables: lettuce, cucumber, } \\
\text { tomato; likes it a lot }(+2) \text { to does not like } \\
\text { it at all }(-2)\end{array}$ \\
\hline $\begin{array}{l}\text { Preference for } \\
\text { generally disliked } \\
\text { vegetables }\end{array}$ & 5 & $-.17(.80)$ & .77 & $\begin{array}{l}\text { How much does your child like the } \\
\text { following vegetables: egg plant, courgette } \\
\text { etc.; likes it a lot }(+2) \text { to does not like it at } \\
\text { all }(-2)\end{array}$ \\
\hline $\begin{array}{l}\text { Modelling outside } \\
\text { the home }\end{array}$ & 3 & $.31(.61)$ & .85 & $\begin{array}{l}\text { My child's teacher eats vegetables } \\
\text { everyday; totally disagree }(-2) \text { to totally } \\
\text { agree }(+2)\end{array}$ \\
\hline $\begin{array}{l}\text { Modelling of } \\
\text { mother }\end{array}$ & 1 & $\mathrm{I} .72(.62)$ & - & $\begin{array}{l}\text { My child's mother eats vegetables } \\
\text { everyday; totally disagree }(-2) \text { to totally } \\
\text { agree }(+2)\end{array}$ \\
\hline Modelling of father & I & $1.67(.76)$ & - & $\begin{array}{l}\text { My child's father eats vegetables everyday; } \\
\text { totally disagree }(-2) \text { to totally agree }(+2)\end{array}$ \\
\hline $\begin{array}{l}\text { Subjective norm } \\
(\mathrm{nb} * \mathrm{mc})\end{array}$ & 2 & $2.18(5.16)$ & - & - \\
\hline Self-efficacy & 2 & $.12(.92)$ & .81 & $\begin{array}{l}\text { Do you think you child is able to increase } \\
\text { her/his vegetable consumption? Definitely } \\
\text { not }(-2) \text { to definitely so }(+2)\end{array}$ \\
\hline $\begin{array}{l}\text { Intention to eat } \\
\text { more vegetables }\end{array}$ & 1 & $-.12(.88)$ & - & $\begin{array}{l}\text { Does your child intend to eat more } \\
\text { vegetables? Definitely not }(-2) \text { to definitely } \\
\text { so }(+2)\end{array}$ \\
\hline
\end{tabular}

The scores for subjective norm for both fruit consumption and vegetable consumption were calculated by multiplying the item that measured motivation to comply ('My child does what we tell him/her to do'; totally disagree (I) to totally agree (5)) with the item that measured normative belief towards the parents ('My child thinks we want him/her to eat more fruit or vegetables; totally disagree (I) to totally agree (5)).

Self-efficacy was assed by two items and intention to eat more fruit was assessed with one. 
The following additional factors were assessed:

Availability of F/V was assessed by two questions: 'Do you always have F/V available at home?' and 'Do you always have F/V that your child likes available at home?' ('Yes, always' (+2) to 'No, never' (-2)). Internal consistency for availability of fruit was $\alpha=.68$ and that for vegetables $\alpha=.54$.

Accessibility (ready-to-eat availability) was measured by one item : 'Do you or your partner prepare F/V for your child (slicing, washing, peeling)?' Respondents could choose from four answers, namely 'My child prepares his or her own fruit' (I), 'Sometimes my child prepares his/her own fruit and sometimes I prepare it' (2) , 'I or my partner always prepare fruit for my/our child' (3) and the last option was 'My child never eats vegetables as a snack'. For the children that did eat vegetables as a snack, the item was dichotomized into made accessible by parents (I) or not made accessible by parents (0).

F\&V exposure was assessed by asking if the child had ever tasted 14 common kinds of fruit and 15 kinds of vegetables (yes/no). Sum scores for taste exposure to fruit and to vegetables were calculated by adding the scores of all items for fruit and those for vegetables.

Habit regarding fruit or vegetable consumption was assessed by three items: 'My child eats F/V routinely', 'Eating F/V suits my child' and 'My child has been eating F/V for a long time', using five answering categories ranging from 'totally agree' to 'totally disagree' (fruit $\alpha=.83$; vegetables $\alpha=.86$ ). The items were selected from the Self-Report Index of Habit Strength (Verplanken \& Orbell, 2003) during a preliminary study (unpublished data) of the Pro Children Project (de Bourdeaudhuij, Klepp, Wind, Due, \& Brug, 2005). They each represent one of the three features of habit strength, namely a history of repetition, automaticity and reflection of personal identity (Verplanken \& Orbell, 2003).

Parental F\&V consumption was assessed with a validated 10 -item questionnaire in which parents were asked to indicate their consumption of citrus fruit, other fruit, and fruit juice, and cooked and raw vegetables (van Assema, Brug, Ronda, Steenhuis, \& Oenema, 2002). 


\section{Statistical analyses}

Data analyses included descriptive statistics of the demographic factors and F\&V consumption. To correct for skewness, the analyses used the square root transformation of the fruit and vegetable intake variables, as recommended by Tabachnick and Fidell (1996). Since we had a nested sampling design (pupils within classes within schools) separate stepwise multi-level regression analyses (Rasbash, Browne, \& Goldstein, 2000) were used to identify factors associated with fruit consumption and with vegetable consumption. To identify interaction-effects with gender and ethnicity, two separate analyzes were performed; (I) including all interactions with gender and (2) including all interactions with ethnicity (separately for fruit and vegetable consumption). All models were adjusted for the following demographic variables: child's sex, age, ethnicity, BMI, siblings (yes/no), and parents' age, marital status and educational level (low-intermediate-high). Attitude, social influence, and self-efficacy were entered in step one, and intention was added in step two. Subsequently, the additional factors of availability, accessibility, F\&V exposure and parental consumption were entered in step three. Finally, habit was entered into the model in step four. A significance criterion of $p<0.05$ was used for both addition and removal of variables. The analyses for fruit consumption did not include the factor preference for tropical fruit, because of too many missing values due to the fact that most of the children had never tasted the tropical fruits. The factor accessibility had to be excluded from the analyses regarding vegetable consumption, because too many parents indicated that their child did not consume vegetable as a snack. Modelling outside the home was not included in the analyses of both fruit- and vegetable consumption, because most children indicated that they did not know whether the mentioned people consumed F\&V everyday. Preliminary stepwise linear regression analyses using pairwise deletion indicated that none of these excluded variables contributed significantly to the explanation of F\&V-consumption, which makes exclusion justifiable.

\section{RESULTS}

The questionnaires were predominantly filled out by the mothers (85\%). Of the parents who filled out the questionnaire, $27 \%$ had a low educational level (primary 
school or basic vocational school), about half (54\%) had an intermediate level of education (secondary vocational school or high school) and 19\% had a high level of education (higher vocational school or university). Of their spouses, $27 \%$ had a low, $46 \%$ an intermediate and $27 \%$ a high level of education. The average age of the child for whom the questionnaire was filled out was 8 (SD 2.5) years. Of these children, $50 \%$ were male. Most of the children had one or more siblings ( $86 \%$ ) and $38 \%$ of the children were non-native. Almost all children (93\%) were part of a two-parent family. According to the Dutch BMI ranges (Hirasing, Fredriks, Buuren van, VerlooveVanhorick, \& Wit, 200I; van Buuren, 2004) which take children's sex and age into account, $19 \%$ of the children were underweight, $67 \%$ had a normal weight and $14 \%$ were overweight. Children consumed about one portion of fruit and about $60 \mathrm{~g}$ of vegetables a day. Parents consumed about two and a half portions of fruit and about three tablespoons $(\cong \mathrm{I} 50 \mathrm{~g})$ of vegetables a day.

Correlations of psychosocial variables and additional factors with F\&V intake All concepts except intention correlated significantly with the children's fruit intake, with correlations ranging from -.05 to $.63(p<0.05)$. Correlations between children's vegetable intake and the various concepts were significant. The correlations ranged from -.05 to $.48(p<0.05)$. Both fruit and vegetable intake had their highest correlation with habit. Intercorrelations between all concepts ranged from -.05 to $.63(p<0.05)$ for the concepts related to fruit intake and from -.05 to $.57(p<0.05)$ for vegetable intake. Correlations are presented in Table $2 \mathrm{a}$ and $2 \mathrm{~b}$. 


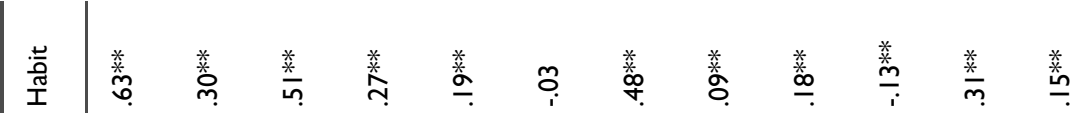
บ 菜

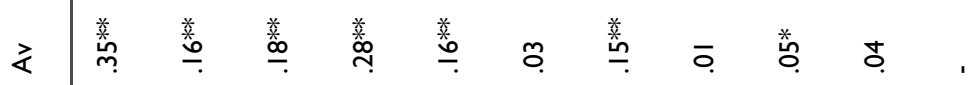

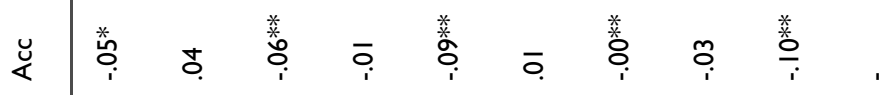

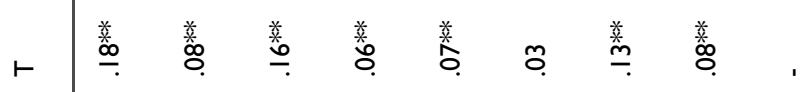

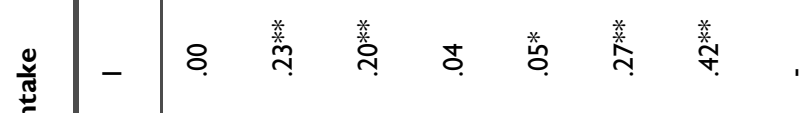

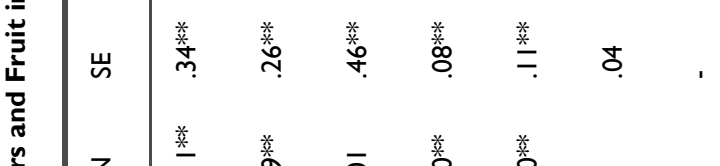
菢 岕

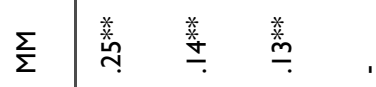

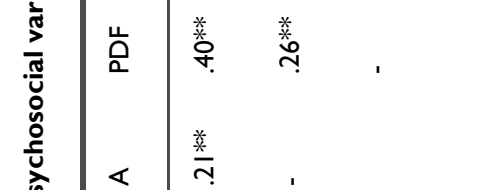

눔

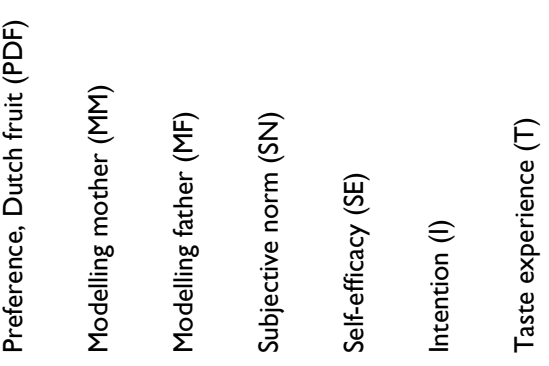




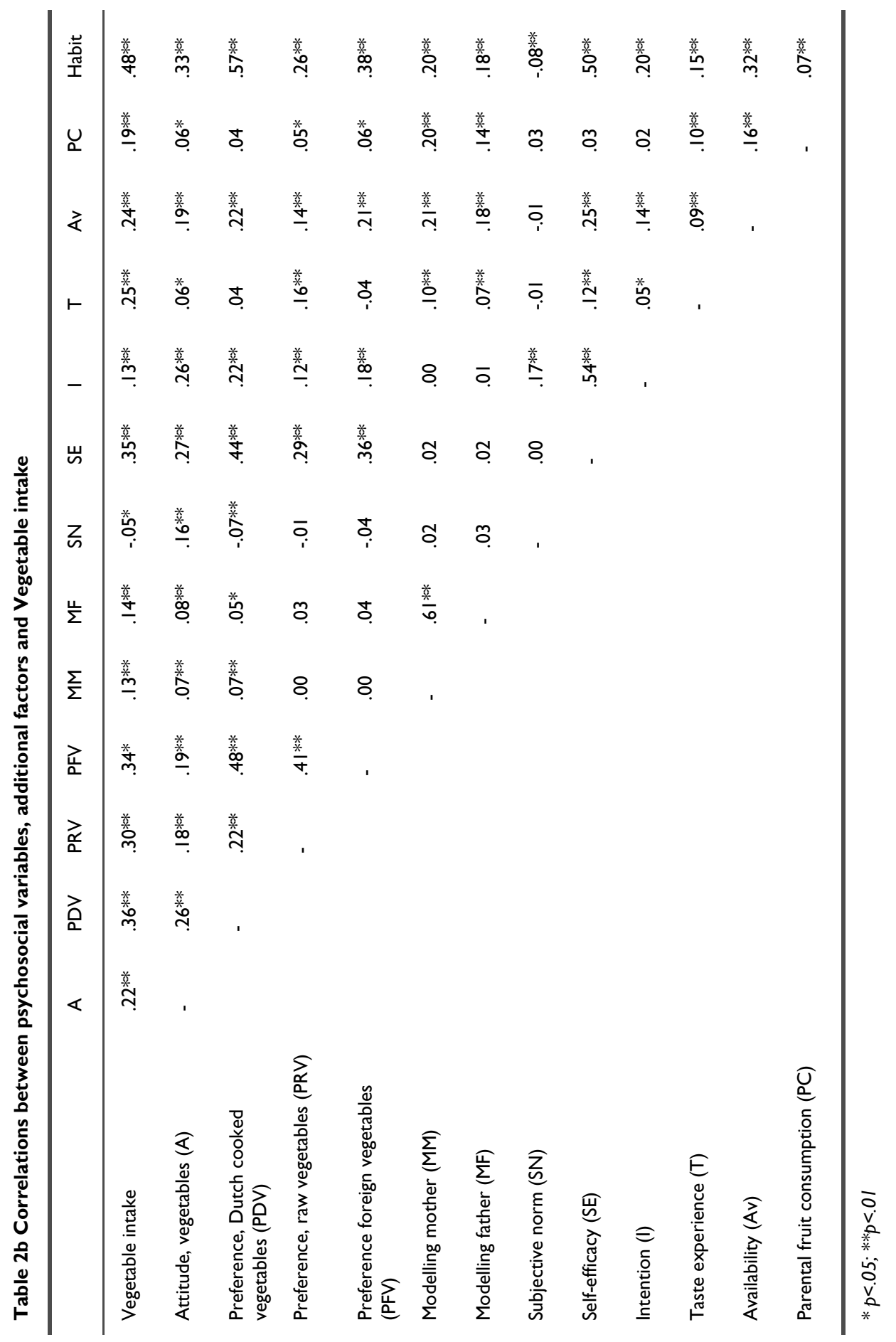


Factors associated with fruit and vegetable consumption

The results of the multi-level regression analyses we did to explain the children's fruit and vegetable consumption are shown in table 3 and 4, respectively. Table 3a and 4a show the results of the analyses including interactions with gender and in table $3 \mathrm{~b}$ and $4 \mathrm{~b}$ show these results for interactions with ethnicity.

\section{Fruit consumption and gender}

The first model for fruit consumption included the psychosocial variables and explained $29 \%$ of the variance. Preference for Dutch fruit, and self-efficacy were identified as most influential correlates of fruit consumption, although the latter seems more influential for girls than for boys. In Model 2, the intention to eat more fruit was added; it contributed an additional $3 \%$ of explained variance $\left(\operatorname{LR}_{2}=44.05 ; p<.001\right)$. All predictors of model I remained significant and intention appeared to more influence girl's fruit consumption. In Model 3, fruit exposure, availability and accessibility, and parental consumption were added, explaining an additional 5\% $\left(\operatorname{LR}_{4}=\mid 43.20 ; p<.00 I\right)$, identifying availability as most influential addition to the model. Finally, habit was entered, and the resulting final model explained $50 \%\left(\mathrm{LR}_{2}=327.95 ; \mathrm{p}<.00 \mathrm{I}\right)$ of the variance in fruit consumption. Furthermore, habit showed to be the most influential correlate in this final model for both boys $(\beta .19, \mathrm{p}<.001)$ and girls $(\beta .13, \mathrm{p}<.00 \mathrm{I})$.

Table 3a Multilevel regression analyses explaining children's fruit consumption including interactions with gender ${ }^{a}$

\begin{tabular}{|c|c|c|c|c|}
\hline $\begin{array}{l}\text { Variables regarding } \\
\text { fruit consumption }\end{array}$ & $\begin{array}{l}\text { Model I } \\
\beta^{\mathrm{b}}\end{array}$ & $\begin{array}{l}\text { Model } 2 \\
\beta^{b}\end{array}$ & $\begin{array}{l}\text { Model } 3 \\
\beta^{b}\end{array}$ & $\begin{array}{l}\text { Model } 4 \\
\beta^{b}\end{array}$ \\
\hline Attitude, fruit & $.04^{* * * *}$ & $.05^{* * * *}$ & $.04 * * *$ & .01 \\
\hline Preference, Dutch fruit & $.15^{* * *}$ & $.15^{* * *}$ & $.13 * * *$ & $.05^{* * * *}$ \\
\hline Modelling by mother & $.05 * * *$ & $.04 * * *$ & $.02 * * *$ & .01 \\
\hline Modelling by father & $.02 * * *$ & $.02 * * *$ & $.02 * *$ & .01 \\
\hline Subjective norm & $-.01 * * *$ & $-.01 * * *$ & $-.01 * * *$ & $-.01 * * *$ \\
\hline Self-efficacy ${ }^{c}$ & $.07 * * * / 09 * * *$ & $.09 * * * / .12 * * *$ & $.08 * * * / .11 * * *$ & $.01 / .06 * * *$ \\
\hline Intention ${ }^{c^{\prime}}$ & & $-.05 * * * /-.07 * * *$ & $-.05 * *-.08 * * *$ & $-.02 /-.06 * * *$ \\
\hline Fruit exposure & & & $.02 * *$ & .01 \\
\hline Accessibility & & & -.04 & .01 \\
\hline Availability & & & $.12 * * *$ & $.08 * * *$ \\
\hline Parental fruit consumption & & & $.03 * * *$ & $.02 * * *$ \\
\hline Habit $^{c}$ & & & & $.19 * * * / .13 * * *$ \\
\hline Explained variance $\left(\mathrm{R}^{2}\right)$ & .29 & .32 & .37 & .50 \\
\hline
\end{tabular}

a All models were adjusted for baseline model variables (parents' age, educational level and marital status, child's age, sex, BMI and ethnicity; family composition (siblings \& marital status); ${ }^{b}$ Standardized regression coefficients; ${ }^{*} p<0.05 ;{ }^{* *} p<0.01 ;{ }^{* * *} p<0.001$; ${ }^{c} \beta$ 's are presented for boys/girls. 


\section{Fruit consumption and ethnicity}

If we take ethnicity into consideration, it appears that fruit consumption is determined by different variables for native and non-native children. If we look at the first three models we see that for native children preference for Dutch fruit is the most influential correlate $(\beta .18 ; \beta .17 ; \beta .15 ; p<.001)$, whereas for non-native children this is attitude ( $\beta$.I2; $\beta$.I2; $\beta$.II; $\mathrm{p}<.00 \mathrm{I})$, and to a lesser degree modelling of the mother $(\beta .08 ; \beta$ $.08 ; \beta .06 ; \mathrm{p}<.00 \mathrm{I})$,. Although self-efficacy is more important for non-native children $(\beta$ $.09 ; \beta .12 ; \beta .1 \mathrm{I} ; \mathrm{p}<.00 \mathrm{I})$, it is also an important correlate of fruit consumption for native children $(\beta .07 ; \beta .09 ; \beta .08 ; \mathrm{p}<.00 \mathrm{I})$. Adding intention to the first model resulted in an additional $3 \%$ explained variance $\left(L R R_{1}=40.17 ; \mathrm{p}<.001\right)$. Of the additional factors added in model $3\left(L_{5}=124.28 ; p<.00 I\right)$, availability seemed the most important for all children. The final model showed that habit was the most important correlate adding an extra $12 \%$ explained variance $(L R,=332.09 ; p<.00 I)$. No differences in the relation between habit and fruit consumption were detected for native and non-native children.

Table 3b Multilevel regression analyses explaining children's fruit consumption including interactions with ethnicity

\begin{tabular}{|c|c|c|c|c|}
\hline $\begin{array}{l}\text { Variables regarding } \\
\text { fruit consumption }\end{array}$ & $\begin{array}{l}\text { Model I } \\
\beta^{\text {b }}\end{array}$ & $\begin{array}{l}\text { Model } 2 \\
\beta^{b}\end{array}$ & $\begin{array}{l}\text { Model } 3 \\
\beta^{b}\end{array}$ & $\begin{array}{l}\text { Model } 4 \\
\beta^{b}\end{array}$ \\
\hline Attitude, fruit ${ }^{\mathrm{c}}$ & $.02 / .12^{* * *}$ & $0.3 * 1.12 * * *$ & $.03 * / .11 * * *$ & $.00 / .06 * *$ \\
\hline Preference, Dutch fruit & $.18 * * * / .05$ & $.17 * * * 1.05$ & $.15 * * * 1.03$ & $.07 * * * / .03$ \\
\hline Modelling by mother ${ }^{c}$ & $.04 * * * / .08 * * *$ & $.04 * * * 1.08 * * *$ & $.01 * 1.06 * * *$ & $.00 / .06 * * *$ \\
\hline Modelling by father & $.02 * * *$ & $.02 * * *$ & $.01 * *$ & .01 \\
\hline Subjective norm ${ }^{c}$ & $\begin{array}{l}-.01 * * * /- \\
.01 * * *\end{array}$ & $-.0 \mathrm{I} * * * /-.0 \mathrm{I} * * *$ & $-.00 * * * /-.01 * * *$ & $-.00 * * /-.01 * * *$ \\
\hline Self-efficacy ${ }^{c}$ & $.06 * * * .10 * * *$ & $.09 * * * 1.12 * * *$ & $.08 * * * / .11 * * *$ & $.02 / .11 * * *$ \\
\hline Intention & & $-.06 * * *$ & $-.06 * * *$ & $-.04 * * *$ \\
\hline Fruit exposure & & & $.02 * *$ & .01 \\
\hline Accessibility & & & -.04 & .01 \\
\hline Availability & & & $.12^{* * *}$ & $.08 * * *$ \\
\hline Parental fruit consumption ${ }^{c}$ & & & $.03 * * * / .02 * * *$ & $.03 * * * 1.02 * * *$ \\
\hline Habit & & & & $.16 * * *$ \\
\hline Explained variance $\left(\mathrm{R}^{2}\right)$ & .28 & .31 & .37 & .49 \\
\hline
\end{tabular}


Vegetable consumption and gender

The same procedure was followed for vegetable consumption. In the first model, all psychosocial factors were entered; these explained $26 \%$ of the variance in vegetable consumption. Preferences for traditional Dutch cooked vegetables, preference for disliked vegetables and modelling by mother were identified as most influential correlates of vegetable consumption. Intention (entered in the second model) explained a further $2 \%$ of the variance $\left(L R_{1}=9.50 ; p<.01\right)$, as did the additional factors in model $3\left(\mathrm{LR}_{3}=37.30 ; \mathrm{p}<.00 \mathrm{I}\right)$. Of these factors only availability seemed not significantly correlated with vegetable consumption. The final model included habit and explained $33 \%$ of the variance $\left(L_{2}=47.73 ; \mathrm{p}<.00 \mathrm{I}\right)$. Although habit was more influential for boys $(\beta .50, \mathrm{p}<.00 \mathrm{I})$ than for girls $(\beta .30, \mathrm{p}<.00 \mathrm{I})$, it was still the most influential correlate in relation to vegetable consumption.

Table 4a Multilevel regression analyses explaining children's vegetable consumption including interactions with gender

\begin{tabular}{|c|c|c|c|c|}
\hline $\begin{array}{l}\text { Variables regarding } \\
\text { vegetable consumption }\end{array}$ & $\begin{array}{l}\text { Model I } \\
\beta^{\mathrm{b}}\end{array}$ & $\begin{array}{l}\text { Model } 2 \\
\beta^{b}\end{array}$ & $\begin{array}{l}\text { Model } 3 \\
\beta^{b}\end{array}$ & $\begin{array}{l}\text { Model } 4 \\
\beta^{b}\end{array}$ \\
\hline Attitude, vegetables &. $.23 * * *$ & $.25 * * *$ & $.24 * * *$ & $.15^{* *}$ \\
\hline $\begin{array}{l}\text { Preference, Dutch cooked } \\
\text { vegetables }\end{array}$ & $.32 * * *$ & $.33^{* * * *}$ & $.31 * * *$ & $.16^{*}$ \\
\hline Preference, raw vegetables & $.24 * * *$ & $.24 * * *$ & $.22 * * *$ & $.18 * *$ \\
\hline $\begin{array}{l}\text { Preference, disliked } \\
\text { vegetables }\end{array}$ & $.31 * * *$ & $.30 * *$ & $.31 * * *$ & $.28 * * *$ \\
\hline Modelling by mother & $.34 * *$ & $.34 * *$ & $.24 *$ & .17 \\
\hline Modelling by father & .10 & .09 & .07 & .05 \\
\hline Subjective norm & -.01 & -.01 & -.01 & -.01 \\
\hline Self-efficacy & $.25 * * *$ & $.34 * * *$ & $.32 * * *$ & $.19 * *$ \\
\hline Intention & & $-.19 * *$ & $-.19 * *$ & $-.15 *$ \\
\hline Vegetable exposure & & & $.14 * *$ & $.12 * *$ \\
\hline Availability & & & -.03 & -.04 \\
\hline $\begin{array}{l}\text { Parental vegetable } \\
\text { consumption }\end{array}$ & & & $.14 * * *$ & $.14 * * *$ \\
\hline Habit $^{c}$ & & & & $.50 * * * / .30 * * *$ \\
\hline Explained variance $\left(\mathrm{R}^{2}\right)$ & .26 & .28 & .30 & .33 \\
\hline
\end{tabular}

a All models were adjusted for baseline model variables (parents' age, educational level and marital status, child's age, sex, BMI and ethnicity; family composition (siblings \& marital status); ${ }^{\mathrm{b}}$ Standardized regression coefficients; * $p<0.05 ; * * p<0.01$; *** $p<0.001$; ${ }^{c} \beta$ 's are presented for boys/girls

\section{Vegetable consumption and ethnicity}

If we look at ethnical differences in explaining vegetable consumption, we can conclude that the influence preference for Dutch cooked vegetables is only significant for native children in all models. The same holds for parental consumption in model 3 and 4 . All 
models added significantly to the explained variance; model 2 vs. I $(L R,=7.45 ; p<.0 \mathrm{I})$, model 3 vs. $2\left(L_{4}=44.00 ; p<.00 I\right)$, and model 4 vs. $3\left(L R_{1}=43.94 ; p<.00 I\right)$.

Table 4b including interactions with ethnicity

\begin{tabular}{|c|c|c|c|c|}
\hline $\begin{array}{l}\text { Variables regarding } \\
\text { vegetable consumption }\end{array}$ & $\begin{array}{l}\text { Model I } \\
\beta^{\text {b }}\end{array}$ & $\begin{array}{l}\text { Model } 2 \\
\beta^{b}\end{array}$ & $\begin{array}{l}\text { Model } 3 \\
\beta^{b}\end{array}$ & $\begin{array}{l}\text { Model } 4 \\
\beta^{\mathrm{b}}\end{array}$ \\
\hline Attitude, vegetables & $.21^{* * *}$ & $.23 * * *$ & $.22 * * *$ & $.14^{*}$ \\
\hline $\begin{array}{l}\text { Preference, Dutch cooked } \\
\text { vegetables }{ }^{c}\end{array}$ & $.48 * * * / .06$ & $.48 * * * / .11$ & $.46 * * * / .10$ & $.29 * * * /-.07$ \\
\hline Preference, raw vegetables & $.23 * * *$ & $.23 * * *$ & $.22 * * *$ & $.18 * * *$ \\
\hline $\begin{array}{l}\text { Preference, disliked } \\
\text { vegetables }\end{array}$ & $.33 * * *$ & $.32 * * *$ & $.34 * * *$ & $.27 * * *$ \\
\hline Modelling by mother & $.33 * *$ & $.33 * *$ & $.23^{*}$ & .15 \\
\hline Modelling by father & .11 & .10 & .09 & .07 \\
\hline Subjective norm & -.01 & -.01 & -.01 & -.01 \\
\hline Self-efficacy & $.26 * * *$ & $.34 * * *$ & $.32 * * *$ & $.18 * *$ \\
\hline Intention & & $-.17 * *$ & $-.16 * *$ & $-.13^{*}$ \\
\hline Vegetable exposure & & & $.13^{* *}$ & $-.11 * *$ \\
\hline Availability & & & .01 & -.07 \\
\hline $\begin{array}{l}\text { Parental vegetable } \\
\text { consumption }^{c}\end{array}$ & & & $.22 * * * / .07$ & $.22 * * * / .07$ \\
\hline Habit & & & & $.39 * * *$ \\
\hline Explained variance $\left(\mathrm{R}^{2}\right)$ & .27 & .28 & .30 & .33 \\
\hline
\end{tabular}

a All models were adjusted for baseline model variables (parents' age, educational level and marital status, child's age, sex, BMI and ethnicity; family composition (siblings \& marital status); ${ }^{\text {b }}$ Standardized regression coefficients; ${ }^{*}<<0.05 ;{ }^{* *} p<0.01$; ${ }^{* *} p<0.001$; ${ }^{c} \beta$ 's are presented for native/non-native children

\section{DISCUSSION}

The present study tried to identify whether factors other than psychosocial ones contribute to the explanation of children's F\&V consumption. Our study found that psychosocial factors do explain F\&V consumption in children, but that including additional factors such as 'availability', 'parental consumption' and 'habit' for fruit consumption and 'exposure', 'parental consumption' and 'habit' for vegetable consumption improved the proportion of explained variance in F\&V intake. 'Habit' was the strongest predictor of these additional factors for both fruit and vegetable consumption, but plays a different role for boys and girls. When 'habit' was added to the model, most psychosocial factors were less strongly correlated with fruit and vegetable consumption. Habit can be defined as perpetuated behaviour that has become habitual by repetition. When a habit is well established, conscious decision making processes no longer determine the behaviour (Ouelette \& Wood, 1998) and the psychosocial factors are therefore of less importance. Although an important feature of habit is a history of repetition (Verplanken \& Orbell, 2003), frequently 
repeated behaviour is not yet a habit. One of the other two features of habit is that it is a form of automaticity, which means that it is deliberate in its behavioural origin, controllable to a limited extent, executed without awareness, and efficient (Bargh, 1994). The final feature of habit, that it is a reflection of someone's personal style, may not hold for all habits, but at least does so for some (Verplanken \& Orbell, 2003).

The fact that habit added a further $13 \%$ of explained variance for fruit, but only $3 \%$ for vegetable consumption indicates that this factor plays a somewhat different role for these two behaviours, in that vegetable consumption is less habitual than fruit consumption. This could be caused by the fact that vegetable consumption by children is often a topic of argument in many households. Many children are more or less forced to 'eat their veggies'. On the other hand, fruit is mostly consumed volitionally and therefore has more potential to become routine. Furthermore, one of the features of habit is that it reflects someone's personal style. Whereas volitional behaviour such as fruit consumption may or may not suit someone, this is unlikely for behaviour that is imposed by others, such as vegetable consumption by children.

Although habit explained the largest amount of additional variance, the factors of 'exposure', 'parental consumption', and 'availability' were also particularly important in explaining children's F\&V consumption. Our results support findings of similar studies (Bere \& Klepp, 2004; Domel Baxter et al., 1996; Gibson et al., 1998; Resnicow et al., 1998), which found that preference is a factor that cannot be ignored in interventions to promote F\&V intake. A study by Wardle (2003) showed that exposure to a particular vegetable for as little as a fortnight can increase children's liking for that vegetable. Our results showed that exposure contributes to the explanation of vegetable consumption even when controlling for preferences. Although the concept is rarely used in determinant studies, it holds important implications for intervention development. Until recently, it was believed that exposure or experience with different tastes was mediated by preference, as was claimed in a review by Birch (1998). She found that after repeated opportunities (5 to 10 times) to try new foods, the liking for the new foods generally increased, leading to greater intake (Birch \& Fisher, 1998). In our study, we operationalized exposure as 'the number of different kinds of F\&V ever tasted', and this showed only moderate associations with preferences, but also contributed to explaining vegetable intake after correction for 
preferences. These results indicate that mere exposure is not only a method for the development of preferences, but that simply recognizing what one was exposed to, may influence consumption. More research into this relationship should yield valuable implications for practice. Consistent with previous research findings (Cooke et al., 2003; Fisher et al., 2002; Gibson et al., 1998; Wind, de Bourdeaudhuij et al., 2006), we found that 'parental consumption' was an important correlate of both fruit and vegetable intake, especially in native children. 'Subjective norm' also remained significant after controlling for habit, but only for fruit consumption. The key role parents play in shaping their children's dietary intake is widely documented and it is especially their role as models that is often stressed (Birch \& Fisher, 1998; Golan \& Crow, 2004). Results of a study that compared the influences of actual parental intake (defined as modelling) and parental control of their children's diet (using rules or rewards) on children's consumption of snack foods showed that modelling of the parents was positively related to children's intake, whereas parents' attempts to use snack food as a reward for the consumption of healthier foods was found to have an adverse effect (Brown \& Ogden, 2004). Although research indicates that the way parents try to control their children's diet does not always influence intake in the way the parents intended (Johnson \& Birch, 1994), parents still believe that these methods can have the desired effect (Burroughs \& Terry, 1992). This indicates that health educators must recognize this misconception and develop interventions that teach parents that a parental role model may be a better method to improve children's F\&V consumption than force. Availability also contributed to explaining the children's F\&V consumption, as has also been found in other studies (Corwin et al., 1999; Reynolds et al., 1999; Weber Cullen et al., 2003). Unlike these studies, however, we studied fruit and vegetable consumption separately, and our results indicate that availability is only important for fruit consumption. This could be explained by the fact that vegetables are usually served for dinner. Fruit consumption is more fully under the children's control, so if a child chooses to eat fruit, availability is the factor that either facilitates or impedes this behaviour. Finally, our study showed that fruit and vegetable consumption are different behaviours, which are influenced by different factors, as has also been found in other studies (Vereecken et al., 2005; Weber Cullen et al., 200I). Consistent with a study among young adolescents (Granner et al., 2004), we showed 
that different factors explain F\&V consumption for children of different ethnic background. For native children F\&V preferences and parental consumption are important factors to consider when explaining F\&V consumption, whereas for nonnative children attitude, modelling of the mother and self-efficacy are important.

Some limitations of our study should be noted. All data was gathered from parents who reported on behalf of their children. This may have resulted in less reliable data on the children's food intake (Livingstone \& Robson, 2000). However, we chose this method because we wanted to identify factors that influence children's F\&V consumption in a broad age group (4-12 years). We realize that different factors are likely to be important for children of a young age compared to older children, for example because of higher food choice autonomy. This warrants further study. Since self-reporting food intake requires several cognitive abilities that are only found in children aged at least eight years (Livingstone \& Robson, 2000), we had to rely on the parents. Although previous research showed that perceptions of concepts could differ between children and their parents (Bere \& Klepp, 2004; van Assema, Glanz, Martens, \& Brug, 2007), it remains unclear what source is more reliable. Therefore, we decided to rely on parental reports for all children. Furthermore, the major limitation of this study is the use of a cross-sectional design. Therefore no predictive relationships can be inferred. Insight into the predictive relationships between determinants and F\&V consumption can only be achieved through longitudinal determinant research.

The results of the current study have several practical implications for promoting F\&V consumption by children. First, considering that habit plays such an important role in both fruit consumption and vegetable consumption, interventions to motivate children to consume F\&V can be made more effective by combining them with strategies to make this behaviour habitual. In doing so, it must be taken into account that fruit consumption and vegetable consumption are clearly different behaviours, with different influencing factors. Although these factors differ for gender and ethnicity, the majority of the most influential correlates, such as habit and availability for fruit and habit and taste preferences for vegetable consumption are the same among all subgroups. This justifies the development of classroom-based interventions. Second, our results concerning environment-related factors such as parental consumption, exposure to $\mathrm{F} \& \mathrm{~V}$, and availability not only illustrate the 
important role of the environment in children's F\&V consumption, but also indicate that parents have to be included in interventions aimed at children. 


\section{Chapter 4}

\section{Parental versus child reporting of fruit $\&$ vegetable consumption}




\section{ABSTRACT}

Background: The purpose of this study was to (I) compare parental and child recording of children's fruit and vegetable (F\&V) consumption, including family-related factors, and (2) to investigate the potential differences in the relation of children's and parents' perceptions of family-related factors.

Methods: Children were recruited from Dutch seventh and eighth grade classrooms. Each child and one of their parents completed parallel questionnaires. A total of 37I matched child-parent surveys were included in the analyses. To compare parental and child reports of consumption and family-related factors regarding F\&V intake several techniques were used such as paired sample t-test, chi-square tests, Pearson's correlations and Cohens's kappa as measurement of agreement. To investigate potential differences between the parent's and children's perceptions of family-related factors, linear regression analyses were conducted.

Results: The results indicated weak agreement for F\&V consumption (Cohen's kappa coefficients of .31 and .20 , respectively) but no differences in mean consumption of fruit at the group level. Regarding the family-environmental factors related to fruit consumption, significant differences were found between the perceptions of subjective norm, and the availability and accessibility of fruit. Perceptions of subjective norm, parental modelling and exposure regarding vegetable consumption were also viewed differently by the two groups. The family-environmental factors reported by the children were similarly associated with F\&V consumption compared to those reported by their respective parents. However, parents rated these factors more favourably than their children did.

Conclusions: The results indicated a low level of agreement between parental and child reporting of F\&V intake and their assessment of family-environmental factors on individual level. This has important implications for the development and evaluation of interventions and we recommend that researchers clearly indicate which source of information they use in their studies as it remains unclear which source is more valid. However, when the effects of interventions are studied at the group level, our results suggest that it makes no difference whether children or parents report the child's fruit 
consumption. The same holds for determinant studies; both parental and child reports can be used. However, perceptions of these factors differ significantly. 


\section{BACKGROUND}

Since the World Health Organization adopted a worldwide strategy making the promotion of a healthy diet a priority in public health policy (WHO, 2004), there has been an increase in the number of initiatives undertaken to promote healthy eating habits such as the daily consumption of sufficient amounts of fruit and vegetables (F\&V). Many of these initiatives focus on children (Pomerleau et al., 2005) because adult eating habits are acquired during childhood (Kelder et al., 1994; Lien et al., 200I) and children are more apt to change their dietary patterns (Birch, 1990).

Recently, several primary school programmes have been developed to increase the poor consumption of F\&V (Anonymous, 1998) among Dutch children aged 4 tol 2 (Brug et al., 2005); Chapter 5). The social ecological perspective (Sallis \& Owen, 1997) assumes that the effectiveness of interventions can be enhanced significantly through the coordination of individuals acting at different levels (Stokols, 1992), such as parents providing their children with an environment that supports F\&V consumption. Parents can increase the availability and accessibility of F\&V at home, and thereby reinforce and model F\&V intake (see Nicklas et al., 200I for a review). They can even shape their children's taste preferences by repeatedly exposing their children to F\&V (Wardle et al., 2003).

Two recent reviews demonstrated the importance of these family-related factors by concluding that taste preferences and the availability and accessibility of F\&V were the most influential determinants of primary school children's F\&V intake (Blanchette \& Brug, 2005; Rasmussen et al., 2006). Parental behaviour, modelling and feeding practices were also identified as relevant determinants of F\&V consumption in children (Blanchette \& Brug, 2005).

Research has shown that children often perceive family-related factors differently than their parents (Bere \& Klepp, 2004; Tak, te Velde, de Vries, \& Brug, 2006; van Assema et al., 2007). Insight with respect to these differences is essential given their implications for intervention development and evaluation. Problems often occur when perceptual differences lead to a lack of parental motivation to create an environment that supports sufficient F\&V consumption by children. For example, a parent may report being supportive by making sufficient F\&V available in the home, while their children report a lack of readily available fruit at home. To ensure 
programme effectiveness, health promotion planners may have to include strategies in their interventions to target these perceptual differences.

A second implication relates to the interpretation of effect studies. Interventions directed at primary school children are often evaluated using parental reporting, because it is generally thought that younger children are limited in their ability to self-report their food intake (Livingstone, Robson, \& Wallace, 2004). However, studies have shown that neither children (Livingstone \& Robson, 2000; Livingstone et al., 2004; McPherson, Hoelscher, Alexander, Scanlon, \& Serdula, 2000) nor parents (Baranowski, Sprague, Baranowski, \& Harrison, 199I) are always reliable reporters of a child's food intake. Since no objective measure of F\&V consumption is available, investigating the differences in perception of intake between these two groups is important.

Our literature review found only two studies that addressed the lack of consensus between child and parental reporting for primary school children. A Dutch study showed low levels of agreement regarding F\&V intake and a limited set of environmental factors including perceived variety of consumption, availability of F\&V and several food rules at home (Tak et al., 2006). In this study, the fourth grade children self-reported a higher F\&V intake compared to their parent's assessment. The level of agreement between perceptions of environmental factors was higher than the level of agreement for consumption measures. However, both were still relatively low. Despite these low levels of agreement, it was concluded that, in the absence of an objective measure of F\&V consumption, parental reporting could be a valid method for measuring children's F\&V intake since the results were supported by previously reported intake levels in the Netherlands.

The second study was aimed primarily at identifying correlates of children's F\&V intake. However, it also compared parents' and children's reporting of children's F\&V accessibility, skills and preferences (Bere \& Klepp, 2004). The results demonstrated that parent-child correlations of these constructs were moderate $(.30<$ $r<.35)$. They also indicated that parents perceived higher levels of F\&V accessibility at home than their children did. Additionally, parents thought their children had less behavioural skills than the children reported having (Bere \& Klepp, 2004). This study concluded that, since parents control the home food environment and since 
differences in perceptions occur, interventions are needed that are directed at the parents.

In the absence of a gold standard or an objective measure of F\&V consumption, no conclusions can be drawn as to whether children's or parents' reporting is more valid. Therefore, to properly interpret the effectiveness of interventions, insight on the lack of agreement between child and parental reporting remains essential. Furthermore, additional insight on differences relating to familyenvironmental constructs and F\&V-consumption between parents and children is imperative.

Supplementary to the studies of Tak (2006) and Bere (2004), the current study also looked into the relation of children's and parents' perceptions of familyrelated factors. Although the relationship between adolescents' perceptions of family food rules and availability (van Assema et al., 2007) has recently been studied, this relation in younger children has not. The perceptions of younger children may be even more significant than the perceptions of older children, given that, for younger children, the family has a greater influence on food access and intake (Perry, 2000). Therefore, the purpose of the study reported here was to $(I)$ compare parental and child recording of children's F\&V consumption, including family-related factors, and (2) investigate the potential differences in the relation of children's and parents' perceptions of family-related factors. The possible implications of these results for intervention development and the interpretation of programme effectiveness are also discussed.

\section{METHODS}

Respondents and procedures

We used data from the baseline measurement of an intervention study (see Chapter 5). The Regional Health Service invited every school in the middle and north region of the province of Limburg, which had at least 200 students $(n=49)$ to participate in the current study. Of these 49 schools, 12 (25\%) agreed to participate. Although nonparticipation was not studied extensively, lack of time was the most mentioned reason not to participate. These reasons were demonstrated previously in both national and international literature (Gorts \& Jonker, 200I; Leurs, Jansen, \& Ruiter, 2002; Lytle, 
Ward, Nader, Pedersen, \& Williston, 2003). Parents were recruited through an information sheet the children took home and informed consent was acquired.

The study presented here focused only on children in the seventh and eighth grade and their parents, since children of this age were considered capable of accurately filling out questionnaires (Livingstone et al., 2004). The parental questionnaires were given to the children to take home and, once completed, were collected by the teachers. The teachers were also responsible for administering the questionnaires to the children in the classrooms. Of the 486 children for which informed consent was obtained, 423 children (87\%) filled out a questionnaire in the classroom and $37 \mathrm{I}$ of the parents returned their parental questionnaire. A total of $37 \mathrm{I}$ matched child-parent pairs were thus assembled for analyses. The 13\% non-response rate among the children was due to their absence at the time the questionnaire was administered.

\section{Questionnaires}

Two similar questionnaires that included parallel indicators of children's F\&V consumption and potential correlates of intake were used. The parental questionnaire had been used in a previous study and is described more extensively in Chapter 3. Parents were instructed that the questionnaire had to be completed by the parent that usually takes care of what the child eats. Parallel demographic indicators included questions regarding the child's weight, height, age, gender and ethnicity. Using the Statistics Netherlands definitions of native and non-native residents, the children were classified as being 'native' when both parents were born in the Netherlands and as 'non-native' when one parent had been born outside of the Netherlands (Centraal Bureau voor de Statistiek (CBS), 2005). The parental questionnaire included additional questions regarding the parent's gender, education level and their F\&V consumption, using a validated 10-item questionnaire (van Assema et al., 2002).

The family- environmental factors measured included modelling, subjective norm, exposure, accessibility and availability. These were assessed separately for F\&V consumption using the same format for both F\&V. Table I presents the number of items, range, Cronbach's $\alpha$, and examples of items. 
Table I Description of family- environmental factors, numbers of items, mean (SD), internal consistency, sample items and range

\begin{tabular}{|c|c|c|c|c|}
\hline & \multirow[t]{2}{*}{$\begin{array}{l}\text { No. of } \\
\text { items }\end{array}$} & \multicolumn{2}{|c|}{$\begin{array}{l}\text { Internal } \\
\text { consistency }(\alpha)\end{array}$} & \multirow[t]{2}{*}{$\begin{array}{l}\text { Examples of questions, response options and } \\
\text { ranges }\end{array}$} \\
\hline & & Child & Parent & \\
\hline \multicolumn{5}{|c|}{ Fruit consumption } \\
\hline $\begin{array}{l}\text { Modelling by } \\
\text { mother }\end{array}$ & 1 & - & - & $\begin{array}{l}\text { My child's mother eats fruit everyday; totally } \\
\text { disagree }(-2) \text { to totally agree }(+2)\end{array}$ \\
\hline $\begin{array}{l}\text { Modelling by } \\
\text { father }\end{array}$ & 1 & & & $\begin{array}{l}\text { My child's father eats fruit everyday; totally } \\
\text { disagree }(-2) \text { to totally agree }(+2)\end{array}$ \\
\hline $\begin{array}{l}\text { Subjective norm } \\
\left(\mathrm{mc}^{*} \mathrm{nb}\right)\end{array}$ & 2 & - & - & $\begin{array}{l}\text { Motivation to comply }(\mathrm{mc}) \text { : My child does what } \\
\text { we tell him/her to do; totally disagree }(\mathrm{I}) \text { to } \\
\text { totally agree }(5) \\
\text { Normative belief }(\mathrm{nb}) \text { : My child thinks we want } \\
\text { him/her to eat more fruit; totally disagree }(-2) \\
\text { to totally agree }(+2)\end{array}$ \\
\hline Exposure & 14 & .72 & .71 & $\begin{array}{l}\text { Has your child ever tasted tangerines, banana, } \\
\text { kiwi fruit, etc? }(0-14)\end{array}$ \\
\hline Accessibility & 1 & - & - & $\begin{array}{l}\text { Do you or your partner (sometimes) prepare } \\
\text { fruit for your child? Yes (I) or no (0) }\end{array}$ \\
\hline Availability & 2 & .51 & .73 & $\begin{array}{l}\text { [I] Do you always have fruit [2] that your child } \\
\text { likes available at home? Yes, always }(+2) \text { to No, } \\
\text { never }(-2)\end{array}$ \\
\hline \multicolumn{5}{|c|}{ Vegetable consumption } \\
\hline $\begin{array}{l}\text { Modelling by } \\
\text { mother }\end{array}$ & 1 & - & - & $\begin{array}{l}\text { My child's mother eats vegetables everyday; } \\
\text { totally disagree }(-2) \text { to totally agree }(+2)\end{array}$ \\
\hline $\begin{array}{l}\text { Modelling by } \\
\text { father }\end{array}$ & I & - & - & $\begin{array}{l}\text { My child's father eats vegetables everyday; } \\
\text { totally disagree }(-2) \text { to totally agree }(+2)\end{array}$ \\
\hline $\begin{array}{l}\text { Subjective norm } \\
\left(\mathrm{mc}^{*} \mathrm{nb}\right)\end{array}$ & 2 & - & - & - \\
\hline Exposure & 15 & .67 & .78 & $\begin{array}{l}\text { Has your child ever tasted cauliflower, broccoli, } \\
\text { carrots, etc? }(0-15)\end{array}$ \\
\hline Accessibility & 1 & - & - & $\begin{array}{l}\text { Do you or your partner (sometimes) prepare } \\
\text { vegetables as a snack for your child? Yes (I) or } \\
\text { no (0) }\end{array}$ \\
\hline Availability & 2 & .49 & .57 & $\begin{array}{l}\text { [1] Do you always have vegetables, [2] that } \\
\text { your child likes available at home? Yes, always } \\
(+2) \text { to No, never }(-2)\end{array}$ \\
\hline
\end{tabular}

Children's fruit consumption was assessed using two questions: (I) 'How many days per week does your child eat fruit/do you eat fruit?' (Answers ranged from one to seven days); and (2) 'How many portions of fruit does your child eat/do you eat on a day that 
he or she/you consume(s) fruit?' (Answers ranged from ' $1 / 2$ portion a day' to '3 portions a day or more' on a six-point scale). The average consumption of whole fruit (in portions per day) was calculated by multiplying both questions and dividing the result by seven.

Children's frequency of vegetable intake was measured using three questions: (I) How many times per week does your child eat cooked or baked vegetables for dinner (including mixed dishes)?; (2) How many times per week does your child eat mixed dishes like macaroni?; and (3) How many times per week does your child eat extra salad items, like lettuce, tomato, or other raw vegetables? The number of days that the children consumed cooked vegetables was calculated by subtracting mixed dishes from cooked or baked vegetables, including mixed dishes. Portion size was assessed using photographs of plates filled with different amounts of cooked vegetables (25-50-100-I 50 grams) or mixed dishes (75-150-300-450 grams). Respondents were asked to select the photograph that best represents the amount of food that the child usually consumes. According to the Netherlands Nutrition Centre, on average, $33 \%$ of a mixed dish consists of vegetables (Donders-Engelen, van der Heijden, \& Hulshof, 2003). The amount of extra salad or raw vegetables was calculated by multiplying frequency per week by 35 grams (the weight of a small bowl of salad). Lastly, the average consumption of vegetables in grams per day was computed as follows: ((the number of days that the children consumed cooked vegetables * portion size) plus (the number of days children ate mixed dishes * $(.33 *$ portion size) plus (the number of days children ate extra salad or raw vegetables $* 35$ gram)) / seven days.

The FFQ method was used in a similar Dutch project (Brug et al., 2005) and was based on the Pro-children questionnaire that was validated by Haraldsdóttir and colleagues (2005).

\section{Data analysis}

Means, standard deviations and percentages were used to describe consumption and family-related factors. The consumption measures and continuous family-related variables were checked for normality. The F\&V consumption measures showed positively skewed distributions $\left(Z_{\text {skewness }}>2\right)$, and all of the family-related factors showed negatively skewed distributions $\left(Z_{\text {skewness }}<-2\right)$. Therefore, results from non- 
parametric tests are reported. To compare parental and child recording of the child's F\&V consumption and family-related factors regarding F\&V intake (research question I), several techniques were used. Wilcoxon signed-rank test and chi-square tests were used to assess differences in means for the intake measures and family-environmental factors. Spearman's correlation coefficients were used to assess associations between parental and child recording. Furthermore, we assessed how many parents reported higher, equal, or lower consumption compared to their children's reports by dividing the consumption levels reported by both child and parent into four equal groups (see Table 2 for a description). We also calculated Cohen's kappa coefficients as a measure of agreement between parental and child reporting. Separate logistic regression analyses were used to study associations between agreement and parent or child characteristics. We used underestimation $(I)$ versus equal estimation $(0)$ of consumption as the dependent variable and the child's gender, ethnicity, age and BMI, and parent's gender, education, F\&V consumption and the child's level of F\&V consumption (below median of averaged parent and child report versus above median of averaged consumption) as independent variables. The same analyses were conducted for overestimation (I) versus equal estimation (0). The analyses were carried out separately for fruit and vegetable consumption. All analyses were performed using SPSS 13.0.

To investigate potential differences between the parent's and children's perceptions of family-related factors (research question 2), multi-level regression analyses (Rasbash et al., 2000) were conducted, extending the fixed regression model with a random school effect. For these analyses the F\&V consumption reported by the child was used as the dependent variable and these were adjusted for positive skewness using square root transformations (SQRT(X)). First, the associations of family-related factors with child-reported F\&V intake were studied in separate analyses using child versus parental reporting of the family related factors (modelling, subjective norm, exposure, accessibility, and availability). The indicator for accessibility of vegetables that focused on vegetable snack consumption (e.g. cucumber, carrot sticks, etc) was excluded from the analyses because too many respondents indicated that their child never consumed vegetables as a snack. Secondly, we tested whether the regression coefficients of parental and child reported family-related factors differed 
significantly. To do this, multilevel regression analyses with F\&V consumption reported by the child as the dependent variable were conducted. Predictors in these analyses were the family-environmental variables, a dummy variable that was coded I for child reporting and 0 for parental reporting, and a variable that was the product of these two variables.

Table 2 Number of respondents, means (SD) and range within each quartile for fruit consumption

\begin{tabular}{|c|c|c|c|c|c|c|}
\hline & \multirow[t]{2}{*}{ Quartile } & \multirow[t]{2}{*}{$\mathrm{n}$} & \multicolumn{2}{|c|}{ Mean (SD) } & \multicolumn{2}{|c|}{ Range } \\
\hline & & & Child & Parent & Child & Parent \\
\hline Fruit & I & $84 / 88$ & $.25(.17)$ & $.27(.16)$ & $.00-.50$ & $.00-.43$ \\
\hline consumption & 2 & $103 / 12 \mid$ & $.7 I(.11)$ & $.69(.11)$ & $.57-.86$ & $.57-.86$ \\
\hline \multirow[t]{2}{*}{ (portions per day) } & 3 & $95 / 72$ & $1.13(.16)$ & I.I4(.I6) & I.00-I.44 & $.94-1.43$ \\
\hline & 4 & $89 / 90$ & $2.05(.48)$ & $1.98(.42)$ & $1.50-3.00$ & $1.50-3.00$ \\
\hline Vegetable & I & $102 / 98$ & $32.53(13.27)$ & $35.55(12.20)$ & $.00-50.00$ & $.00-50.00$ \\
\hline consumption & 2 & $84 / 91$ & $60.70(5.22)$ & $58.6 I(4.02)$ & $50.71-70.00$ & $50.71-65.00$ \\
\hline \multirow[t]{2}{*}{ (grams per day) } & 3 & $94 / 90$ & $82.66(7.76)$ & $73.15(4.84)$ & $71.16-97.86$ & $65.45-83.57$ \\
\hline & 4 & $91 / 92$ & $121.49(19.53)$ & $107.74(\mid 8.58)$ & $98.28-185.00$ & $84.29-175.00$ \\
\hline
\end{tabular}

\section{RESULTS}

Of the total sample of children, $47 \%$ was male, $53 \%$ was female and most were of Dutch origin (72\%). On average, the children were II.0 (Standard Deviation 0.8) years old, ranging from 9 to 13 , and the mean BMI was 17.5 (SD 2.9), indicating a normal weight according to international standards for children (Cole, Bellizi, Flegal, \& Dietz, 2000). The parental questionnaires were completed most often by the mother (83\%) and the parents' mean age was 4 I.3 (SD 5.0). Of the parents, 33\% had a low level of education, $52 \%$ a medium level of education and $15 \%$ had a high level of education. The parents consumed about 2.5 (SD 2.5) portions of fruit, including fruit juice, and about 3.3 (SD I.6) tablespoons of vegetables per day (the equivalent of approximately 165 grams per day).

Comparison between parental and child recording of children's F\&V consumption As shown in Table 3, parents' and children's reported intake of the fruit consumption of the child did not differ. However, children did report their own vegetable consumption significantly higher than parent's reported $(\mathrm{p}<.0 \mathrm{I})$. Correlations between parent and child reporting of the child's consumption were .55 (fruit consumption) and 
.39 (vegetable consumption), indicating a large and moderate correlation (Cohen, 1988). Almost half of the child-parent pairs were in the same quartile for fruit consumption (Table 3), 37\% were in an adjacent quartile and $15 \%$ in a different quartile ${ }^{3}$. About $40 \%$ of the pairs were in the same quartile for vegetable consumption, $36 \%$ were in an adjacent quartile and $24 \%$ were in a different quartile ${ }^{3}$. Cohen's kappa's for F\&V consumption were significant but low, with $.3 \mathrm{I}$ and .20 , respectively. Logistic analyses showed a significant association between underestimation of fruit consumption and ethnicity. In comparison to parents of native children, parents of non-native children more often reported lower fruit consumption than their children (OR 2.19, 95\%Cl: I.19-4.II). Results also showed a significant association between overestimation of fruit consumption and child's BMI and fruit consumption level. Parents of children with a high BMI (OR I.I2; 95\%Cl: I.0I-I.23) and parents of children that consume higher amounts of fruit (OR 2.69; 95\% Cl: $1.49-4.95)$ reported more often higher fruit consumption than their children. Furthermore, parents of children that consumed higher amounts of vegetables reported a lower vegetable intake for their child (OR I.98; $95 \% \mathrm{Cl}$ : I. I4-3.44), compared to the child report.

Table 3 Estimation of F\&V consumption by parents using child as reference and quartiles

\begin{tabular}{|c|c|c|c|c|}
\hline & $\begin{array}{l}\text { Lower quartile } \\
\text { compared to child } \\
\mathrm{n}(\%)\end{array}$ & $\begin{array}{l}\text { Same quartile } \\
\text { as child } \\
\mathrm{n}(\%)\end{array}$ & $\begin{array}{l}\text { Higher quartile } \\
\text { compared to child } \\
\mathrm{n}(\%)\end{array}$ & Cohen's kappa \\
\hline Fruit consumption & $105(28.3)$ & $179(48.2)$ & $87(23.5)$ & $.31 * * *$ \\
\hline Vegetable consumption & $109(29.4)$ & |48(39.9) & I I4(30.7) & $.20 * * *$ \\
\hline
\end{tabular}

Family-environmental factors and associations with F\&V consumption

Table 4 displays the differences between the parental and child reporting of subjective norm, accessibility, and availability of fruit, as well as modelling by mother and father, subjective norm and exposure regarding vegetable consumption. Parents reported more positively on all these constructs than their children. Correlations between parent and child were significant but mostly low to moderate, ranging from .27 to .52 $(p<.001)$.

3 This data is not included in the table but can be obtained from the author upon request. 


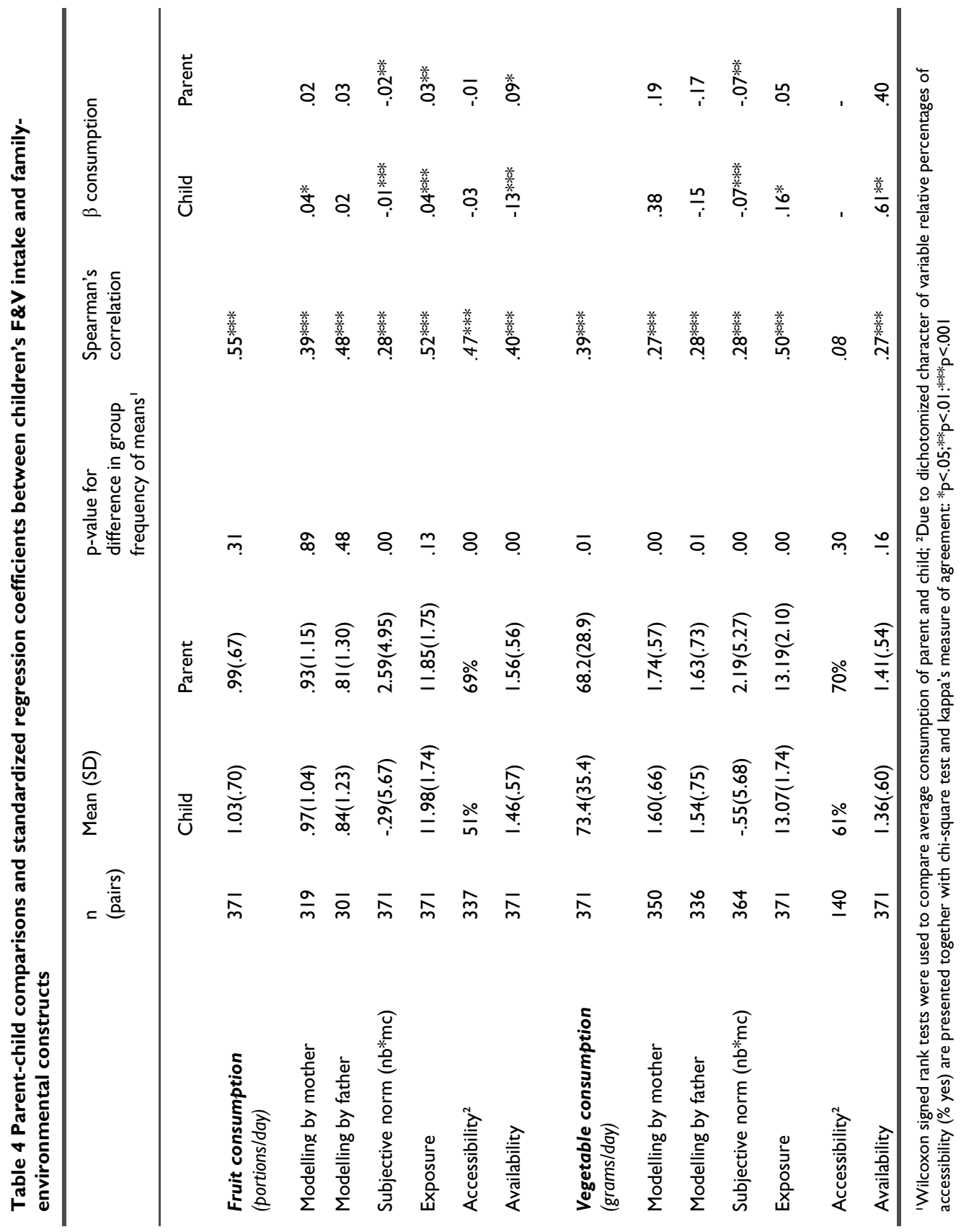


Subjective norm, exposure, and availability were significantly associated with fruit consumption with both parents and children. Subjective norm and availability were significantly correlated for vegetable consumption in parental and child measures. Only in the children's reports was exposure also correlated with vegetable consumption. No statistical differences between regression coefficients of the parents and the children were found, indicating similar associations.

\section{DISCUSSION}

This study compared parental and child reporting of F\&V consumption and familyrelated factors. Our results demonstrated a low level of agreement between child and parental reporting for both $\mathrm{F} \& \mathrm{~V}$ intake. These results are comparable to the results of a similar study (Tak et al., 2006). However, we must conclude that, contrary to previous findings, both agreement and correlation between child and parental reporting are better for fruit consumption than for vegetable consumption. This could be due to the sensitivity of the measurements. To evaluate fruit consumption, we asked to report the number of servings per day. To evaluate vegetable consumption, we asked the respondents to report portion sizes (in grams). A study by Frobisher and Maxwell (2003) demonstrated that parent and child estimations of portion size, even when using photographs, are often inaccurate. This could account for the lower level of agreement for vegetable consumption. Furthermore, we found similar numbers of parents reporting higher estimates of their child's consumption compared to their child's reports, as the number of parents that estimated lower levels of consumption when compared to their respective children.

However, our results showed that parents of high consumers more often perceived their child's fruit intake higher, and their child's vegetable intake lower, compared to the child report. In line with our results, Tak et al. (2006) showed that high consumers of both fruit and vegetables had poorer levels of agreement than low consumers. This is perhaps due to a higher range in intake levels among the high consumers and may thus indicate a floor effect among the low consumers. Our results showed that parents of non-native children perceived their child's fruit intake lower 
than their child did. This is surprising, considering that the non-native children consumed more fruit compared to native children $(\mathrm{p}<.05)^{4}$.

An earlier study among children in the Netherlands also showed that nonnative children are among the high consumers (Brussaard, Brandts, Erp-Baart, Hulshof, \& Kistemaker, 1999) and based on this one would expect that parents of non-native children therefore should 'overestimate' their child's intake. Tak et al. (2006) also found mixed results regarding level of agreement and ethnicity, so further study into this relation is needed. The finding that parents of children with a higher BMI perceived their child's fruit intake to be higher might be caused by the fact that parents could feel responsible for their child's weight status and therefore report in a more social desirable way.

Regarding family-environmental factors, our results indicated that child and parental reporting of fruit consumption differed significantly for subjective norm, accessibility and availability. Moreover, with respect to vegetable consumption, differences were found for subjective norm, exposure and modelling of vegetable consumption by parents. Combined with the low to moderate correlation between the reporting of both groups, we can conclude that perceptions of important familyenvironmental factors differ between children and their parents. These results are in accordance with previous studies (Bere \& Klepp, 2004; van Assema et al., 2007) and are thus cause for concern. Since parents perceived these environmental factors more positively than their children did, they may believe that that they are creating a supportive environment and therefore see no need to change the home environment in a way that can facilitate their children's consumption of F\&V. Their children, conversely, perceive the environment to be less supportive. This is especially important for program development, because the majority of interventions targeting children include a parental component (Burchett, 2003; Knai et al., 2006; Pomerleau et al., 2005). Unfortunately, the situation described above could hinder the implementation of strategies aimed at parents and thereby limit the effectiveness of interventions.

${ }^{4}$ Data not published. 
The second objective of the study was to examine the relationship between familyrelated factors and F\&V intake. We found that subjective norm, exposure and availability were important correlates of fruit consumption in both child and parental measures. Subjective norm and availability were significantly correlated with vegetable consumption for both parallel scales but exposure was only identified as a correlate when the child's reports were used. Interestingly, no differences in the association of family-related factors with F\&V consumption between child and parent reports were detected. To date, only one similar study was found that focused on adolescents and their parents (van Assema et al., 2007). As in our study, the researchers did not find differences in the relationship between accessibility or availability and fruit consumption.

The most important limitation of studies that compare intake based on reporting by children and their parents is that determining whether the child's or parent's report is the more valid measure is impossible. There is no objective measure with which these reports can be compared. It is also important to note that this study focused on a limited number of family-environmental factors. More and more research indicates the importance of parenting practices, like food rules, and parenting styles that foster a healthy lifestyle (Golan \& Crow, 2004; Kremers et al., 2003; van Assema et al., 2007). Consequently, we contend that additional research on how the role of parenting can generate healthy nutrition of children is necessary. Finally, we used one or two items to measure most family-environmental factors. However, these measures can be considered if the item reflects a homogeneous construct (Loo, 200I; Wanous \& Reichers, 1996; Wanous, Reichers, \& Hudy, 1997). Although these items are common in comparable studies (e.g. de Bourdeaudhuij et al., 2006), single-item measures usually have a low reliability. Therefore, multiple-item measures are still more desirable, but the time required filling out the questionnaire limited the use of these measures.

In sum, we found a low level of agreement between parental and child reporting of both fruit and vegetable intake at the individual level. For empirical purposes, we recommend that researchers clearly indicate which source of information they use in their studies as it remains unclear which source is more valid. A combination of both kinds of reporting in effect studies is preferred. However, when the effects of interventions are studied at the group level, the lack of differences in 
mean fruit consumption and the large correlation between parental and child reporting suggest that it makes no difference whether children themselves, or parents as a proxy, report the child's fruit consumption.

The same holds for determinant studies. When looking at important correlates of F\&V consumption, one can conclude that the same family-environmental factors appear to be important independent of the source of reporting. Thus, when conducting determinant studies, both parental and child reports can be used. However, perceptions of these factors differ significantly. This has important practical implications for intervention development. Those who develop interventions must take these differences in perception into account and also endeavour to inform parents about these discrepancies.

\section{CONCLUSIONS}

We conclude that parental and child reporting of both fruit and vegetable intake show low levels of agreement on the individual level, but are acceptable for fruit consumption studied at the group level.

Furthermore, independent of source of reporting, the same familyenvironmental factors are important regarding F\&V intake. However, perceptions of these factors differ significantly between parent and children. 
Part 2

Impact and Process Evaluation

1/ites + Froer

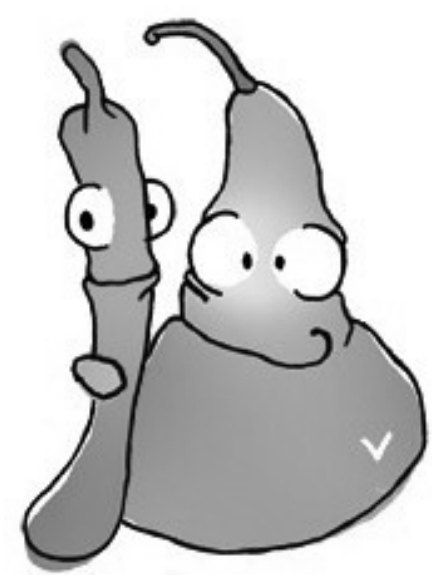




\section{Chapter 5}

\section{Increasing children's fruit \& vegetable consumption: distribution or a multi- component program?}

Published as: Reinaerts, E., de Nooijer, J., Candel, M. \& de Vries, N.K. (2007). Increasing children's fruit \& vegetable consumption: distribution or a multi-component program? Public Health Nutrition, 10, pp. 939-947. 


\section{ABSTRACT}

Objective: To measure the effects of two school-based interventions on children's intake of fruit and vegetables.

Design and methods: A total of six primary schools were randomly assigned to (I) a free fruit and vegetable (F\&V) distribution program, or (2) a multi-component program, consisting of a classroom curriculum and parental involvement. The two interventions were evaluated on their effects and compared to six control schools in a pretest - posttest design. Two methods were used for dietary assessment: a prestructured food recall and a food frequency questionnaire including only fruit and vegetables.

Subjects: A total of 939 parents of children aged four-to-twelve years filled out the questionnaire both at pre-test and post-test. The response rate was $54 \%$.

Results: Multi-level analyses showed that both programs were equally effective in increasing children's fruit consumption with 0.2 portions per day. The free F\&V distribution increased vegetable intake among non-native children and the oldest age group, and the multi-component program among the oldest children and girls. The distribution also caused an increased consumption of $24 \mathrm{~h}$ fruit, juice and vegetable intake among the youngest and the oldest age groups, and the multi-component program among all children.

Conclusion: The results of this study indicate that both interventions showed to be effective for different subgroups regarding age, gender and ethnicity. When comparing both interventions the distribution program showed to be more effective, especially in increasing vegetable consumption. An important next step will be to investigate which intervention has the largest potential to be implemented at primary schools. 


\section{INTRODUCTION}

Substantial evidence shows that higher intake levels of fruit and vegetables are associated with lower rates of cancers, cardiovascular diseases and several other diseases (WHO, 2003). Current Dutch guidelines recommend that children should eat at least two servings of fruit and 200 grams of vegetables a day (Anonymous, 1998). As most European children (Yngve et al., 2005), Dutch children have lower fruit and vegetable intake (F\&V) than recommended. According to the latest Dutch Food Consumption Survey, 4 to 12 year old children consume on average about 70 grams of vegetables and less than one serving of fruit daily (Anonymous, 1998). Considering that dietary habits such as F\&V consumption have been shown to persist throughout life (Kelder et al., 1994; Lien et al., 200I), attempts to increase children's F\&V consumption could be more efficient than interventions aimed at adults who developed a habit of their low consumption patterns (Krebs-Smith et al., 1995).

From previous reviews, it can be concluded that the majority of programmes aimed at primary school children have been classroom-based and multi-component. Most were implemented in the United States (Burchett, 2003; French \& Stables, 2003; Knai et al., 2006; Pomerleau et al., 2005). These reviews indicate that the majority of these interventions lead to increased consumption at least on the short term. Reported effects ranged from 0.14 to 0.99 servings/day higher intake in the intervention groups at follow-up (Knai et al., 2006; Pomerleau et al., 2005). Studies that incorporated an environmental factor, such as making F\&V available at school, used a multi-component design so that the independent contribution of for example availability to the effectiveness of the study could not be determined. The review of French (2003) identified only three solely environmental interventions and only one of these attempted to change the F\&V consumption of children by only distributing F\&V at schools (French \& Stables, 2003). This paid F\&V subscription scheme provided 6-10 year old children with one piece $F$ or $V$ per day and was implemented in four schools. Three schools in Denmark served as controls. It resulted in an increased fruit intake after five weeks of 0.4 pieces among subscribing children, and of 0.3 pieces among nonsubscribing children. The beneficial effect for non-subscribers was interpreted as an unintentional effect of stimulating parents of non-subscribers to supply their children with fruit. Contrary to the non-subscribers, the subscribers did not increase their total 
F\&V intake, indicating that F\&V consumption at school led to less consumption later in the day (Eriksen et al., 2003). This could be the result of parents reducing the amount of F\&V they give their child normally at home. Recently, a similar Norwegian subscription scheme has been implemented and shown to be effective. This program consisted of three conditions: a free subscription implemented in nine schools; a paid subscription implemented in nine schools; twenty schools served as the control condition receiving no fruit. After one year the free fruit subscription showed a net effect of 0.9 portions during school time and I.0 portion during the whole day. Furthermore, the results showed that at follow up, the subscription program caused differences between the free fruit group, the paid fruit group and the control group in F\&V intake during school time (mean intakes were I.I, 0.4 and 0.2 portions, respectively). For F\&V intake all day the free fruit group differed from paid, and control group (2.4, I,8 and I.8, respectively) (Bere et al., 2005).

When developing school-based interventions, health promotion planners encounter the problem that motivating schools to participate in health promoting activities has become very difficult. Reasons for refusal are mostly time constraints in the classroom and limited resources at school. More and more schools are held responsible for a growing amount of health-related issues and are swamped with imposed or voluntary initiatives to improve the health of their students. Thus, it seems important to gain more insight into the effects of school-based interventions that require minimal classroom or teacher time, such as F\&V distribution at school. Moreover, we examined differences in effects between a programme that solely distributed F\&V at school and a programme that focused on motivating parents and children to bring F\&V to school, without making F\&V available at school. Furthermore, most multi-component school-based programmes to increase F\&V intake of children have been aimed at $4^{\text {th }}$ or $5^{\text {th }}$ graders. In this study we wanted to focus on the effects of programmes that involve all children of primary school.

The present study tests the effects on fruit and vegetable intake of a free F\&V distribution and a multi-component curriculum, compared to a control group, in a field study with a pretest and a one-year follow-up posttest. 


\section{METHODS}

\section{Study design}

Schools were recruited by the Regional Health Service that invited every school in the middle region of the province of Limburg, which had at least 200 students $(n=28)$. Six primary schools (21\%) accepted the invitation to participate in the study. These schools were paired, based on ethnic composition because the proportion of foreign students can differ substantially among primary schools. Of each pair, one school was randomly assigned to the distribution condition ( \pm 690 children) and one to the multicomponent condition ( \pm 648 children), resulting in two intervention groups each consisting of three schools. Six control schools ( \pm II 68 children) were identified in the northern region of the province of Limburg, matched on ethnicity and school size. All children in the intervention schools were offered one of the two the interventions and children of the control schools received the curriculum program after the study period. The effects of the intervention were examined by assessing F\&V intake two weeks before the start of the interventions (T0; October 2004) and again at the end of the school year (TI; June 2005).

In the Netherlands, children can go to primary school when they reach the age of four, but when they are five years old it is compulsory. The first two levels (group I and 2) are kindergarten. When the children leave group eight, they go to secondary school.

Both interventions were delivered to all primary school children between October 2004 and the beginning of July 2005. Informed consent was acquired from parents prior to the study. Children's F\&V consumption was measured through a frequency questionnaire and a pre-structured food recall that all children brought home to be completed by one of their parents.

\section{Interventions}

In an attempt to increase the F\&V consumption among Dutch school children, the Regional Health Service (GGD NML) and the Universiteit Maastricht cooperated in the development of two different interventions. These were developed according to the Intervention mapping protocol, a stepwise approach to ensure a systematic evidencebased and theory-driven development and implementation of health promoting 
interventions (Bartholomew et al., 200I), that has proven to be usable in the development of programmes aimed at improving F\&V intake in children (Pérez-Rodrigo et al., 2005; Weber Cullen et al., 1998). The interventions were based on two program objectives: ( $\mathrm{I}$ ) increasing children's daily F\&V consumption and (2) creating an environment (at home and at school) that supports children's F\&V consumption.

The first intervention consisted of free F\&V distribution at school and aimed at creating a daily routine by incorporating a recurring moment at which children ate the distributed F\&V together. By daily exposure to F\&V, children learn to like the taste of F\&V and furthermore they become each other's peer models. Every school day, all children were provided with one serving of fruit (two times per week), fruit juice (one time a week) or raw vegetables (two times per week). The distributor ensured a large variety of F\&V during the intervention year and prevented that the same kind of F\&V was served within one week. The distribution was delivered twice a week, ready-toeat and in a separate box for each class. The boxes were brought to the classrooms by a pupil or school employee and the F\&V was handed out to the children during the morning break. Children stayed in their classroom to eat the fruit together with their teacher.

The second intervention was a multi-component school-based program that consisted of a classroom curriculum and parental involvement. Children received a lunchbox that was especially designed to bring F\&V to school undamaged. Classroom activities were developed in cooperation with school teachers and were adapted to the children's age resulting in three different programmes: one for preschoolers (aged four to five years (further referred to as age group I), one for first, second and third graders (age group II) and one for children of the fourth, fifth and sixth grade (age group III) (see Chapter I). Every two months, new activities were dispersed among the teachers. By use of recurrent newsletters and homework activities brought home by their children, we tried to motivate parents to create a home environment that facilitates F\&V consumption. Furthermore, posters with the project mascots were displayed at local supermarkets serving as an environmental component aimed at reminding parents to buy F\&V for their children. 


\section{Measurements}

To assess F\&V, the parents of all children completed intake survey questionnaires. These included a pre-structured food recall, a food frequency questionnaire (FFQ), demographic questions and potential correlates of the children's F\&V intake, assessed separately for fruit and for vegetable consumption.

Demographics of the children included age, sex and ethnicity. Asking for the country of birth of both parents assessed ethnicity of the children. Children were classified as 'native' when both parents had been born in the Netherlands and as 'nonnative' when one or both parents had been born outside the Netherlands, based on the definition used by Statistics Netherlands (Centraal Bureau voor de Statistiek (CBS), 2005).

The pre-structured 24-h food recall assessed the number of times children consumed food (among which fruit or vegetables) the previous day and aimed to focus parents on the total food intake of the day before and not only F\&V. The recall consisted of 16 items for example 'Did your child eat fruit as a snack between meals' or 'a slice of bread with his/her breakfast'. Parents could indicate whether or not their child consumed the specific item the day before. However, only the information on fruit, juice and vegetable intake (24h FJV) was included in the analysis. In the Netherlands, no school meals are typically offered. Most children go home for lunch or bring their own sandwiches to eat at school. Therefore, parents should know what their child consumes during school time.

Another measurement of F\&V consumption was the FFQ. Two questions were used to assess children's consumption of whole fruit: 'How many days per week does your child eat fruit?' (I-7 days) and 'How many portions of fruit does your child eat on a day that he or she consumes fruit?' ranging from ' $1 / 2$ portion a day' to ' 3 portions a day or more' on a six-point scale. The average consumption of whole fruit (in portions per day) was calculated by multiplying both questions and dividing the result by 7 .

The frequency of vegetable intake was measured by three questions, informing how many times per week the child eats (I) cooked or baked vegetables for dinner (including mixed dishes), (2) mixed dishes like macaroni and (3) extra salad, like lettuce, tomato or other raw vegetables? The number of days that the children 
consumed cooked vegetables was calculated by subtracting (2) mixed dishes from (I) cooked or baked vegetables including mixed dishes. Portion size was assessed using photographs of plates filled with different amounts of cooked vegetables (25-50-100150 grams) or mixed dishes (75-150-300-450 grams). Parents had to select the photograph that best represented the amount of food that their child usually consumes. According to the Netherlands Nutrition Centre, on average, 33\% of a mixed dish consists of vegetables. The amount of extra salad or raw vegetables was calculated by multiplying frequency per week with 35 gram (the weight of a small bowl of salad). Finally, the average consumption of vegetables in grams per day was computed by ((the number of days that the children consumed cooked vegetables * portion size) plus (the number of days children ate mixed dishes * $(.33 *$ portion size) plus (the number of days children ate extra salad or raw vegetables * 35 gram)) / 7 days. To assess daily intake of 'snack vegetables' we asked how many times per week the child eats vegetables separately as a snack between meals (like a tomato or a piece of cucumber) or as part of breakfast or lunch (I-7 days), and we divided this by 7 .

The FFQ method was used in a similar Dutch project and based on the Prochildren questionnaire that was validated by Haraldsdóttir (2005).

\section{Statistical analyses}

Data analyses included descriptive statistics of the demographic factors and F\&V consumption. Attrition was studied by means of multilevel logistic regression analysis with attrition as the dependent variable and child's age, sex and ethnicity, child's F\&V consumption at baseline (average and $24 \mathrm{~h}$ ) and condition as predictors. Chi-square tests and F-tests were used to compare baseline characteristics between study groups. Data on F\&V consumption that was gathered using the FFQ measures were not distributed normally. Therefore the data were square root transformed to improve normality.

Since we had a nested sampling design (pupils within classes within schools) multilevel analyses (Rasbash et al., 2000) were conducted. By extending the fixed regression model with a random school effect and a random class effect, the intraclass correlation was taken into account (Snijders \& Bosker, 1999). Four sets of multilevel models were analyzed to test the influence of both interventions on: 
I. Average fruit consumption (fruit consumption in portions/day)

2. Average vegetable consumption (vegetable consumption at dinner in grams/day)

3. Vegetable snack consumption (frequency of vegetable snack consumption in times/day)

4. 24h fruit, juice and vegetable consumption (frequency of FJV consumption during previous day in times/day)

All analyses, included a dummy variable for the distribution and the multi-component intervention group as main independent variables (control group was taken as a reference), controlling for child's ethnicity, gender, age group and baseline consumption level. These analyses were repeated with distribution group as a reference to check for differences in effect between the two interventions. We tested for interaction effects between condition and gender, ethnicity and age group. If necessary, these were followed by subgroup analyses. All analyses were done according to a 'top-down' procedure, that is, starting with the most elaborate model and leaving out successively the least significant and non-significant effects.

To indicate effect size of the interventions, the net effect was used, being equal to the change in fruit and vegetable intake between the intervention and control group. Thus, net effect $=\left(\right.$ Follow-up intake intervention - Baseline intake $\left._{\text {intervention }}\right)-($ Followup intake control $_{-}$Baseline intake control $)$.

\section{RESULTS}

\section{Participants}

At baseline, a total of 1739 (68\%) parents filled out the questionnaire for their child. Of these parents, 939 (54\%) also filled out the questionnaire at follow up, equally distributed across all three groups.

Attrition analyses revealed that parents of non-native children dropped out more often than parents of Dutch children ( $52 \%$ vs. $42 \%, p<0.00 I)$. No further differences were found between dropouts and participants. 
Baseline characteristics of the children

The average age of the children was 9 years $(S D=2.3)$, ranging from five to fourteen, and $51.5 \%(n=482)$ were girls. Before conducting multilevel analyses to examine the effectiveness of the interventions, preliminary analyses were done to determine whether children began the interventions with differences in age, sex, ethnicity, and baseline consumption levels. There were no significant differences between the three intervention groups in demographic variables at baseline, except for ethnicity (control vs. multi-component vs. distribution: $14 \%$ vs. $12 \%$ vs. $50 \%$ non-native; $p<0.001$ ). This difference probably occurred due to children that enrolled in the schools in the period between the assignment of the interventions to the schools and the start of the interventions, approximately four months including summer holiday. Regarding F\&V intake, children in the distribution group consumed more often 24h FJV at baseline than children in the multi-component $(p<0.00 I)$ and control group $(p<0.00 I)$. They also consumed more often vegetable snacks than children in the control group $(p<0.01)$.

\section{Effects}

Average fruit, vegetable and vegetable snack consumption and 24h FJV consumption at baseline and follow up are presented by medians with interquartile range and as means with standard deviations separately for the distribution program (Table I) and the multi-component program (Table 2). Furthermore, in these tables the effects of the interventions when evaluated against the control group are reported.

Both the free distribution and the multi-component program were effective in increasing children's average fruit consumption. Both increased consumption with a net effect of 0.2 portions $\left(+15 \%^{5} ; \mathrm{p}<.00 \mathrm{I}\right)$ per day including weekend days. For all other outcome measures our results showed different effects of the interventions for different subgroups.

\footnotetext{
${ }^{5} \mathrm{Net}$ effect compared to baseline intake of intervention group
} 


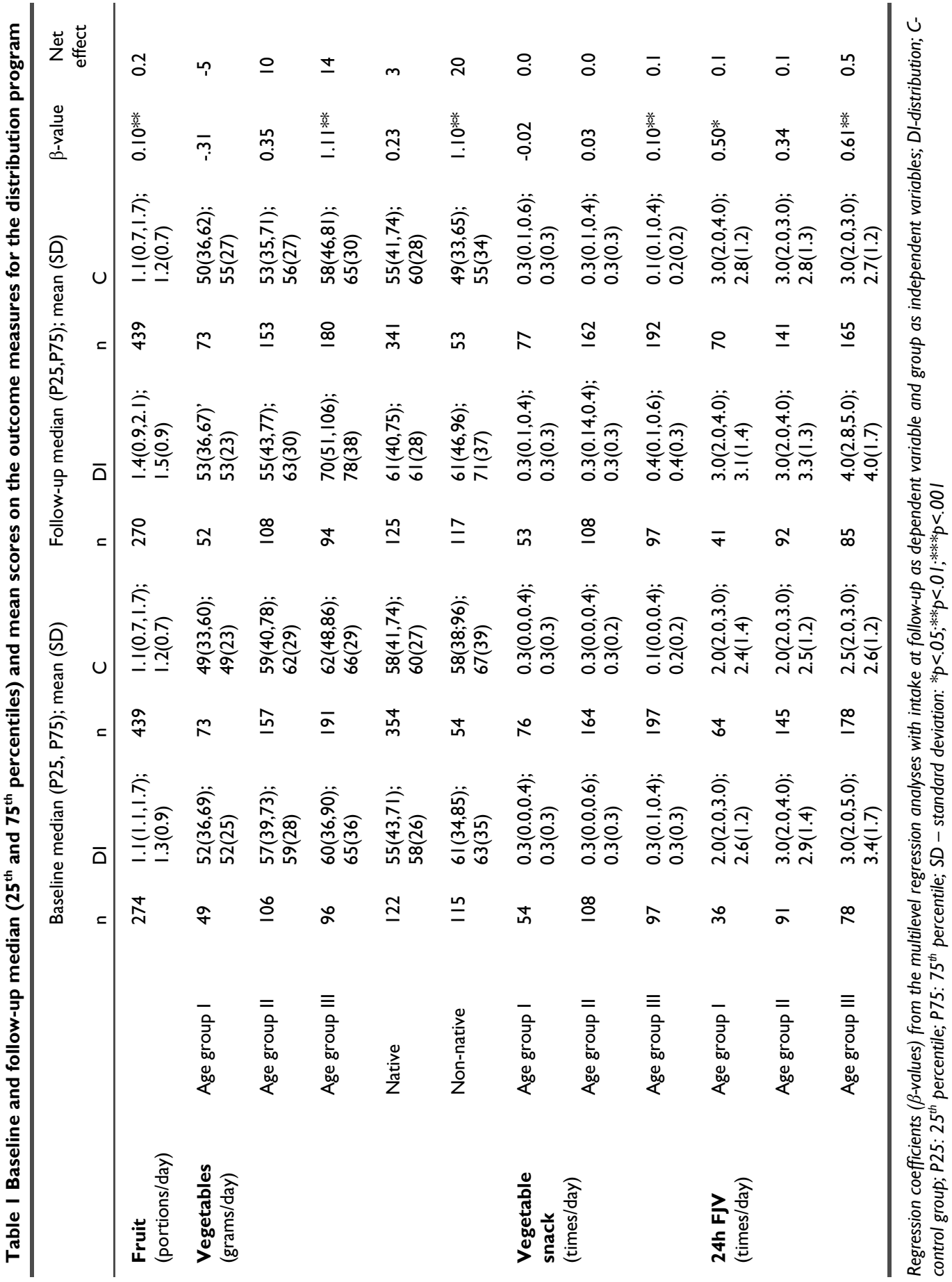




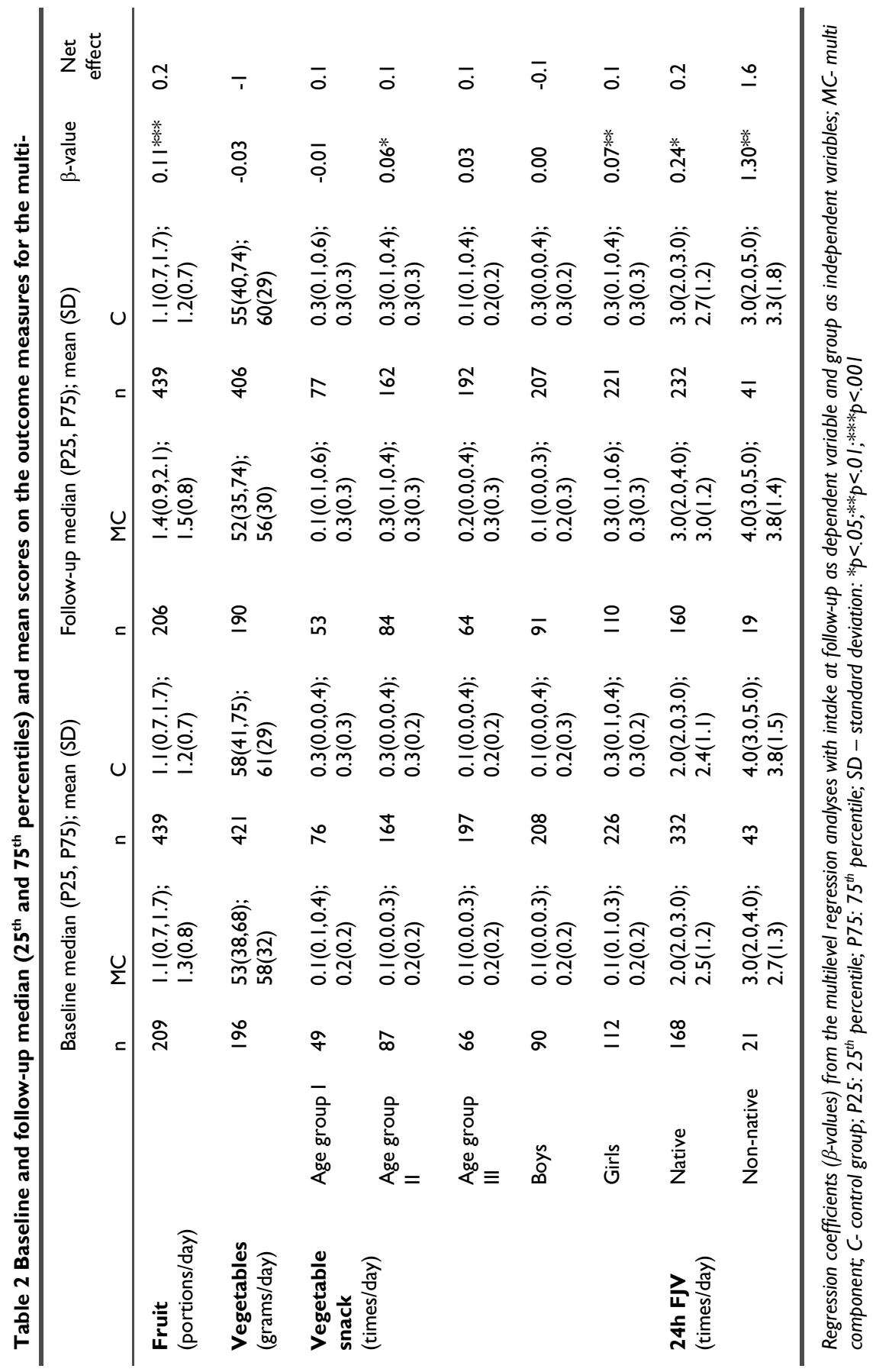


Vegetable intake at dinner was only increased by the distribution program for age group III (+22\%; $\mathrm{p}<.0 \mathrm{I})$ and for non-native children (+32\%; $\mathrm{p}<.0 \mathrm{I})$. Regarding, vegetable snack intake the distribution program was effective for age group III $(+33 \%$; $p<.0$ I) and the multi-component program for age group II $(+50 \%$; $p .05)$ and for girls $(+50 \%$; $\mathrm{P}<.01)$.

Effects on 24h fruit, juice and vegetable consumption (on school days) were found among the children that received the multi-component program, but these effects differed by ethnicity; native children increased their consumption with 0.2 times/day (+8\%; $p<.05)$ and non-native children with I.6 times/day $(+60 \% ; p<.01)$. The distribution program also increased the $24 \mathrm{~h}$ fruit, juice and vegetable consumption, for age group I with 0.1 times/day $(+4 \%$; $<.05)$ and for age group III with 0.5 times/day $(+15 \% ; p<.01)$.

In order to identify the most effective intervention, we compared the distribution and the multi-component program by repeating all multilevel analyses, using the distribution program as reference. If previous effect analyses revealed a significant subgroup effect for one of the interventions, we compared both interventions for that particular subgroup (Table 3).

Our results showed that both interventions were equally effective in increasing fruit consumption. The distribution program was more effective than de multi-component program in increasing vegetable intake at dinner for age group III $(\beta=$ $-1.34 ; \mathrm{p}<.00 \mathrm{I})$ and for non-native children $(\beta=-\mathrm{I} .4 \mathrm{I} ; \mathrm{p}<.0 \mathrm{I})$, and in increasing vegetable snack intake for age group III $(\beta=-.08 ; p<.05)$ and boys $(\beta=-.06 ; p<.05)$. Regarding $24 \mathrm{~h}$ fruit, juice and vegetable intake, both programs showed to be equally effective for all age groups, native, and non-native children. 
Table 3 Regression coefficients ( $\beta$-values) from the multi-level regression analyses comparing the distribution program (DI) versus control group (C), multi-component program (MC) versus control group (C), and multi-component program (MC) versus distribution program (DI)

\begin{tabular}{|c|c|c|c|c|c|}
\hline & & DI vs. C & $M C$ vs. $C$ & MC vs. DI & $\begin{array}{l}\text { Pairwise } \\
\text { comparisons }{ }^{\#}\end{array}$ \\
\hline & & $\beta$ & $\beta$ & $\beta$ & \\
\hline Fruit (portions/day) & & $.10 * * *$ & $.11 * * *$ & .01 & $\mathrm{DI}, \mathrm{MC}>\mathrm{C}$ \\
\hline \multirow[t]{5}{*}{ Vegetables (grams/day) } & Age group I & -.31 & -.41 & -.10 & ns \\
\hline & Age group II & .35 & .22 & -.13 & ns \\
\hline & Age group III & $1.11 *$ & -.32 & $-1.34 * * *$ & $\mathrm{DI}>\mathrm{MC}, \mathrm{C}$ \\
\hline & Native & .23 & -.04 & -.26 & ns \\
\hline & Non-native & $1.10 * *$ & -.32 & $-1.4 I^{* *}$ & $\mathrm{DI}>\mathrm{MC}, \mathrm{C}$ \\
\hline \multirow[t]{5}{*}{$\begin{array}{l}\text { Vegetable snack } \\
\text { (times/day) }\end{array}$} & Age group I & -.02 & -.01 & .01 & ns \\
\hline & Age group II & .03 & $.06 *$ & .04 & $M C>C$ \\
\hline & Age group III & $.10 * *$ & .03 & $-.08^{*}$ & $\mathrm{DI}>\mathrm{MC}, \mathrm{C}$ \\
\hline & Boys & $.06^{*}$ & .00 & $-.06 *$ & $\mathrm{DI}>\mathrm{MC}, \mathrm{C}$ \\
\hline & Girls & .03 & $.07 * *$ & .04 & $M C>C$ \\
\hline \multirow[t]{5}{*}{ 24h FJV (times/day) } & Age group I & $.50 *$ & .17 & -.33 & $\mathrm{DI}>\mathrm{C}$ \\
\hline & Age group II & .34 & $.40 *$ & .06 & $M C>C$ \\
\hline & Age group III & $.61 * *$ & $.39 *$ & -22 & $\mathrm{DI}, \mathrm{MC}>\mathrm{C}$ \\
\hline & Native & $.38 * *$ & $.24 *$ & -.14 & $\mathrm{DI}, \mathrm{MC}>\mathrm{C}$ \\
\hline & Non-native & $.81^{* *}$ & $1.30 * *$ & .49 & $\mathrm{DI}, \mathrm{MC}>\mathrm{C}$ \\
\hline
\end{tabular}

$* p<.05 ; * * p<.01 ; * * * p<.001$

${ }^{\#} n s=$ no significant difference

\section{DISCUSSION}

The present study was an effect evaluation of two Dutch school-based intervention programmes aimed at increasing the F\&V consumption of primary-school children. Results indicate that both the multi-component program and the F\&V distribution were equally effective in increasing children's fruit consumption. Regarding the other outcome measures we conclude that both programmes differ in effectiveness for different subgroups. The distribution program seems especially effective among the oldest children (age group III), because these children benefited from the distribution on all outcome measures. The program even increased vegetable intake during dinner for the oldest children and for non-native children. Especially this effect is promising since vegetables were only distributed at school and no further efforts were done to increase consumption at home. A possible explanation for this effect is that children 
increased their liking of vegetables by repeated exposure at school. This effect was shown in a study by Wardle et al (2003) where children showed an increased liking for a specific vegetable after repeated exposure to this vegetable for only a fortnight (Wardle et al., 2003).

Although, this additional effect on vegetable intake during dinner was not shown by the multi-component program, the latter was effective in increasing vegetable snack consumption among children of the first to third grade (age group II) and for girls, contrary to the distribution program. Furthermore, the multi-component program increased $24 \mathrm{~h}$ FJV consumption for all children, but a larger effect was shown for non-native children.

It has to be noticed, that in some situations the effect analyses showed a different effectiveness for the interventions, however this difference could not be detected when we compared both interventions against each other. These seemingly contradictory results may occur when the difference between the control and an intervention group are large enough to reach significance, while at the same time the differences between the two intervention groups are not large enough to become significant.

The increase in fruit consumption by the multi-component is comparable to similar multi-component programmes situated at the primary school (Burchett, 2003; Knai et al., 2006; Pomerleau et al., 2005). Our results showed that vegetable consumption is more difficult to change. This was also concluded in a review of Miller and Stafford (2000) and could be explained since children usually accept fruit more than vegetables (Baxter \& Thompson, 2002; Burchett, 2003), maybe because its sweetness and greater energy density (Gibson \& Wardle, 2003).

Also the effects of the distribution programme are comparable with similar studies (Bere et al., 2005; Eriksen et al., 2003). Bere (2005) showed that the total F\&V intake (portions/day) increased by a daily free subscription programme in $7^{\text {th }}$ grade children. The study of Eriksen (2003) compared a paid subscription to no subscription among children of grades 0-3 and found effects on $24 \mathrm{~h}$ fruit consumption after five weeks. Surprisingly, non-subscribing classmates also increased their fruit intake.

Contrary to the study of Bere (2005), we also analyzed the effects of the programmes separately for fruit and vegetables. As we did not know exactly how many 
children received a portion of fruit and how many received vegetables on the day their parents filled out the survey, we chose also to use a FFQ measure that computed the daily consumption based on a week. By including weekend days in this measure, the effects of the distribution on a school day could even be underestimated, since F\&V were only distributed during school days. Our confidence in the effectiveness of the interventions is bolstered since this more 'robust' frequency measure found effects for both interventions, contrary to the study of Eriksen (2002).

In contrast with most school-based interventions aimed at increasing F\&V intake, this study focused on all children of the primary school. This means that similar activities, although adapted to the age of the children, were developed for all grades. Furthermore, the whole school adopted the intervention and thereby may have made visible to the children and the parents that consuming F\&V at school is the social norm at school. We think that this approach has an important surplus value over interventions that solely focus on a selection of primary school children.

As we were interested in the effects on all children (aged 4 to 12 years), we had to use self-reported data from parents, since the youngest were not able to fill in questionnaires. The measures we used, although similar to those used in other intervention studies, were not validated among the target population. This should be regarded as a limitation of the study.

A second limitation is the randomisation procedure. Schools were not randomly assigned to the intervention or control groups, but matched based on school size and ethnicity. Baseline analyses, however, showed that schools were comparable except for ethnicity and baseline consumption levels. These were therefore included as covariates in all analyses.

Furthermore, only $21 \%$ of the schools decided to participate in the study. This low participation rate might be caused by an overwhelming number of requests to primary schools to take part in all kinds of extracurricular initiatives, and it may have led to the selection of schools especially interested in health related activities. This could limit generalizability of the study results.

Our aim was to conclude this paper with recommending the 'best' intervention (either the distribution or the multi-component program) for increasing children's F\&V consumption at primary schools. Our results showed that we cannot 
simply conclude that one of the two was most effective for all children, because both interventions showed different effects on children of different age, gender and ethnicity. However, when comparing both interventions we must conclude that distributing F\&V was more effective: beside an increase in fruit and $24 \mathrm{~h}$ fruit, juice and vegetable consumption, the distribution program was also effective in increasing vegetable consumption for different subgroups.

Although both interventions resulted in significant increases in F\&V consumption, these are probably not enough to reduce disease risks. The number of children that meets the Dutch standards after these relative small increases will remain low. In terms of public health effects, more efforts are needed. Our interventions, however were relatively easy to implement (compatible with normal school procedures) and not very expensive.

Since we now know that both strategies are more or less effective, a combination of both interventions could also be considered. If children are motivated (by a multi-component program) to eat more F\&V and this is made available at school every day, an opportunity is created for the children to put their intention into practice. This strategy might close the gap between intention and behaviour, which might result in an even larger effect on F\&V intake.

Unfortunately, effectiveness is not the only consideration that has to be taken into account. When resources are limited, other factors also become important. For example, the multi-component program is relatively low in costs, but takes much classroom time, and is labour-intensive to put into practice (Baranowski et al., 2000; Burchett, 2003; Perry et al., 1998; Reynolds, Franklin, Binkley et al., 2000). Also a lack of adoption or (loyal) implementation of curricula due to time constraints has been reported (Nicklas, Johnson, Myers, Farris, \& Cunningham, 1998). A free distribution, on the other hand, is easier to implement because it becomes a daily routine, but is far more expensive compared to a multi-component program. To discover factors that inhibit the success of these school-based programmes, it is essential to conduct an extensive process-evaluation, certainly encompassing the key actors of program delivery, the teachers. 


\section{Chapter 6}

\section{Increasing fruit \& vegetable intake among children: comparing long-term effects of a free distribution and a multi-component program}

Accepted (with minor adaptations) for publication as: Reinaerts, E., Crutzen, R., Candel, M., de Vries, N.K. \& de Nooijer, J. Increasing fruit \& vegetable intake among children: comparing longterm effects of a free distribution and a multi-component program, Health Education Research. 


\section{ABSTRACT}

The aim of this study was to evaluate and compare the effectiveness of two primary school-based interventions on children's fruit and vegetable consumption (F\&V) on the long term. Six primary schools were recruited and randomly assigned to (I) a daily free distribution program for the whole school, or (2) a multi-component program, consisting of a classroom curriculum and parental involvement (without free F\&V), and six schools served as controls. Follow-up measurements were conducted at the end of the intervention (follow-up I) and one year later (follow-up II). Random coefficient analyses for longitudinal data showed that the effects of both interventions did not differ between the two follow-up measurements. The results showed that both the free distribution program and the multi-component program were equally effective in increasing children's fruit consumption over time. The distribution program also increased children's vegetable consumption over time, even after repeating the analyses using a pessimistic scenario. The distribution program is therefore considered as the most effective intervention of the two, and implementation on a larger scale should be investigated. 


\section{INTRODUCTION}

Dutch children consume less fruit and vegetables (F\&V) than recommended (Anonymous, 1998), and compared to other European children their consumption is low (Yngve et al., 2005). Especially since dietary habits are formed in childhood (Kelder et al., 1994; Lien et al., 200I), interventions targeted at increasing young children's F\&V consumption are needed. Moreover, children are more open to changes in their dietary pattern (Birch, 1990) than grown-ups or parents for whom their limited consumption of F\&V often has become habitual (Krebs-Smith et al., 1995).

It is well recognized that the school setting provides many opportunities to improve dietary behaviours such as F\&V consumption (French \& Wechsler, 2004). In the past decades several school-based interventions have been developed and most of them have reported small but significant increases in children's F\&V consumption, at least on short-term (Burchett, 2003; French \& Stables, 2003; Knai et al., 2006). The effects of these interventions on the longer term are seldom reported (Knai et al., 2006), but can give important indications about the sustainability of the child's behavioural change.

In the Netherlands, initiatives to improve children's F\&V consumption have been undertaken, including the national 'Fruitables at School (Schoolgruiten) project (Tak et al., 2006) and the Pro children project (Brug et al., 2005). Both projects combined a free distribution of F\&V at school (twice a week) with other components such as curriculum activities and parental involvement. This design however, makes it impossible to evaluate the effect of the single components of the interventions. An extensive review of environmental interventions to increase $\mathrm{F} \& \mathrm{~V}$ intake recommended that more research into the direct comparison of environment only and multicomponent interventions was necessary in order to establish effective intervention components (French \& Stables, 2003). Therefore, the Universiteit Maastricht in cooperation with the Local Health Service Noord and Midden Limburg developed and tested two different types of interventions: (I) a daily free F\&V distribution program for the whole school and (2) a multi-component program, consisting of a classroom curriculum and parental involvement (without free F\&V). Both interventions tried to make daily F\&V-consumption habitual, but used different strategies. The distribution program was developed to create a habit unintentionally, by frequently and consistently 
repeating the same behaviour under the same circumstances (Bargh \& Chartrand, 1999). Children consumed a free portion of F\&V every day at the same time in the classroom. The multi-component program was used to create a habit intentionally by motivating respondents to purposefully engage in the desired behaviour, both frequently and consistently (Bargh \& Chartrand, 1999). Parents and children were motivated to bring F\&V to school every day (frequently and consistently) and similar to the distribution program, a special moment was created to eat the F\&V together in the classroom.

A recent evaluation of both interventions showed significant effects on fruit, juice and vegetable (FJV) consumption at the end of the intervention (one year). The distribution program showed to be more effective than the multi-component program, especially in increasing vegetable consumption (Chapter 5). After one year of intervention, both interventions were completely terminated. This means that the free distribution stopped and parents and children were no longer actively motivated to bring F\&V to school.

The purpose of this study is to explore whether the short-term effects were sustained one year after the end of the intervention year. It was expected that the effects would decrease but not disappear completely, since both interventions were aimed at creating habitual behaviour. Because two different strategies were used to make F\&V consumption habitual, we wanted to know whether the two (intervention) strategies differed in sustainability.

\section{METHODS}

Design \& participants

Six schools were recruited to receive an intervention. These schools were paired, based on ethnic composition because the proportion of foreign students can differ substantially among primary schools. Of each pair, one school was randomly assigned to the distribution condition ( $n \approx 690$ children) and one to the multi-component condition $(n \approx 648)$, resulting in two intervention groups each consisting of three schools. Six control schools $(n \approx 1 \mid 68)$ were identified and matched to the intervention schools based on ethnicity and school size. The interventions started in October 2004 and lasted throughout the school year (until June 2005). Both interventions are 
described in more detail in Chapter I of this dissertation. Informed consent was acquired from parents prior to the study.

Questionnaires were brought home by the children to be completed by one of their parents. At the second follow-up the oldest children had entered secondary school, so the questionnaires were mailed to their home addresses. Baseline measurements were conducted in October 2004, while the first follow-up was conducted in June 2005 and the second in June 2006.

At baseline, a total of 1739 parents filled out the questionnaire for their child. Of these parents a total of 940 (54\%) also filled out the second one in June 2005 and $436(25 \%)$ filled out all three measurements. All analyses were performed using the parents that filled out the questionnaire on all three measurements.

\section{Measures}

The main outcome measures were assessed using a pre-structured food recall, and a food frequency questionnaire (FFQ). The pre-structured 24-h food recall assessed the number of times children consumed food (among which fruit or vegetables) the previous day and aimed to focus parents on the total food intake of the day before and not only F\&V. The FFQ (also completed by a parent) was used to assess children's fruit consumption in portions per day, vegetable intake during dinner in grams per day and vegetable snack intake in times per day. The FFQ method was used in a similar Dutch project and based on the Pro-children questionnaire that was validated by Haraldsdóttir and colleagues (2005). Both the pre-structured food recall and the FFQ are presented and explained in more detail in Chapter 5.

Demographics of the children included age, sex and ethnicity. The country of birth of both parents assessed ethnicity of the children. Children were classified as 'native' when both parents had been born in the Netherlands and as 'non-native' when one or both parents had been born outside the Netherlands, based on the definition used by Statistics Netherlands (Centraal Bureau voor de Statistiek (CBS), 2005). 


\section{Data analyses}

Attrition between baseline and the second follow up (June 2006) was studied by means of multilevel logistic regression analysis with attrition as the dependent variable and child's age, sex and ethnicity, child's F\&V consumption at baseline and the intervention factor as predictors. Chi-square tests for proportions and F-tests for continuous variables were used to compare baseline characteristics between study groups.

Long-term intervention effects were analyzed using random coefficients analyses for longitudinal data (Twisk, 2005), using MLwiN (Rasbash et al., 2000). Separate analyses were performed for each of the outcome measures. To adjust for dependency in the measurements, a three-level data structure was used in the analysis model, where the three levels were the time of the follow-up measurement (level I), pupil (level 2) and school (level 3). In all analyses dummy variables for the distribution and the multi-component intervention group as main independent variables were included, and the model adjusted for the effects of child's age, ethnicity, and baseline value of the outcome measure. Furthermore, all analyses included interactions between time and the dummy indicating the distribution group and between time and the dummy indicating the multi-component group. All analyses were done following a 'top-down' procedure, i.e. starting with the most elaborate model and successively leaving out the most non-significant effects. Regression coefficients in the model were statistically tested using the Likelihood Ratio test and the Wald statistic, setting significance at $(=0.05)$.

Missing values for individual scale items were substituted by the mean score of all respondents on the item. There were no items that had more than $20 \%$ missing values. All outcome measures were checked for normality and if necessary transformed as described by Tabachnik \& Fidell (Tabachnick \& Fidell, 1996). Fruit (portions/day) and vegetable snack consumption (times/day) were adjusted for positive skewness using square root transformations (SQRT(X)).

To quantify the effect of the interventions, the net effect was used, indicating the differences in change in fruit and vegetable intake between the intervention and control group. Thus, the net effect $=\left(\right.$ Follow-up intake intervention - Baseline intake $\left._{\text {intervention }}\right)$ - (Follow-up intake control $_{\text {- Baseline intake }}$ control $)$. Furthermore, effect sizes were calculated for both follow-up measurements following Cohen (Cohen, 1988). 


\section{RESULTS}

Baseline characteristics and dropout analysis

The mean age of the children was 8 years $(S D=2.2$ years), $47 \%(n=206)$ were boys and $82 \%(n=357)$ were of Dutch origin. Exploratory analyses showed that children in the control group were 0.7 years $(p<.05)$ older than the children in the multicomponent group, and that the distribution of ethnicity among the three groups differed significantly (control vs. multi-component vs. distribution: $38 \%$ vs. $14 \%$ vs. $48 \%$ non-native; $\mathrm{p}<.00 \mathrm{I})$. Children in the distribution group consumed more vegetable snacks at baseline than children in the control group $(p<.05)$. To correct for these differences these factors were included as covariates in all effect analyses.

Multilevel logistic analyses of drop-out at first and second follow-up (combined) did reveal some selective drop-out. Parents of non-native children $(\mathrm{OR}=1.67 ; 95 \% \mathrm{Cl}=1.16-2.38)$ dropped out significantly more often ( $19 \%$ native vs. $32 \%$ non-native). Children of parents that dropped out consumed 0.1 portion less fruit per day $(\mathrm{OR}=0.69 ; 95 \% \mathrm{Cl}=0.69-0.93)$ at baseline compared to the children whose parents filled out all three surveys. These factors were already included in the model as covariates.

\section{Main outcome measures}

Table I shows summary statistics (raw scores) for children's 24h Fruit, Juice and Vegetable consumption (24h FJV), fruit, vegetable snack, and vegetable consumption at baseline, follow-up I and follow-up II. Furthermore, the effects of the distribution program and the multi-component program across time on the main outcome measures are presented. For none of the outcome measures the interaction between time and intervention condition was significant, indicating that the effect of the intervention did not differ between the two follow-up measurements.

A significant intervention effect of the distribution program compared to the control group $(p<.05)$ was found on all outcome measures. This means that the distribution program was effective in increasing children's fruit and vegetable consumption and that this effect sustained after the intervention was terminated. Uncorrected data from Table I shows that at the second follow-up children that received the distribution program had increased their consumption with a net effect of 
0.13 times of FJV on the day prior to data collection, they consumed 0.09 more portions of fruit per day and 0.07 times more a vegetable snack compared to the control group. Furthermore, the uncorrected data showed that children from the distribution group consumed 3.25 grams more vegetables during dinner. The multicomponent program showed to be effective over time in increasing children's 24h FJV $(p<.05)$ and fruit consumption $(p<.05)$ compared to the control group. At second follow-up they had increased their consumption with a net effect of 0.32 times FJV and 0.19 portions fruit per day compared to control group. No effects were found for vegetable snack intake and vegetable intake during dinner.

In order to identify the most effective intervention, we compared the distribution and the multi-component program by repeating all analyses, using the distribution program as reference. The results of these analyses showed that both interventions were similarly effective in increasing $24 \mathrm{~h} \mathrm{FJV} \mathrm{and} \mathrm{fruit} \mathrm{consumption,} \mathrm{but}$ that the distribution program was more effective in increasing vegetable snack intake ( $\mathrm{P}<.05)$ and vegetable intake during dinner $(\mathrm{P}<.0 \mathrm{I})$.

\section{Analyses including dropouts}

Unfortunately, a considerable number of parents (75\%) withdrew from the study before the second follow-up measurement. Therefore, here could be a risk for informative dropout. This means that whether or not parents dropped out could be dependent on their child's unknown F\&V consumption at the first or second follow-up, respectively. To address this problem we repeated the analyses using a pessimistic scenario, which assumed that all respondents who had missing values did not change their baseline consumption during the intervention period. Therefore, the baseline value (T0) of each dropped-out respondent was used as a substitute for the missing values on the first (TI) and/or second follow-up (T2). These conservative analyses revealed the same results for both interventions on all outcome measures except for 24h FJV consumption and vegetable consumption during dinner. Contrary to the complete-case analyses, the analyses did not show a significant effect of the multicomponent program on 24h FJV. Vegetable consumption during dinner was increased by the distribution program, but we only found this effect on the short term (follow-up I). 


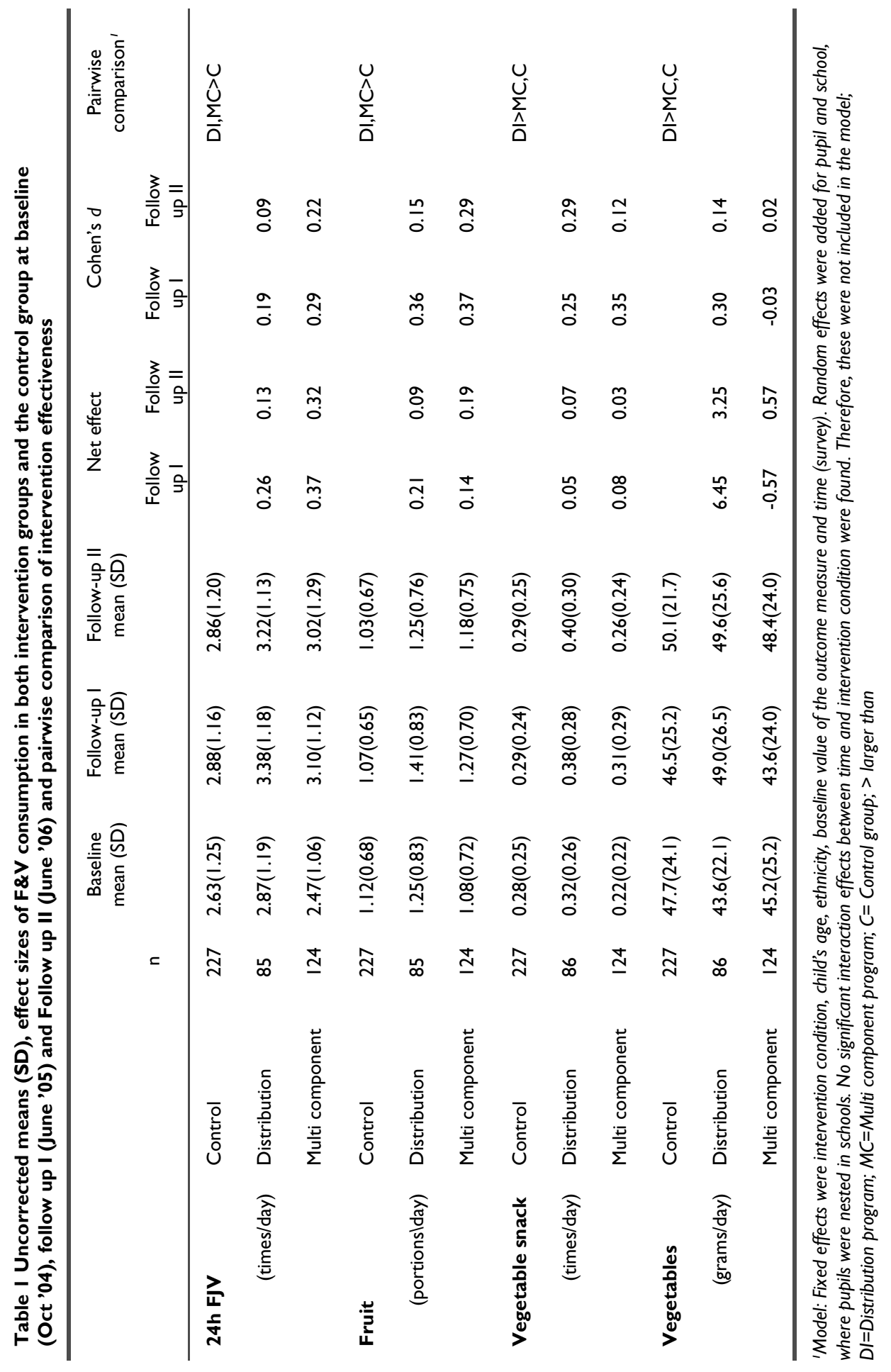


For fruit consumption, the significant time by intervention interaction revealed that the effect of both programs decreased over time. However, separate analyses for the first and the second follow-up showed that both interventions remained effective at both measurements.

\section{DISCUSSION}

The aim of the current study was to evaluate the effects of two school-based interventions aimed at increasing children's F\&V-intake over time, and to identify which of the two interventions was most successful after the intervention had completely stopped.

This study indicated that the multi-component program was effective in increasing children's 24h FJV-consumption and fruit consumption over time, and the distribution program was effective on all outcome measures, but effect sizes were small to medium according to the criteria of Lipsey (Lipsey, 1990). Although the effects on F\&V-consumption on the second follow-up were smaller compared to the first follow-up, the general lack of intervention by time interactions indicates that the shortterm effects of these interventions as reported previously (see Chapter 5) sustained one year after terminating the intervention. After comparing both interventions we must conclude that although both programs were equally effective in increasing $24 \mathrm{hFJV}$ and fruit consumption over time, the distribution program showed to be more effective especially in increasing children's vegetable consumption. Although no efforts were made at all to increase consumption at home, the distribution even increased vegetable consumption during dinner. This is especially promising considering that vegetable consumption has been shown to be difficult to change (Miller \& Stafford, 2000), because children tend to accept fruit more easily than vegetables (Baxter \& Thompson, 2002; Burchett, 2003). An explanation for this effect could be that children in the distribution program increased their liking for vegetables, because they were more frequently exposed to different kinds of vegetables compared to the children that received the multi-component program. The effects of repeated exposure were previously demonstrated by Wardle et al. (2003a; 2003b).

Our results showed that the distribution program was more effective on the long term compared to the multi-component program. This could indicate an 
increased liking for F\&V due to repeated exposure. On the other hand it could indicate that only in the distribution program the same behaviour was repeated frequently and consistently enough to create a habit at least for the outcome measures related to vegetable consumption. The process evaluation of both interventions showed that the multi-component program was less fully implemented compared to the distribution program (see Chapter 7), which supports the last explanation.

Our results are more or less comparable to those previously reported in similar intervention studies (Bere et al., 2007; Wind, Te Velde et al., 2006), but these studies looked at long-term effectiveness while the distribution component of the interventions was partly continued. The European Pro Children study (Wind, Te Velde et al., 2006), for example, combined a free distribution of F\&V twice a week with a school curriculum. At second follow-up children reported to eat fruit 0.24 times more often per day and they ate 0.29 more portions of fruit on the day prior to data collection. Daily frequency of vegetable intake increased with 4.6\% (Wind, Te Velde et al., 2006). Contrary to the present study, the free distribution was sustained after the intervention period. More in line with our study is the one reported by Bere (2007) that also found a sustained effect of a free subscription scheme in Norway after three years. The estimated long term effects for $F \& V$ consumption were 0.38 portions per day for boys and 0.44 for girls (Bere et al., 2007). In this study a small part of the children still participated in the national (paid) school fruit program the years following the intervention. This mediated the effects partly, but after correcting for the subscription long-term effects remained significant. Combined with our results, this indicates that a free subscription is an effective method to increase children's F\&Vconsumption even in the long-term. The distribution program not only seemed to be more effective than the multi-component program, previous research into implementation of both interventions also concluded that a distribution scheme has more potential to be implemented and sustained at primary schools (Chapter 7).

Although both interventions were statistically effective in increasing fruit consumption compared to no intervention, it should also be concluded that the net effects were small to medium. The intake of fruit consumption, for example, increased with 0.1 to 0.2 portions per day. A serving of fruit weighs on average about 80 grams, so the consumption of fruit was increased with about 8 to 16 grams per day. One can 
wonder whether this increase results in public health benefits. According to a Norwegian study reported by Bere (2007), a lifelong increase of 2.5 grams F\&V per day is sufficient to make a free distribution during primary school (10 years) cost-effective and therefore our results could be considered practically relevant. Nevertheless, more research into the cost-effectiveness of these kinds of interventions is needed.

The present study has some limitations. Although schools were randomly assigned to the intervention conditions, the control schools were matched to the intervention schools based on school size and ethnicity. This resulted unfortunately in differences at baseline regarding ethnicity and baseline consumption levels, which have been controlled for. Because we wanted to include all children that received the interventions into our effect analyses, and younger children are limited in their ability to report their own food intake (Livingstone et al., 2004), we had to rely on parental reports of the children's F\&V intake. Reasons for dropout have not been studied. However, studies reported that neither parents (Baranowski et al., 199I) nor children are reliable reporters of children's food intake (Livingstone \& Robson, 2000; Livingstone et al., 2004; McPherson et al., 2000). Furthermore, a recent study showed low levels of agreement between child and parental reporting of F\&V intake (Tak et al., 2006). Therefore, it should be recommended to study effectiveness of interventions by using both parental and child reports.

Using parental reports unfortunately resulted in a large dropout between the baseline measurement and the first and second follow-up. However, the analyses using a pessimistic scenario by imputing all missing values with the respondent's baseline intake values, revealed similar effectiveness for the distribution program (except for long-term effectiveness on vegetable consumption ) compared to the complete-case analyses. The multi-component program only remained effective in increasing fruit consumption.

In sum, the present study showed that both a free distribution program and a multi-component program are effective in increasing children's fruit consumption over time. The distribution program also succeeded in increasing children's vegetable consumption over time, and it is therefore considered as the most effective intervention of the two. In view of the positive results reported, implementation of a distribution scheme on a larger scale should be investigated. 


\section{Chapter 7}

\section{Fruit \& vegetable distribution program versus a multi component program to increase F\&V consumption: which should be recommended for implementation?}

Published as: Reinaerts, E., de Nooijer, J. \& de Vries, N.K. (2007). Fruit \& vegetable distribution program versus a multi component program to increase F\&V consumption: which should be recommended for implementation? Journal of School Health, 77. pp.679-686. 


\section{ABSTRACT}

This chapter describes and compares the implementation, evaluation and potential for adoption of two primary school-based interventions aimed at increasing fruit and vegetable (F\&V) consumption in children, both with proven effectiveness: (I) a free daily F\&V distribution scheme for all primary school children and (2) a multicomponent age-specific program consisting of a classroom curriculum, parental involvement and an environmental component. A total of 48 teachers who worked with either of these programs filled out a questionnaire at the end of the intervention period. Additionally, 24 of the teachers who worked with the multi-component program filled out periodic monitoring reports during the intervention. Results showed that compared to the F\&V distribution, the multi-component program was less fully implemented and that implementation of activities decreased over time. Both programs were evaluated favourably and about half of the teachers indicated that they were willing to use the program again in the following school year. Teachers who used the multi-component program experienced more social pressure to implement the program. They rated the program they had used as more complex than the other group rated the distribution program. We conclude that the free distribution program has the greatest potential for being adopted by schoolteachers, but that efforts must be made to acquire funding for it. Until these resources are available, the multicomponent program seems to be a good alternative, if improved as suggested. 


\section{INTRODUCTION}

Two programs to increase children's fruit and vegetable (F\&V) consumption have recently been implemented at Dutch primary schools: a free F\&V distribution scheme and a multi-component curriculum. These programs were developed and implemented by the Universiteit Maastricht and the Regional Health Service for the northern and central parts of the province of Limburg (GGD NML), using the Intervention Mapping (IM) protocol. IM is a stepwise approach that ensures a systematic evidence-based and theory-driven development and implementation of health promotion interventions (Bartholomew et al., 200I). IM has proved to be suitable for the development of programs to stimulate children's F\&V intake (Pérez-Rodrigo et al., 2005; Weber Cullen et al., 1998). In an earlier study, the two interventions (the distribution scheme and the multi-component program) were evaluated for their effects and compared with a comparison condition in a pretest - posttest design. The results showed that although there were different effects for subgroups (age groups, ethnicity and gender) on several outcome measures, both interventions were effective in significantly increasing children's F\&V intake. For the distribution scheme we found that the youngest children (age 4-5) increased their 24h fruit, juice and vegetable (FJV) consumption from 2.6 times per day at baseline to 3.I times per day after the intervention. Children aged 1012 years increased their consumption from 3.4 to 4.0 times per day. The multicomponent program accounted for an increase from 2.5 to 3.0 times per day among native children and an increase from 2.7 to 3.8 times per day for the non-native children. For more details see Chapter 5 . Since the impact of such effective programs can be relevant if implemented on a large scale, the questions arise which of the two programs should be recommended for implementation and which aspects of the programs could facilitate or impede their implementation?

Planning models stress the importance of process evaluation because data on the implementation and appreciation of health promoting interventions are essential for several reasons. First, information on how the program was implemented and received by those involved is required to distinguish between the consequences of poor program delivery and those of intrinsically ineffective interventions, so that the findings of effect evaluations can be interpreted correctly (Bartholomew et al., 200 I; Green \& Kreuter, 1999; Potvin et al., 200I; Rossi et al., 1999). Second, data on process 
evaluation can be used to identify key facilitating and inhibiting factors for future program implementation and dissemination (Klepp et al., 2005).

Key actors in the delivery of the two programs, namely teachers, were approached to acquire process evaluation data on the quality of the implementation of the two programs and on their appreciation. Because effectiveness alone is not enough to ensure the dissemination of a school-based program, we additionally assessed the probability of adoption by primary school teachers, and tried to identify components that need to be improved to maximize future dissemination.

A well-known model to study the dissemination of preventive innovations is the Diffusion Theory by Rogers. Rogers (2003) states that certain characteristics of an innovation as perceived by intermediaries are important determinants of the rate of adoption. According to Rogers (Rogers, 2003), adoption of an innovation depends on its relative advantage (the extent to which the innovation is perceived as advantageous), compatibility (the degree to which the innovation is perceived as consistent with existing work procedures), complexity (the degree to which the innovation is perceived as easy to understand and to use), trialability (the extent to which the innovation can be tested) and observability (observability of the results of the innovation to others). Innovations that are perceived as having greater relative advantage, being more compatible, trialable and observable, and not being too complex will be adopted more rapidly than other innovations (Rogers, 2002). Zaltman and Duncan (1977) also identified concepts that influence the adoption process, such as reversibility (the extent to which an innovation can be reversed or discontinued), risk (the degree of uncertainty caused by introducing the innovation), modifiability (the extent to which the innovation van be updated or modified), communicability (communication about the innovation), commitment (the required commitment to work with the innovation), the time required for implementation and the impact on social relations (influence of the innovation on the social relations within the organization).

The way adopters perceive the characteristics of an innovation in a trial or try-out yields information that can be used to improve the program's characteristics so as to maximize future adoption. This is of special importance for school-based programs in the Netherlands, since the Dutch government does not interfere in the selection of teaching materials (Euridyce, 2005). 
Although the above characteristics are expected to influence adoption, there are also 'characteristics of the user of the innovation' that are expected to determine the adoption decision (Fleuren, Wiefferink, \& Paulussen, 2004; Paulussen, 1994). According to Paulussen (1994) the Theory of Planned Behaviour (TPB)(Ajzen, 199I) can be used to structure these user characteristics, because teaching can be considered an intentional act that is guided by a teacher's beliefs (Paulussen, Kok, \& Schaalma, 1994). The present study examined teachers' attitudes, subjective norms, perceived behavioural control and intention toward program use. Insights into the characteristics of the innovations and into TPB-related constructs can help program planners assess if a new program is likely to be adopted and which components have to be improved to maximize diffusion. The present study addressed the following research questions:

(I) To what extent were the two F\&V programs implemented by teachers?

(2) How did teachers appreciate each program and its components?

\section{METHODS}

\section{Program description}

Development of the current interventions was based on two objectives; (I) getting children to increase their daily F\&V consumption and (2) creating an environment (especially at school) that supports children's F\&V consumption. Both interventions started in October 2004 and continued until June 2005. The effects of the F\&V distribution scheme and the multi-component curriculum were studied in a randomized trial with a pre-test and a one-year follow-up post-test. A total of six primary schools were matched in terms of school size and ethnic composition. Of each pair, one school was randomly assigned to the distribution condition and one to the multi-component condition, resulting in two intervention groups each consisting of three schools. There were also six comparison schools, in a different region.

Free distribution program. Children were provided with one serving of fruit, fruit juice or raw vegetables during the morning break of every school day. The F\&V were delivered to the schools twice a week in ready-to-eat form and distributed among the classrooms by a school employee or a pupil. Teachers were encouraged to 
eat the F\&V together with the children. At the start of the project, parents received a newsletter introducing the project.

Multi-component program. This program tried to motivate children and their parents to bring F\&V to school as a morning break snack. It consisted of a classroom curriculum, parental involvement and an environmental component. To stimulate children to bring F\&V to school, they received a lunchbox that was especially designed to take F\&V into school undamaged. The classroom curriculum was adapted to the children's age, resulting in three different programs; one for children aged 4-5 years (age group I), one for children aged 6-9 (age group II), and one for children aged 10-12 years (age group III). A total of 12 to 14 different activities were developed for each age group, including tasting sessions, skills training, and homework assignments. The intervention year was divided into three periods, each lasting two to three months. Materials and instructions for the activities were distributed among the teachers at the beginning of each period, instead of all at once, to improve implementation. At the beginning of each period, one teacher in each school was invited to attend a meeting where the new activities were presented and explained. Subsequently, these teachers presented the materials to their colleagues at school, so they were reminded of the project and the activities that had to be implemented in the next two or three months. We tried to improve parental involvement by means of three newsletters, several homework activities (for instance a family interview about preferences for fruit and vegetables), and cues like a refrigerator magnet that was designed to remind parents to give their child F\&V to take to school. The environmental component consisted of posters with the project mascots that were on display in local supermarkets near the intervention schools, thereby reminding parents to buy F\&V for their children.

\section{Subjects}

At the end of the intervention period, all teachers $(n=60)$ of the six intervention schools were invited to take part in the evaluation. A total of 48 teachers (80\%) responded; 28 teachers (85\%) who had delivered the distribution program and 20 (74\%) who had delivered the multi-component stimulation program. Respondents were teachers of all primary school grades, i.e. age groups I (33\%), II (46\%) and III 
(21\%). On average, teachers had been teaching for 19.5 years $(S D=12.5)$, and $71 \%$ were female.

The teachers who implemented the multi-component program (27 in total) used three teachers' monitoring reports during the whole intervention period. A total of $24(89 \%)$ teachers handed in monitoring reports at least once. Twenty-one (78\%) of them handed in the reports after both the first and second intervention periods. After the third period, the response dropped significantly, to I5 teachers $(55 \% ; p<0.05)$. The overall response did not differ between the three age groups.

\section{Instruments}

Questionnaire - The questionnaire for the teachers of the free distribution scheme and the multi-component stimulation program consisted of 78 and 65 items, respectively. Implementation of the distribution program was assessed by asking how much time teachers had spent per day on the distribution of F\&V, if they had consumed the F\&V together with the children in the classroom (yes/no) and at what moment they had done so. How often the teachers had consumed F\&V in the presence of the children ('always or almost always'( $I$ ) to 'never or almost never'(5)) and how many children had actually eaten the fruit and vegetables provided ('everyone or almost everyone'(I) to 'no-one or almost no-one'(5)), was also assessed. Teachers were asked to evaluate the total program, the quality, variation and portion sizes of the F\&V distributed and the delivery system, in an appreciation grade ranging from I (very poor) to 10 (excellent). Teachers who had implemented the multi-component program evaluated the total program, the newsletters, the fruit box and the classroom activities in general.

For both interventions, the innovation characteristics were assessed by means of several propositions, reflecting the theoretical concepts proposed by Rogers (1995) and Zaltmann and Duncan (1977). The TPB-related constructs were operationalized as described by Ajzen (2002) (Table I). Finally, teachers were asked to indicate the amount of time they had spent on the F\&V program (in minutes/day). 


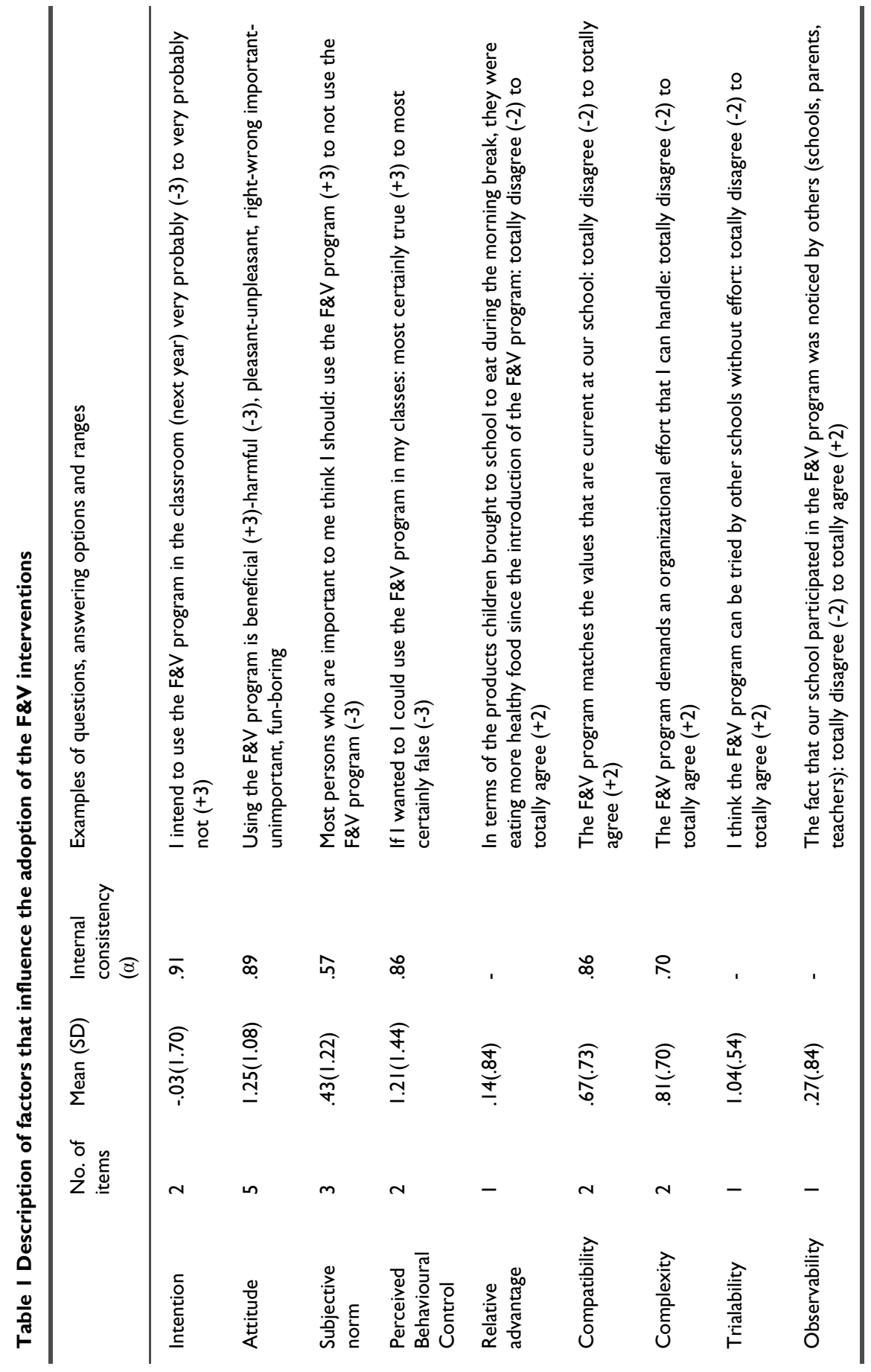




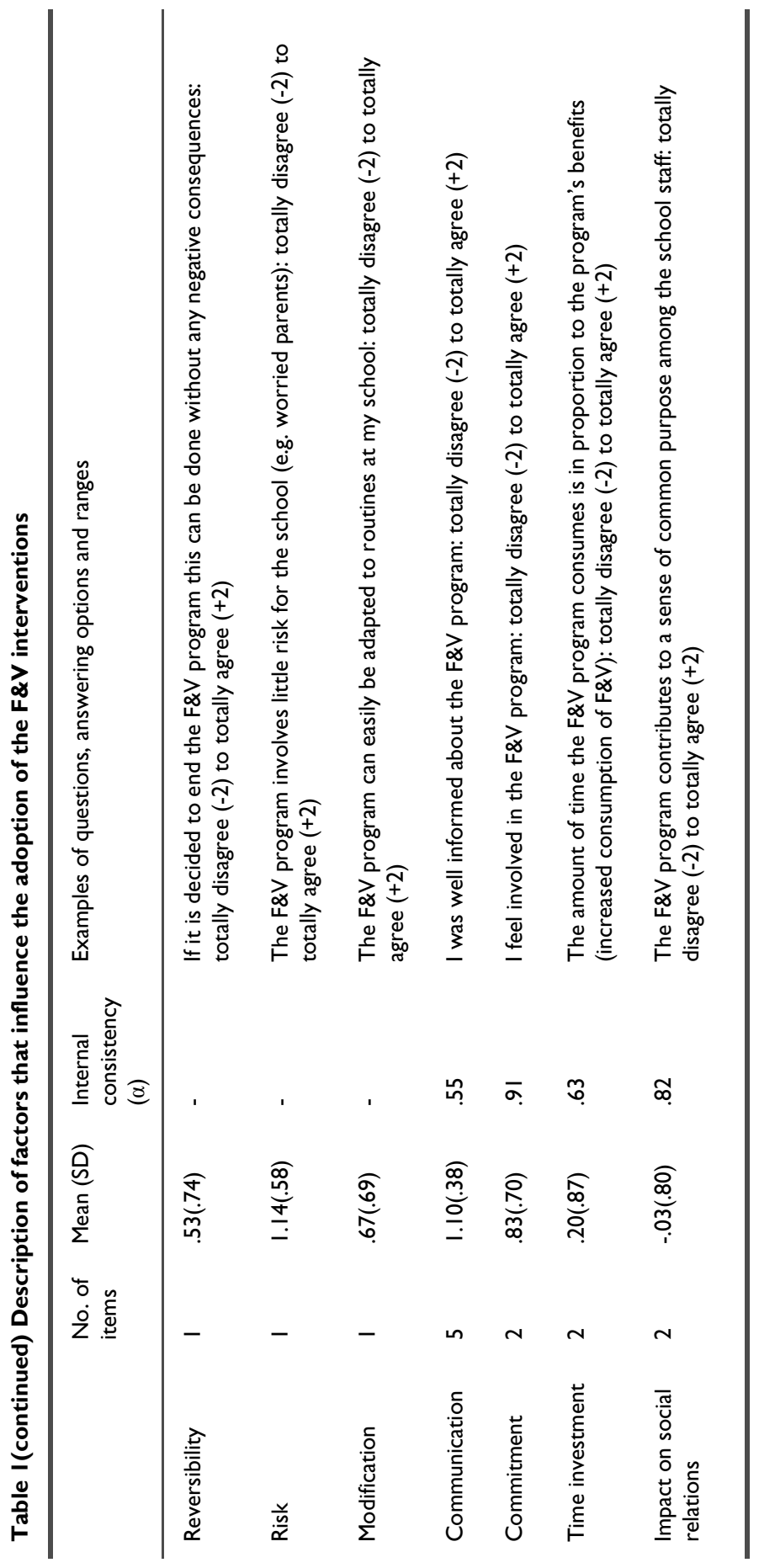


Monitoring reports - Data on the implementation of the lessons that were part of the multi-component program were collected during the intervention period by means of monitoring reports. Teachers filled out a form with questions on teaching time (preparation and delivery), activities completed (yes/no), use of the instruction manuals ('completely followed the instruction manual' (I) to 'did not follow the instructions at all' (4)), and evaluation of the lesson in an appreciation grade ('very poor' (I) to 'excellent' (10)). The number of items on the monitoring reports ranged from 42 to 57 depending on the number and kind of activities implemented in the preceding period.

\section{Data Analysis}

Differences in implementation program implementation of the multi-component program between the three intervention periods and between age groups were tested with $X^{2}$-tests and t-tests in SPSS 12.0. Because we had a nested design (teachers within schools) multi-level regression analyses (MLwiN version I.10.0007) were used to test differences between the two interventions regarding appreciation, psychosocial concepts and innovation characteristics. All analyses used a $p<.05$ significance level.

\section{RESULTS}

Program implementation

Almost all teachers (82\%) at the 'distribution' schools had consumed F\&V in the classroom. Eighty-nine percent of them ate the F\&V with the children at a fixed time, mostly at the beginning of the morning break (7I\%). When the F\&V were consumed, $79 \%$ of the teachers said they modelled the consumption of the distributed F\&V 'usually' to 'always'. Sixty-eight percent of the teachers said that 'almost every child' had eaten the F\&V they distributed; whereas about $25 \%$ of the teachers said that 'more than half the children' had consumed the F\&V and the remaining two teachers (7\%) said that 'about half of the children' had actually eaten the F\&V. The F\&V left over were taken home by children or teachers.

Table 2 summarizes the implementation of activities in the three periods of the multi-component program, the percentage of teachers who followed the instruction manual largely or completely, the teaching time involved, and the appreciation of the activities. These results show that the teachers had implemented 
most of the lessons, but more so in the first period than in the third $\left(\mathrm{F}_{(2,54)} ; 4.9\right.$, $\mathrm{p}<0.05)$. They had followed the instruction manual largely or completely and evaluated the lessons fairly favourably, with average appreciation grades for activities during an intervention period ranging from 7.3 to 8.2 on a 10-point scale. Teachers of age group I had spent about 15 minutes preparing a lesson and 27 minutes delivering it. For teachers of age group II, these times were 14 and 37 minutes, respectively, and for teachers of age group III I 8 and 44 minutes. Teachers of age group III had spent significantly more time overall on lesson delivery than the teachers of the youngest children $\left(\mathrm{F}_{(2,52)} ; 3.4, \mathrm{p}<0.05\right)$. The teachers of age group I had spent more time preparing the activities of the third period than those of the first period $\left(F_{(2,11)} ; 5.3, p<0.05\right)$.

Table 2 Lessons implemented, \% of teachers who followed the instructions completely or largely, teaching time and appreciation by teachers.

\begin{tabular}{|c|c|c|c|c|c|c|c|c|}
\hline & & \multirow[t]{2}{*}{$\begin{array}{c}\text { Total } \\
\text { lessons }\end{array}$} & \multicolumn{2}{|c|}{$\begin{array}{c}\text { Lessons } \\
\text { Implemented }\end{array}$} & \multicolumn{2}{|c|}{ Minutes } & \multirow[t]{2}{*}{$\begin{array}{c}\text { Followed } \\
\text { Manual }\end{array}$} & \multirow[t]{2}{*}{$\begin{array}{l}\text { Appreciation } \\
\text { (out of I0) }\end{array}$} \\
\hline & & & $M(S D)$ & Range & Preparation & Delivery & & \\
\hline \multirow{3}{*}{$\begin{array}{l}\overline{0} \\
\frac{0}{4} \\
\frac{0}{\partial} \\
\frac{1}{0}\end{array}$} & Period I & 5 & $3.7(1.0)$ & $2-5$ & 12 & 21 & $73 \%$ & 7.5 \\
\hline & Period II & 5 & $2.8(I . I)$ & $\mathrm{I}-4$ & 14 & 30 & $96 \%$ & 7.7 \\
\hline & Period III & 4 & $2.8(0.5)$ & $2-3$ & 19 & 30 & $100 \%$ & 7.7 \\
\hline \multirow{3}{*}{ 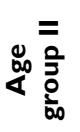 } & Period I & 4 & $3.7(0.5)$ & $3-4$ & 15 & 46 & $79 \%$ & 7.6 \\
\hline & Period II & 4 & $2.7(1.0)$ & $\mathrm{I}-4$ & 13 & 31 & $86 \%$ & 7.3 \\
\hline & Period III & 4 & $2.5(0.8)$ & $2-4$ & 13 & 34 & $73 \%$ & 7.3 \\
\hline \multirow{3}{*}{ 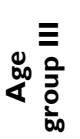 } & Period I & 4 & $2.6(1.1)$ & $\mathrm{I}-4$ & 19 & 53 & $76 \%$ & 8.2 \\
\hline & Period II & 5 & $2.4(1.4)$ & $0-4$ & 19 & 35 & $79 \%$ & 7.6 \\
\hline & Period III & 4 & $1.0(1.1)$ & $0-2$ & 16 & 43 & $94 \%$ & 7.8 \\
\hline
\end{tabular}

\section{Program evaluation}

At the end of the intervention period, the teachers evaluated the programs and their components favourably, with appreciation grades ranging from 7.I to 8.7 out of 10 . There were no differences in appreciation between the two programs, except for the newsletters (Table 3). Teachers who had implemented the multi-component program gave the newsletters a higher appreciation grade than those who had implemented the distribution program $(\beta=.76, p<0.05)$, but both were evaluated favourably. The amount of time the teachers had spent on the F\&V program was larger in the distribution 
group $(\beta=-4.91, p<0.05)$. The distribution took teachers 10 minutes (SD 4.3 minutes) per day, while the activities of the multi-component program took about 105 minutes per month (SD 60.5 minutes), which corresponds to 5 minutes per day, including preparation. Means of scores, percentage agreement and results of the t-tests for both the psychosocial concepts are described in Table 4. There were no differences between the two programs regarding the teachers' intention to use the program in the future. In both interventions, about half (48-58\%) of the teachers indicated that they were willing to use the program again in the following school year. Teachers' attitude toward the F\&V program was generally positive in both groups. About $80 \%$ of the teachers perceived the program as beneficial, pleasant, right, important, and fun. The teachers in the multi-component program experienced greater social pressure from important others with respect to implementing the F\&V program than did the teachers in the distribution program. Most teachers were positive about their ability to apply the F\&V program.

Table 3 Means, SD and t-tests of the appreciation of the program components by teachers

\begin{tabular}{|c|c|c|c|c|}
\hline & & $\begin{array}{l}\text { Distribution } \\
\text { program }\end{array}$ & $\begin{array}{l}\text { Multi-component } \\
\text { program }\end{array}$ & \\
\hline & & Mean (SD) & Mean (SD) & $\mathrm{P}$ \\
\hline \multicolumn{5}{|l|}{ Evaluation of } \\
\hline & Total program & $7.8(.69)$ & $7.6(.60)$ & ns \\
\hline & Newsletters & $7.1(1.08)$ & 7.9(.77) & $D<M C^{a * * *}$ \\
\hline & Fruit box & & $8.7(.91)$ & \\
\hline & Curriculum activities & & $7.4(.70)$ & \\
\hline & Quality of fruit & 8.I (.8I) & & \\
\hline & Quality of vegetables & $7.9(1.03)$ & & \\
\hline & Quality of fruit juice & $8.4(1.14)$ & & \\
\hline & Variation & $7.6(1.29)$ & & \\
\hline & Delivery system & $8.6(.87)$ & & \\
\hline & Portion size & $7.9(1.35)$ & & \\
\hline
\end{tabular}

Innovation characteristics

For all characteristics of the innovation, except relative advantage, observability, reversibility, time investment, and impact on social relations, at least half (ranging from $50 \%$ to $100 \%$ ) of the teachers agreed with the propositions assessing that characteristic. Teachers of the two interventions differed in their scores on two 
characteristics, namely complexity, and risk (Table 4). Teachers in the distribution program perceived the program delivery as less complex than those who used the multi-component program $(\beta=-.67, p<0.01)$, though the majority of teachers who used the multi-component program also perceived it as easy to use. Moreover, teachers of the multi-component program perceived less risk involved in implementing the program $(\beta=-.33, p<0.05)$, though the majority of teachers in both programs actually thought that adopting the program involved little risk.

Table 4 Means, SD and differences between the programs on intention, attitude, subjective norm, perceived behavioural control and innovation characteristics

\begin{tabular}{|c|c|c|c|c|c|}
\hline & \multicolumn{2}{|c|}{$\begin{array}{l}\text { Distribution program } \\
n=28\end{array}$} & \multicolumn{2}{|c|}{$\begin{array}{l}\text { Multi-component program } \\
n=20\end{array}$} & \multirow[t]{2}{*}{$\mathrm{P}$} \\
\hline & Mean (SD) & $\%$ & Mean (SD) & $\%$ & \\
\hline Intention & $-0.39(1.85)$ & 47.8 & $0.42(\mathrm{I} .43)$ & 57.9 & ns \\
\hline Attitude & $1.23(1.16)$ & 80.0 & $1.28(1.00)$ & 81.0 & ns \\
\hline Subjective norm & $0.03(1.34)$ & 52.4 & $0.85(.95)$ & 75.0 & $\mathrm{D}<\mathrm{MC} \mathbf{C}^{\mathrm{a} *}$ \\
\hline $\begin{array}{l}\text { Perceived behavioural control } \\
\text { Characteristics of the innovation }\end{array}$ & $\mathrm{I} .14(\mathrm{I} .6 \mathrm{I})$ & 68.2 & $0.30(\mid .25)$ & 85.0 & ns \\
\hline Relative advantage & $0.00(.90)$ & 32.1 & $0.33(.73)$ & 47.6 & ns \\
\hline Compatibility & $0.56(.88)$ & 74.1 & $0.81(.46)$ & 100.0 & ns \\
\hline Complexity & $1.04(.47)$ & 96.4 & $0.36(.86)$ & 78.6 & $\mathbf{D}>\mathbf{M C} * *$ \\
\hline Trialability & $1.07(.54)$ & 96.4 & $1.00(.55)$ & 86.7 & ns \\
\hline Observability & $0.29(.94)$ & 50.0 & $0.24(.70)$ & 38.1 & ns \\
\hline Reversibility & $0.61(.50)$ & 60.7 & $0.43(.98)$ & 47.6 & ns \\
\hline Risk & $1.00(.61)$ & 89.3 & $1.33(.48)$ & 100.0 & $D<M C *$ \\
\hline Modification & $0.64(.78)$ & 67.9 & $0.7 I(.56)$ & 76.2 & ns \\
\hline Communication & $1.06(.32)$ & 100 & $1.15(.45)$ & 100 & ns \\
\hline Commitment & $0.88(.59)$ & 58.7 & $0.76(.85)$ & 71.4 & ns \\
\hline Time & $0.48(.89)$ & 67.9 & $-0.19(.70)$ & 23.8 & ns \\
\hline Impact on social relations & $-0.1 I(.73)$ & 29.6 & $0.07(.88)$ & 38.1 & ns \\
\hline
\end{tabular}

${ }^{\mathrm{a}} \mathrm{D}=$ Distribution; MC=Multi-component; ${ }^{*} \mathrm{p}<.05 ; * * \mathrm{p}<.0 \mathrm{I}$

\section{DISCUSSION}

The present study assessed whether two school-based interventions to stimulate children's fruit and vegetable (F\&V) intake, both with proven effectiveness, were implemented as originally planned, and to identify program components that need improvement. In addition, the two programs were compared in terms of the likelihood of future adoption. 
The study found that the first program, involving free-of-charge distribution of F\&V at school, was implemented as intended by a large majority of the teachers: they consumed the F\&V together with the children in their classroom at a fixed daily moment. The implementation of the classroom activities of the second program, a multi-component stimulation program, was somewhat disappointing but comparable to that of other school-based nutrition interventions (Baranowski \& Stables, 2000; Davis et al., 2000). These results are probably somewhat optimistic, because implementation rates that are measured using self-reports are usually inflated (Davis et al., 2000; Perry et al., 1998).

Additionally, we found that implementation of the activities decreased over time. The activities of the third and final intervention period, which was scheduled for the last two months of the school year, were less completely implemented. Lack of time was the most important reason given, especially by the teachers of the oldest age group, who also spent more time on program delivery than the teachers of the other age groups. The end of the school year is a very busy time for teachers, because of activities related to the closing of the school year, such as school camps for the oldest children. It would therefore be better to schedule program activities earlier in the year, especially for the oldest age group. At the same time, it must be admitted that implementation will always be threatened, because teachers have to cope with unexpected circumstances that interfere with their planning.

The evaluation of both programs and their components was relatively favourable, with appreciation grades all above 7.I out of 10. About half of the teachers expressed their intention to use the program again during the following year, even though funding for this had not yet been acquired at that time. It is especially the distribution scheme that relies on financial support for continuation. This means that teachers of the schools implementing this program could even have underestimated their intention to continue the program, because they knew that no resources for it were available for the next year. Teachers' attitudes toward both programs were positive, as was their perceived behavioural control, that is, their confidence about being able to implement the programs. Teachers delivering the distribution program experienced less support from important others, probably because teachers do not 
feel that schools are responsible for children's F\&V intake, as was apparent from interviews we held with some teachers prior to the interventions.

With respect to the characteristics of innovations that are expected to influence their adoption, teachers in the two groups differed in their evaluation of two characteristics: complexity and risk. The distribution program was considered less complex. This is plausible because daily free F\&V distributions become a habitual routine. Nor does this require much effort compared to the multi-component program, in which activities have to be planned and prepared by the teachers. That teachers of the multi-component program experienced the implementation as less risky than the distribution group, may perhaps be explained by the fact that an important part of the multi-component program was the classroom curriculum. This consists of teaching activities that are more familiar to school teachers than implementing a distribution system.

The limitations of this study regard the validity and reliability of the measures used. Although in some studies a Cronbach's alpha of .60 is considered satisfactory (McKinley, Manku-Scott, Hastings, French, \& Baker, 1997), in general an alpha of .70 is recommended for group comparison (Bland \& Altman, 1997; Peterson, 1994). In our study seven of the ten scales used approached this standard, but three scales had a quite low internal consistency (Cronbach's $\alpha$ 's ranging from .55 to .63) and although this is close to McKinley's definition, we considered this a limitation of the study. A second important limitation of the study is that the questionnaires, despite that the same kind of questionnaires were used in a similar study (Reubsaet, Reinaerts, Brug, van Hooff, \& van den Borne, 2004), have not been validated.

It can be concluded that some components of especially the multi-component program need some improvement before wider dissemination can be considered. The fact that the classroom activities of the multi-component program were not fully implemented suggests that the program might have been more effective in terms of behavioural change if the children had been as fully exposed to the program as intended. Implementation of program components by intermediaries such as teachers, even after training and contacts with researchers to stimulate implementation during the intervention period, remains a problem in field settings. The only effective alternative is using project staff to implement activities, as was done in the High 5 
project (Reynolds, Franklin, Leviton et al., 2000) for example, but this is not considered a realistic option for interventions designed for large-scale dissemination, because of limited resources (Auld, Romaniello, Heimendinger, Hambidge, \& Hambidge, 1999). Training of teachers, on the other hand, seems to be critical for the fidelity of the implementation (Story et al., 2000) and has to become part of the multi-component program. In addition, the complexity of the multi-component program has to be reconsidered. Although the complexity of this program was evaluated as acceptable, program planners have to take care that programs do not become impossible to deliver for the intermediaries.

The question remains which of the two interventions is more likely to be adopted for future dissemination. Our effect studies indicate that the distribution program is slightly more effective in increasing children's fruit and vegetable consumption (see Chapter $5 \& 6$ ), and it also seems to have the greatest potential to be adopted by schoolteachers. This was suggested by several of our findings. First, the distribution scheme was more fully implemented than the multi-component program. Second, the implementation of the multi-component program activities by teachers decreased over time. And third, the distribution program was considered less complex.

Unfortunately, schools do not have the resources to distribute free $F \& V$, so funding has to be acquired for these kinds of initiatives. Additionally, effective strategies have to be developed to secure financial resources so the distribution scheme can be continued in the future. An example of such a strategy might be an annual sponsored run at primary schools, allowing children to earn their own F\&V distribution funds. If free distribution is not yet an option, the multi-component program would seem to be a good alternative, especially when improved as suggested. More research into the implementation of school-based programs is necessary to achieve optimal dissemination of effective programs. 


\section{General Discussion}




\section{INTRODUCTION}

The present dissertation reports on the development, implementation and evaluation of two school-based interventions aimed at increasing the F\&V consumption of primary school children. The project included several studies. To begin with, two interventions were developed (using the Intervention Mapping protocol), based on theory, literature and a qualitative and a quantitative study to obtain insight into important determinants of children's F\&V intake. Subsequently, a study comparing parental and child reports of children's F\&V consumption and family-related factors was conducted to identify differences in perceptions between parents and their children. Finally, the interventions were evaluated on impact in two studies (short and long-term effects), and a process evaluation was done. The purpose of this final chapter is to relate the main findings of the various studies to each other and to discuss several potential explanations for the findings. Methodological issues are discussed, as well as implications for future research and practice.

\section{Explanation of main results}

Part I: Development of Interventions

The first part of this dissertation described the development of two interventions aimed at increasing F\&V consumption of four-to-twelve year old children using IM. During the IM process we learned that we had to deal with knowledge gaps that, according to the protocol, required additional research. Therefore, we conducted two determinant studies (chapter 2 and 3) that yielded some important results that will be discussed next. Unfortunately, we also experienced that there was simply not enough time and resources to study all the identified knowledge gaps extensively. However, we believe that recognizing the areas in which knowledge gaps exist at least ensures that each decision is considered thoroughly.

IM was selected as a planning model for several reasons. The most important one was that IM uses an ecological perspective. This perspective can be especially important in studying children's dietary behaviour, since children are likely to be influenced by factors from other levels such as the home setting or the school environment. This was demonstrated by our additional data collected among parents and children aged 
four to twelve years (Chapter 2 and 3). In the study described in Chapter 3, we tried to explain F\&V consumption by including additional concepts that were strongly related to the environment of the child, like exposure, accessibility, availability, parental consumption and habit. It has been shown previously that researchers were only able to explain limited amounts (<30\%) of F\&V intake using only psychosocial correlates (Baranowski et al., 1999). However, we were able to explain about $50 \%$ of the fruit and $30 \%$ of vegetable intake of $4-12$ year old children by including these additional concepts. These results demonstrated the surplus value of these environmental concepts, and were in line with results from the qualitative study (Chapter 2). The identified correlates of F\&V consumption were also consistent with findings from recent reviews among children (Blanchette \& Brug, 2005; Rasmussen et al., 2006), although these reviews included mostly studies that focussed on children older than nine years. We also included younger children in our studies. Environmental factors are likely to be influenced by parents. Unfortunately, the perceptions of these factors differed between parents and there children, as was described in Chapter 4 and also reported in previous studies (Bere \& Klepp, 2004; van Assema et al., 2007). This has implications for intervention development, since parents perceived the factors that they can influence (such as availability of fruit at home or exposure to vegetables) more positively than their children. Similar contrasting perceptions were also shown in the interviews we conducted with children and parents (Chapter 2). Although parents reported to reinforce their children when eating F\&V, children reported not to experience such encouragement.

Based on the combined results of our studies and the literature, we conclude that family-environmental factors are important correlates that have to be addressed in interventions aimed at increasing children's F\&V intake. However, special efforts have to be undertaken to make parents aware of these inconsistencies, so they can behave properly to foster F\&V intake. Parents themselves also consume less F\&V than is recommended (Anonymous, 1998), so first we have to learn them to be an adequate model for their children. Second, we need to teach parents which family-environmental factors, for example accessibility, visibility and verbal encouragement, facilitate F\&V consumption in their children. Since the interviews showed that parents are not willing to participate actively in school-based activities to improve children's F\&V 
consumption, we first have to learn what motivates parents to take part in these kinds of interventions.

Differences in perceptions between parents and children were not only found for family-environmental factors, but also for actual F\&V consumption. Chapter 4 showed a low level of agreement between child and parental reports of F\&V consumption at the individual level. This may have important implications when effects of interventions are studied. We showed that when interventions are evaluated on the group level, it makes no difference for fruit consumption whether parents as a proxy or children themselves reported their behaviour. Vegetable consumption, however, was partially dependent on whether child or parental reports were used. This difference between fruit and vegetable reporting was probably caused by sensitivity of the measures. Fruit consumption was measured in servings per day, while vegetable consumption was assessed in grams per day by including portion size. Frobisher and Maxwell (2003) showed that both parents and children inaccurately estimate portion size. In studies, the source of data should therefore at least be mentioned and preferably both parental and child reports should be used. Unfortunately, this is not always possible considering that younger children have shown to be unable to report their food intake (Livingstone et al., 2004). When evaluating interventions for these younger age groups, researchers are forced to depend on parental reports. However, also parents are imperfect reporters of their child's food intake (Baranowski et al., 1991).

Although we were able to explain considerable amounts of the variance in F\&V intake, still a large part remains unaccounted for. We believe that determinants differ not only between fruit and vegetable consumption, but also for different contexts or situations, like fruit consumption at school or vegetable consumption at dinner. Maybe we will be able to better explain these behaviours by studying determinants in a situation-specific way. This was for example done by van Empelen (2006) in a recent study into condom use among 14-16 year old adolescents. They showed that factors were differentially related to behaviour if the situational context differed (in this case steady versus casual sexual relationships). Furthermore we can conclude that for children, consumption of fruits and of vegetables are clearly two different behaviours with different aetiology. We conclude 
this firstly because different factors were correlated with the consumption of fruit (i.e. subjective norm, availability) and vegetables (i.e. attitude, self efficacy, exposure) (Chapter 3 and 4), as has also been demonstrated in studies among older children (Vereecken et al., 2005; Weber Cullen et al., 200I). This implies that if we want to change F\&V intake, we must use methods and strategies that are aimed at different determinants. This will probably lead to different intervention components aimed specifically at fruit or vegetable intake. Secondly, it becomes apparent in the different role of the most influential determinant of the two behaviours; habit. Habit accounted for $13 \%$ explained variance of fruit consumption, but only $3 \%$ for vegetable consumption, indicating that fruit consumption is more habitual than vegetable consumption. The basic mechanisms of habit formation are repetition of behaviour, and, maybe even more important, reinforcement. Repetition depends on whether the outcome of that particular behaviour is more desirable (i.e. reinforcing) than the outcomes of alternative behaviours (i.e. Verplanken \& Wood, 2006). For children immediate reinforcement is important and taste is such a reinforcer. Research showed that children mostly prefer fruits over vegetables (Baxter \& Thompson, 2002; Burchett, 2003) and this is reflected in the frustration reported by parents regarding the vegetable consumption of their children (Chapter 2). Fruit is mostly consumed voluntarily and therefore could have more potential to become a habit.

Since earlier research demonstrated that habit was the most important correlate of adult F\&V consumption (Brug et al., 2006), and because we replicated this result for children's F\&V intake, we conclude that the factor cannot be ignored in intervention development aimed at increasing F\&V consumption. Furthermore, intervention effectiveness depends not only on the ability to change unhealthy behaviour, but also on maintenance of the new behaviour. So, including creation of habitual behaviour as an intervention goal could enhance the chance of long-term effectiveness and thereby increase the cost-effectiveness of interventions.

In our interventions creating a habit was an explicit goal; unfortunately we learned during the IM process that little is known about methods and strategies to form habits. According to Verplanken and Wood (2006) this is partly due to the history and definition of habit. Historically, researchers often equated habit with frequency of occurrence. Only recently it was experimentally demonstrated that habit 
is a mental construct involving features of automaticity, such as lack of awareness, difficulty to control and mental efficiency (Verplanken, 2006). By defining habit in terms of the automatic cueing of behaviour by stable performance circumstances, learning a habit can be an intervention goal (Verplanken \& Wood, 2006). However, to date, we are not aware of any dietary interventions that have adopted habit development as an explicit goal, like we did in our interventions. We therefore used more fundamental theory on habit formation and automaticity and tried to translate this to practical strategies.

In sum, our experiences learned that IM can be a helpful tool in the development of dietary interventions especially for target groups such as children, whose dietary behaviour is under the influence of factors from other levels (i.e. home setting).

IM helps program planners to identify areas that need additional research. The additional studies described in this dissertation yielded some important and new insights regarding factors related to young children's F\&V consumption. First, we learned that factors from the (family-) environment, especially factors related to parents, have to be addressed in dietary interventions aimed at children. Adopting the social-ecological perspective, as prescribed by the IM protocol, can have a surplus in the development of such interventions. Second, it is important to understand that also for children fruit and vegetable consumption are clearly different behaviours with different determinants. Targeting intervention components at fruit and vegetable consumption separately should enhance effectiveness. Finally, we learned that habit is the most important correlate of F\&V intake in children and therefore has to be addressed in interventions. However, at this time little evidence is available about how to make dietary behaviour habitual for children.

We furthermore advocate describing intervention development using IM. We think that when effective intervention components and the theoretical and empirical base for these components are clearly described, they can easily be adopted by program planners working in practice. Unfortunately, most publications on intervention research report only on program effectiveness and program components are poorly described. 
Part 2: Impact and Process Evaluation

The primary goal of the three evaluation studies was to indicate which of the two interventions should be recommended for large-scale implementation. The objectives of the effect evaluations (short-term and long-term) were first to determine whether or not both interventions were effective, and second which of the two was most effective in increasing F\&V intake. Furthermore, the objective of the process evaluation was to compare both interventions on implementation possibilities and potential for adoption.

As shown in chapters 5 and 6, both a free distribution program and a multicomponent program are effective strategies for increasing primary school children's fruit intake. The results described are comparable to those reported in other studies evaluating multi-component interventions (Burchett, 2003; Knai et al., 2006; Pomerleau et al., 2005) or interventions including a distribution component (Bere et al., 2005; Wind, Te Velde et al., 2006). However, the distribution program showed to be the most effective program, because contrary to the multi-component program, it increased children's vegetable consumption. This effect is promising since it has been shown that vegetable intake is difficult to change (Miller \& Stafford, 2000) and the distribution program even increased vegetable consumption during dinner.

Although both interventions appeared to be effective compared to no interventions, the net effects for fruit consumption were 0.2 portions on short term, and effect sizes were small to medium (Lipsey, 1990). The question remains whether these kind of increases lead to public health benefits. Recently, health effects were quantified for the Dutch 'Fruitables at School' (Schoolgruiten) project. The results showed that children participating in this project who would increase their daily F\&V consumption with 50 grams should raise their life expectancy by 0.37 years.

Furthermore, these children would stay healthy for a longer period of time, resulting in less medical costs during childhood (Buchner, Hoekstra, van den Berg, Wieleman, \& van Rossum, 2007). However, these calculations were based on a very optimistic increase in consumption, since recent results of 'Fruitables at School' showed a (significant) effect of 0.23 pieces on fruit intake (approximately 18 grams), but only for children of Dutch ethnicity. Vegetable intake was increased with 21 grams per day, but only for children of non-Western ethnicity (Tak et al., 2007). So, the intervention was 
not effective for the whole population and effects were smaller than assumed. Furthermore, the estimation assumed long-term effects, which have not been demonstrated at this time. A Norwegian cost-effectiveness study reported by Bere (2007), however, showed that a lifelong increase of 2.5 grams F\&V per day is sufficient to make a daily free distribution during 10 years of primary school cost-effective. Based on this last study, our results can be considered practically relevant.

Chapter 6 showed that even in absence of any intervention or booster activities, sustained effects on fruit consumption were demonstrated after one year for both interventions. The distribution program also caused a sustained effect on vegetable consumption. This may indicate that we succeeded in making fruit consumption habitual for children. Although this could have been expected for the multi-component program, because these children were taught to bring their own fruit to school, the results are somewhat more surprising for the distribution program. For this intervention we expected that the consumption (response) was strongly linked to the free distribution in the classroom (cue). According to research on habit formation, habits are disrupted by changes in the specific environmental cues that trigger habit performance (Verplanken \& Wood, 2006; Wood, Witt, \& Tam, 2005). An explanation for the sustained effect of the distribution program after disrupting the performance context might be an increased influence of intention on behaviour. This effect was demonstrated by a study among students that moved from one university to another. Specifically, when the transfer involved a change in the circumstances in which the students typically exercised, watched TV, or read the newspaper, habit performance was disrupted, and behaviour tended to come under intentional control (Wood et al., 2005). The children in our distribution intervention may have continued their F\&V consumption intentionally, because they had increased their liking for F\&V during the intervention period. That preferences can increase by repeated exposure has been demonstrated earlier (Jane Wardle et al., 2003; J Wardle et al., 2003). These studies showed that repeated exposure for two weeks to the taste of unfamiliar foods is a promising strategy for promoting liking of previously rejected foods in children. Another explanation is that the children got used to eating F\&V during the break in the classroom. Their formed habit might have survived the termination of the distribution, because the cue-response link was not between the free distribution and consumption. 
It could have involved other contextual components, for example the daily-recurring moment to eat F\&V in the classroom. It is possible that the schools maintained this recurring moment and that this triggered the consumption, even in absence of free F\&V at school. Children could have planned to bring F\&V to school intentionally as a response to the fruit break, and by doing so they established an association between a cue (fruit break) and a response (eating F\&V) that after frequent repetition functions automatically (Verplanken \& Wood, 2006). This association is the same as the one created by the distribution, only this time it is established by deliberate planning (similar to implementation-intentions (Gollwitzer, 1999), instead of unintentional repetition of behaviour.

If this shift towards more self-control even occurred without any encouragement, the transition from 'distribution' to 'bringing F\&V' to school could be even more successful if facilitated by intervention components focussing on these processes. Such an intervention should consist of the basic mechanisms for habit formation, namely reinforcement and repetition (i.e. Verplanken \& Wood, 2006). Therefore, we advocate starting the intervention with a period of daily distribution at school. This should include the recurring fruit break in the classroom that eventually cues the consumption of F\&V. By using a daily distribution, children could learn to appreciate consumption of F\&V (reinforcement), and daily repetition of this behaviour is facilitated. After a period of time the consumption of F\&V has become habitual, as was shown by our results. Little is known about the time required to form habitual behaviour and more research into this is necessary. After the habit is formed unintentionally, the distribution could be limited to two or three times a week. On the other days children have to bring their own F\&V to school themselves, making the consumption more under individual control. Our results showed that even in absence of the distribution, children maintained their increased F\&V consumption. Therefore, we are hopeful that continuation of the daily-recurring fruit break in the classroom preserves the cue-response link between the context (fruit break) and the behaviour (F\&V consumption), and habitual F\&V becomes independent of the distribution. Supported by the long-term results of the study described in this dissertation we believe that, even in absence of the distribution, habitual F\&V will maintain. This should 
also increase the chances that F\&V consumption survives the transition from primary to secondary school.

Although the effect studies on short and longer term indicated that the distribution program is somewhat more effective compared to the multi-component program, there are other benefits of a distribution system. These benefits have to do with implementation and sustainability and are especially important when interventions are recommended for large-scale dissemination. Chapter 7, for example, showed that the distribution has the greatest potential to be adopted by school teachers. First, this intervention was more fully implemented than the multi-component program, probably because the daily distribution could be easily embedded in the daily school routine. Second, the implementation of the multi-component program activities by teachers decreased over time. This happened even when teachers were involved in the development and implementation was monitored. If this intervention should be implemented on a larger scale, it is to be expected that implementation becomes worse due to limited involvement and monitoring. Third, the distribution program was considered less complex, which is an important condition for implementation (Rogers, 2003). Moreover, research showed that an integrated school approach, especially with long-term implementation of prevention programs such as a distribution system, is likely to be more effective than short-term classroom-based prevention programs, like the multi-component program (St Leger, 1999; St Leger \& Nutbeam, 1999; Wells, Barlow, \& Stewart-Brown, 2003). By an integrated whole school approach, we mean health promoting activities that focus on all primary school children, and are structurally embedded in daily school practice. Therefore they are more likely to be sustained. This approach should include changes in the physical environment of the school that facilitate healthy choices (i.e. making F\&V available or changing school policy). Additionally, it should include a social environment that fosters healthy behaviour. However, this is only possible if the initiative is owned by the teachers and other school personnel (St Leger, 1999).

When thinking about dissemination, it might be an option to combine the distribution intervention with components adopted from the multi-component intervention, as was done in the Pro Children study (Brug et al., 2005) and the national 'Fruitables at School' initiative (Tak et al., 2007). An interaction effect between the 
distribution and a component from the multi-component intervention could enhance the effectiveness of the distribution program. However, the magnitude of the effects found in the studies that combined the two interventions is comparable with the results we found for the distribution program. Furthermore, the studies of Bere (2005; 2006) showed that the effect sizes of an intervention including a free distribution combined with a multi-component program were of similar magnitude compared to a free distribution alone (Bere, Veierød, Bjelland, \& Klepp, 2006a; Bere et al., 2005). He also showed that this multi-component program alone was not effective in changing children's F\&V consumption (Bere, Veierød, Bjelland, \& Klepp, 2006b). These results indicate that the effects found in these combined programs are most possibly due to the distribution component.

Based on the results described in the second part of this dissertation, we conclude that the free distribution program is the more successful program of the two. However, can we recommend this intervention for large-scale implementation?

Keeping in mind that resources are scarce, policy makers are interested in the best returns to investments in public health. In the next section, we discuss that policy decisions cannot be based upon effectiveness alone, but also have to include other dimensions such as reach.

\section{Public health policy recommendation}

Considering that public health interventions tend to be complex and context dependent, reliance on effect evaluations alone is not enough to make recommendations and can attenuate public health decisions (Rychetnik, Frommer, Hawe, \& Shiell, 2002). Instead, policy decisions about interventions should be based on a more comprehensive evaluation, as for example described by the RE-AIM model (Glasgow, Vogt, \& Boles, 1999).

The RE-AIM model conceptualizes public health impact of interventions as a function of five dimensions: reach, efficacy, adoption, implementation, and maintenance. The ultimate impact is due to the combined effects of these dimensions. 'Reach' of the interventions is defined as the level of individual participation. Looking at our interventions we believe that by using a whole-school approach, we maximized reach in both interventions. All children of the participating primary schools were reached by 
the interventions. Considering 'efficacy', we concluded that the distribution program was more effective in increasing children's vegetable intake, compared to the multicomponent program. They were equally effective in increasing fruit consumption. Furthermore, parents of the children appreciated the distribution program more positively than the parents whose children received the multi-component intervention. The 'adoption' of the programs needs more attention. When recruiting schools for our interventions only about $20 \%$ responded positively. Schools that were not willing to participate gave lack of time as most important reason. However, when we recruited the schools, both interventions still had to be developed so we could not describe specifically what was expected from the schools and how much time the interventions required. At this moment we have more insight in time investment, for example that the distribution program takes approximately 10 minutes per day. We furthermore know that the majority of the teachers that implemented the interventions are willing to use the intervention again the following school year. We believe that adoption can be improved if teachers can experience working with the interventions for a while. With respect to the 'implementation', we concluded that the distribution program was more complete and more faithfully implemented compared to the multi-component program. Moreover, the implementation of the curricular activities decreased over time. We believe that the distribution program also has more potential to be 'maintained' over time. Not only did this intervention demonstrate long-term effectiveness on both fruit and vegetable intake, it was also probably more institutionalized as a daily routine and has more potential to be continued. Combining all these dimensions, we believe that including a distribution program in interventions to promote F\&V intake, has the largest public health impact and should therefore be recommended for implementation. However, financial resources have to be secured for maintenance of these kinds of programs. More research into implementation strategies that include acquisition of structural resources is therefore necessary. 


\section{Combining research and practice}

The studies discussed previously were conducted by the Universiteit Maastricht, but in close collaboration with local public health practice (GGD NML). This collaboration led to some important challenges that we had to overcome, because there is a gap between academic research and practice-oriented research (see (Jansen, 2007). However, we would like to discuss in this section what was learned from this collaboration and how we think that both settings can complement each other.

One of the problems related to the poor fit between academic research and practice-oriented research is that it is difficult to make good use in practice of evidence from academic research. There is a lack of formal regulation of collaboration and communication between academic research, policy and practice. For example, multidisciplinary working groups are only formed in exceptional cases, and practitioners have no easy access to scientific publications and vice versa (Jansen, 2007). This can have the potential to stifle progress in public health goals (Nutbeam, 1996). The different paradigms that are used in academic and practice-oriented research might even contribute to this poor fit and therefore we advocate an integration of these paradigms. The so-called problem-oriented research approach is the predominant paradigm for academic public health research and focuses on identifying aetiologies and correlates of disease factors and subsequently determining solutions (Robinson \& Sirard, 2005). However, this approach is very time-consuming due to high standards of reliability and validity. Since policy makers have to decide about allocation of resources in a specified period to achieve certain outcomes, this problem-oriented approach could delay the potential benefits of research to public health policy. Furthermore, public health practitioners want to solve the immediate health problems of individuals or groups, and are often required to intervene in advance of the establishment of good academic evidence (Nutbeam, 1996). The predominant research paradigm for public health professionals is a solution-oriented paradigm, as it is primarily focused on testing solutions to improve health, rather than causes of poor health which is the subject of study in the problem-oriented approach. Solution-oriented research has a more direct relation with practice, because under this paradigm hypotheses about actual solutions are tested, directly indicating what does and does not work to improve health (Robinson \& Sirard, 2005). 
When conducting academic research in close collaboration with practice, as demonstrated in our current studies, we learned that these two paradigms can complement each other. Academic researchers can provide public health practitioners with an important source of hypotheses for solution-oriented research and they can add a more evidence-based focus on public health practice. In conducting the current research, we developed interventions using Intervention mapping and public health practitioners were actively involved in this process. As a result of this, practitioners got more acquainted with the systematic way in which interventions can be developed and could later apply this in practice. On the other hand, public health professionals can prevent researchers from excessively analyzing health problems and as thereby accelerate advancement of the science base supporting interventions. In the current project, the public health practitioners often prevented the academic researchers from elaborating on each small aspect of the intervention, and made sure the interventions were developed in time.

We believe that public health could be enhanced, if academic researchers and public health practitioners jointly develop evidence-based public health initiatives. Preferably, this collaboration should include policy makers to ensure practical implementation and attention to policy implication of the established evidence (Jansen, 2007). As a result of that, the gap between research and practice should become smaller.

\section{Methodological issues}

This section addresses several methodological issues regarding research designs and data collection procedure of the studies presented in this dissertation. These issues should be considered in interpreting the findings of the studies.

\section{Methodological issues related to the research designs}

The first issue concerns the cross-sectional design that was chosen to study determinants of children's F\&V intake. Although this design is only suitable to identify correlates of behaviour, it was selected because it quickly provided information on a target group for which knowledge gaps were identified, namely young Dutch children. However, cross-sectional studies cannot demonstrate causality between determinants 
and behaviour. Other research designs, such as experimental and longitudinal designs, are more appropriate (Tabachnick \& Fidell, 1996). Because decisions about continuation of the interventions had to be made in the foreseeable future, we started the evaluation of the interventions focussing on the consumption measures. We therefore did not yet study effects of the interventions on the determinants that were included in the questionnaire. Consequently we are not able to say what determinants have effectively been changed and why the interventions worked. Mediation models can be useful to reveal these kinds of causal mechanisms (Shrout \& Bolger, 2002).

The second issue relates to the order in which studies were conducted. For the determinant study described in Chapter 3, the baseline data of the intervention studies was used. According to the Intervention Mapping protocol, this study should have preceded intervention development (Bartholomew et al., 200I). Unfortunately, time was lacking to perform the studies in this preferred order, and we had to base the core of our interventions on extensive literature research and the qualitative determinant study described in Chapter 2. However, since the development of the activities of the multi-component program continued during the intervention, we were able to also use the results of the quantitative determinant study as input for the program components later in the intervention.

The third issue considers the randomization procedure. Although a wellconducted RCT is the best design for evaluating effectiveness of interventions, it is considered too rigid and inappropriate for public health settings (Rychetnik et al., 2002). Moreover, the nature of the interventions made it impossible to do random assignment of the individual children, especially in the distribution condition. We wanted to use interventions that addressed the whole school and required changes in the school environment, i.e. a fruit break in the classroom. By doing so we tried to shift the social norm towards F\&V intake. This resulted in a nested sampling design (children within classes within schools). It is believed that children are likely to interact and influence each other within these clusters, and therefore all quantitative studies described in this dissertation used multilevel analyses (Rasbash et al., 2000; Snijders \& Bosker, 1999).

To assess the effects of our interventions we used a pretest-posttest design in which schools were first paired on school size and ethnic composition, and then 
randomly assigned to either the distribution or the multi-component group. After that, control schools were matched to the intervention schools. In a perfect scenario the schools should have been randomly assigned to one of the three conditions. We were not able to do this in our study because we wanted to involve teachers in the development of the programs by creating a linkage group. Baseline analyses revealed that the schools were comparable except for ethnicity and consumption levels. This was taken into account by including these as covariates in the determinant and effect studies.

Another issue is a possible self-selection bias: the systematic differences between the characteristics of selected and non-selected subjects in a study. In some of our studies this bias could have been occurred. First, the parents that participated in the telephone interviews that were part of the first determinant study (Chapter 2) were self-selected. They could therefore be more interested in their children's diet, and be more involved in dietary practices at home. However, the parents that took part in the group interviews did not know the subject of the discussion on forehand. We do not expect this was a selective group that was more interested in health related issues.

Only a small part of the schools approached (about 20\%) agreed to participate in the intervention study. The main reason for refusal was lack of time. The schools that did participate were therefore self-selected and could differ from the nonparticipating schools. This might limit the generalizability of the results.

Methodological issues related to the data collection procedure

First, we would like to mention that we made use of a self-developed questionnaire. Unfortunately we were not able to perform a validation study due to time constraints and available resources. However, both the FFQ method and similar psychosocial and social-environmental concepts were used in the Dutch 'Fruitables at School' project (Tak et al., 2006). Both were based on the Pro Children questionnaire. As part of this European project several validation studies were performed and showed satisfactory results regarding validity, reliability and reproducibility of the FFQ and the mentioned concepts (de Bourdeaudhuij et al., 2005; Haraldsdóttir et al., 2005). Further improvements of intake measures that can be included in large population-based 
studies are needed, because neither parents (Baranowski et al., 199I) nor children (Livingstone \& Robson, 2000; Livingstone et al., 2004; McPherson et al., 2000) showed to be adequate reporters of children's food intake. However, the fact that we were able to show effectiveness of the interventions even using the FFQ measure that is considered less responsive to changes in consumption (Kristal, Beresford, \& Lazovich, 1994; Thomson et al., 2003) increases our confidence about the reliability of our results.

Second, we only used single or few items per scale to measure the psychosocial and social-environmental factors. These single-item scales can be considered if the item reflects a homogeneous construct (Loo, 200I; Wanous \& Reichers, 1996; Wanous et al., 1997). Although these items are common in similar research (e.g. de Bourdeaudhuij et al., 2006)), single-item measures usually have a low reliability. Therefore, multiple-item measures are still more desirable, but in questionnaire development there is always a trade-off between precision and extensiveness (de Bourdeaudhuij et al., 2005).

A third limitation of the data collection procedure is that we made use of parents that reported on the food intake of their children in the majority of the studies described. We realize that this might have resulted in less reliable data on the children's F\&V intake (Livingstone \& Robson, 2000), especially because the study described in Chapter 4 showed low levels of agreement between child and parental reporting, similar to other studies (Bere \& Klepp, 2004; Tak et al., 2006; van Assema et al., 2007). As yet it remains unclear which of the two sources is more reliable. The main reason for using parents as a proxy for their children was that we wanted to have data from children of a broad age group (4 to 12 years), and self-reporting requires several cognitive abilities that are only found in children of at least eight years (Livingstone \& Robson, 2000). Repeating the effect studies using child reports is recommended and would possibly bolster the results already found using the parental data. Another limitation of using self-reported data is that both parents and children might have the tendency to respond in a social desirable way. The child questionnaires were administered in the classroom in the presence of teachers and peers. Social pressure might have caused children to answer even in a more social desirable way. The same holds for the parents who are considered more or less responsible for their 
children's F\&V intake (Chapter 2). No measurement to assess this tendency was included in the questionnaires. We did try to minimize social desirability by stressing to the children that there were no right or wrong answers, and by informing the parents about their anonymity to the researchers.

Using parental reports for the effectiveness studies, instead of the child reports, could have caused the large dropout between the baseline measurement and the first (46\% drop-out) and second follow-up (75\% drop-out). This could lower the generalizability of the results to other, less motivated, populations. We therefore repeated the effect analyses using a pessimistic scenario by imputing all missing values with the respondent's baseline intake values. These conservative analyses revealed similar effectiveness for the distribution program (except for long-term effectiveness on vegetable consumption). The multi-component program remained effective in increasing fruit consumption (Chapter 6). We therefore are confident about the validity of our results.

Finally, we have to mention that we 'lost' a large part of the oldest children at the second follow-up measurement. Because these children had moved from primary to secondary school, the questionnaires were sent to their home addresses. Only a very small number of these parents returned the questionnaires. We therefore were not able to study the effects of school transition on F\&V consumption.

\section{Implications for research}

The recommendations for research relate mainly to knowledge gaps encountered during the Intervention Mapping process, and issues that remained unclear after the current studies.

\section{Intervention Development}

First, applying the Intervention Mapping protocol revealed some important knowledge gaps that warrant further study. More longitudinal research is needed to identify important determinants of F\&V consumption in children. Preferably, this research will focus on fruit and vegetable consumption as different behaviours with their own specific determinants. It would furthermore be interesting to study whether looking into situation-specific intake of F\&V, as shown by Van Empelen and colleagues (2006) in 
the case of condom use will increase predictability. Since children are influenced by factors from different levels (i.e. home setting) and factors from these levels are likely to interact, it would also be interesting to focus on interactions of determinants across these levels. Previous studies showed that availability of F\&V in the home setting moderated the influence of psychosocial variables, such as children's self-efficacy and parental attitudes, on children's F\&V consumption (Jago, Baranowski, \& Baranowski, 2007; Kratt et al., 2000).

Second, more research is needed regarding behavioural change theories. Applying theory in intervention development should improve the effectiveness of interventions aimed at changing behaviour. Regrettably, it was shown that psychosocial variables favoured by health behaviour theory are of little value for interventions research regarding dietary behaviour (Jeffery, 2004). Furthermore, although many theories are available that try to explain behaviour, theories that focus on explaining behavioural change are still lacking (Brug \& Oenema, 2005), as we experienced during IM step 3. We learned that there is limited evidence especially on how environmental changes could lead to behavioural change and how to create habitual behaviour. We thus strongly support Brug's (2005) recommendation that behaviour change theory needs to be further developed and should focus on changing behaviour rather than people's intentions. We believe that if the current focus on cognitive factors in behavioural change is complemented with research about modifiable aspects of the environment, we will be more successful in developing effective dietary interventions, for example by making the healthy choice the easiest choice. At primary schools the school policy could be changed more towards healthy choices by prohibiting all snacks except F\&V. There have been examples of changing the products on offer in school food environments (i.e. (Nutrition and Physical Activity Branch, 2006) and a recent study showed that policy changes on foods sold in schools can result in changes in student consumption. However, if all environments do not make similar changes, compensation may occur (Weber Cullen, Watson, Zakeri, \& Ralston, 2006). Furthermore, more research on how to make dietary behaviour habitual is needed in order to maximize intervention effects. We believe that Intervention Mapping can be used to guide this research. 
Implementation research and sustainability

Based on the results of this dissertation and other research on distribution programs, we conclude that distribution of F\&V at primary schools has high potential. However, little is known about ways to implement and maintain these kinds of interventions. More research into implementation strategies for distribution programs is therefore necessary. At this time the second phase of the national program 'Fruitables at School' has started. The aim of this phase is to identify effective ways for sustainable implementation of a school-based F\&V distribution twice a week, by comparing three scenarios. In the 'delivery' model, F\&V is delivered by the distributor at school once a week; while in the 'take-away' model no F\&V is delivered at school. School employees or volunteers will go to the distributor once per week and bring the F\&V to school themselves. The last model is called the 'bring-to-school' model and in this model school policy prescribes that parents are obliged to give their children F\&V to school twice a week. We prefer the first two implementation strategies, since the last is without obligation to the schools and depends largely upon involvement of the teachers. It has been demonstrated in smoking research that school policy changes only are effective if fully implemented and strongly reinforced by school personnel (Griesbach, Inchley, \& Currie, 2002; Lovato, Sabiston, Hadd, Nykiforuk, \& Campbell, 2007). Based on the results of Chapter 7 , we do not believe that this is the best strategy and should not recommend this strategy for practice at least not in the suggested form.

However, we strongly believe in combining distribution with school policy that prescribes bringing F\&V to school on the days that it is not provided at school. In our opinion this strategy should be preceded by a period of daily distribution in order to link F\&V consumption to a daily recurring moment in the classroom, and as a result of this make habit happen. This period of (preferably free) daily distribution could have some more benefits, since parents were more willing to pay for a distribution system after they had tried a free system for a while (data not shown).

This is an important issue since it was demonstrated in Chapter 2 and in other research (i.e. Wind, Te Velde et al., 2006) that parents were not willing to participate in school-based interventions aimed at healthy nutrition. We showed that parental influences are especially important to support these interventions. 
Unfortunately parents have more positive perceptions of important environmental factors that they can influence than their children (Chapter 4). Therefore, more information is needed on determinants of parental involvement in interventions aimed at their children and subsequently in ways to alter these determinants. The family reciprocal determinism model (Baranowski, 1997), claims that parents not only influence their children, but children can also influence their parents' behaviour, skills and cognition by providing information, rewards and punishment. This model might be used to study strategies that children use to influence their parents.

\section{Evaluation}

First, in order to prevent large dropout and potential selection bias, child reports should be used in future studies as well. However, using whole-school interventions requires evaluation among all participants. Therefore, efforts must be made to develop measures that are appropriate for children younger than ten years, such as the Day in the Life Questionnaire developed by Edmunds and colleagues (2002). This questionnaire was developed as a supervised classroom exercise to measure children's (7-9 years) consumption of F\&V by using words and pictures. The questionnaire showed good to acceptable validity, reliability and sensitivity (Edmunds \& Ziebland, 2002). If these kinds of measures become available, interventions can be evaluated using both parental and child reports. Combining the two will strengthen the results demonstrated in evaluation studies, and better policy recommendations can be made.

Furthermore, our results showed long-term effectiveness of both interventions in absence of any booster activities. If these results can be found after just one year of intervention, one could imagine that this effect will be even larger if interventions are aimed at children during all eight years of primary school. Currently, schools are enrolling in distribution systems that are financed by schools or parents, and that have the potential to be sustained for several years. This may provide researchers with possibilities to study the effects of eight years of F\&V distribution. Furthermore, the effects of the transition from primary to secondary school on F\&V consumption can be studied, as well as whether a habit created during primary school is strong enough to 'survive' this transition. 
Since we did not study effects of the interventions on the determinants that were selected in the developmental phase; we were not able to say what determinants have been effectively changed and why the interventions worked. We recommend future intervention research to study these determinants and to use mediation models to reveal causal mechanisms and identify which intervention components were the effective ones. Finally, it would be interesting to look at beneficial side effects of the interventions described. If the interventions for example reduced snack intake at school, the public health benefits would even be larger than when looking solely on the main outcome measures. Future evaluation research should therefore also include measures for side effects.

\section{Implications for practice}

The distribution program showed to have more benefits compared to the multicomponent program. Therefore we recommend that if interventions aimed at increasing F\&V consumption are disseminated on a large scale, they should include a distribution component. However, we should learn more about strategies to implement these interventions in such a way that effects are maximized and sustainability is guaranteed. To ensure effectiveness the whole school should adopt the distribution interventions and not a small part of the children. If parents can subscribe voluntarily to a paid distribution system, we believe that only a small part of the children will be reached by the intervention and effects will diminish. This was demonstrated in the Norwegian subscription scheme (Bere et al., 2005), and is likely to happen considering the disappointing reluctance of parents to participate in these interventions found in the current studies. To guarantee sustainability, financial resources other than parents have to be secured so the distribution scheme can be continued in the future. An example of such a strategy might be an annual sponsored run at primary schools, allowing children to earn their own F\&V distribution funds and simultaneously be physically active. Furthermore, we believe that the intervention should include daily distribution of F\&V, at least for a period of time, instead of only twice a week. If the goal of the intervention is to create habitual behaviour, we believe that a period of daily repetition is necessary for the behaviour to be maintained. As a 
consequence, the increased $F \& V$ intake might even survive the transition to secondary school.

If the multi-component program would be implemented, public health practitioners should bear in mind that implementation of activities will be even more disappointing than described in Chapter 7. During the current studies teachers were contacted regularly and motivated to do the activities. In practice this is impossible and therefore the implementation potentially even worse. The multi-component intervention might be less expensive compared to the distribution program, but also less cost-effective since effects are expected to be limited. Alternatively, trained staff can be used to deliver the program, as has been demonstrated earlier (Reynolds, Franklin, Leviton et al., 2000; Story et al., 2000). This will, however, include a substantial raise in costs.

\section{Future perspective: 'Vita \& Froet' goes 'Schoolgruiten'}

Partly based on the results described in this dissertation the project 'Vita \& Froet' is continued. At this moment, the Local Health Authority cooperates with the national 'Fruitables at School' project to implement a F\&V distribution among all primary schools in Noord and Midden Limburg. A so-called 'Gruit coordinator' is hired to approach primary schools for participation and to support implementation. The main component of 'Vita \& Froet goes Schoolgruiten' is the consumption of F\&V together in the classroom at least twice a week. To make this possible F\&V is distributed to the children on these days. Additionally, teaching materials regarding healthy nutrition are provided.

Schools have to secure funding for this distribution (about 20 euros per child per year), and the coordinator supports school boards in findings ways to do so (i.e. sponsored run, funding from local businesses). The coordinator contacts local F\&V distributors and provides help with administration and logistics. Furthermore, she manages the project. The Local health Authority hopes that $50 \%$ of the primary schools have started with 'Vita \& Froet goes Schoolgruiten' at the end of next school year. 
Vitcition

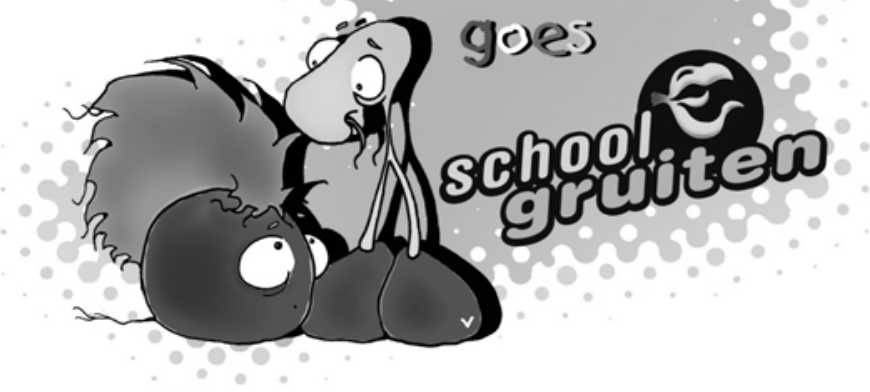




\section{References}


Aarts, H., Paulussen, T., \& Schaalma, H. (1997). Physical exercise habit: on the conceptualization and formation of habitual health behaviours. Health Education Research, 12, 363-374.

Achterberg, C., \& Miller, C. (2004). Is one Theory Better than Another in Nutrition Education? A viewpoint: More is better. Journal of Nutrition Education and Behavior, 36, 40-42.

Ajzen, I. (199I). The Theory of Planned Behavior. Organizational Behavior and Human Decision Processes, 50, I79-2II.

Ajzen, I. (2002). Constructing an TpB Questionnaire: Conceptual and Methodological Considerations. Retrieved, 2005, from the World Wide Web: http://www.ru.nl/socgeo/n/onderwijs/ruimgedrag/tpb.measurement.pdf Anonymous. (1998). Dutch Food Consumption Survey (1998): Zo eet Nederland 1998. Resultaten van de Voedsel Consumptie Peiling 1997-1998 [Results of the Dutch Nutrition Survey 1997-1998]. The Hague: Voedingscentrum.

Auld, G. W., Romaniello, C., Heimendinger, J., Hambidge, C., \& Hambidge, M. (1999). Outcomes from a School-based Nutrition Education Program Alternating Special Resource Teachers and Classroom Teachers. Journal of School Health, 69, 403-408.

Bandura, A. (1986). Social Foundations of Thought and Action: A Social Cognitive Theory. New York: Prentice Hall.

Baranowski, T. (1997). Families and Health Actions. In D. S. Gochman (Ed.), Handbook of Health Behavior Research I: Personal and Social Determinants (Vol. I, Pp. I70206). New York: Plenum Press.

Baranowski, T., Cullen Weber, K., \& Baranowski, J. (1999). Psychosocial correlates of dietary intake: advancing dietary intervention. Annual Review of Nutrition, 19, 17-40.

Baranowski, T., Davis, M., Resnicow, K., Baranowski, J., Doyle, C., Lin, L. S., Smith, M., \& Wang, D. T. (2000). 'Gimme 5 Fruit, Juice and Vegetables for Fun and Health: Outcome Evaluation. Health Education and Behavior, 27, 96-III.

Baranowski, T., Domel Baxter, S., Gould, R., Baranowski, J., Leonard, S., Treiber, F., \& Mullis, R. (1993). Increasing Fruit and Vegetable Consumption among 4th and 
5th Grade Students: Results from Focus Groups Using Reciprocal

Determinism. Journal of Nutrition Education, 25, I | 4 - 120.

Baranowski, T., Sprague, D., Baranowski, J., \& Harrison, J. A. (1991). Accuracy of maternal dietary recall for preschool children. Journal of the American Dietetic Association, 91, 669-674.

Baranowski, T., \& Stables, G. (2000). Process Evaluation of the 5-a-day Projects. Health Education \& Behavior, 27, 157-166.

Bargh, J. A. (1994). The Four Horsemen of Automaticity: Awareness, Intention, Efficiency and Control in Social Cognition. In R. S. Wyer (Ed.), Handbook of Social Cognition (Vol. I, pp. I-40). New York: New York University.

Bargh, J. A., \& Chartrand, T. L. (1999). The Unbearable Automaticity of Being. American Psychologist, 54, 462-479.

Bartholomew, L. K., Parcel, G. S., \& Kok, G. (1998). Intervention Mapping: A process for Developing Theory- and Evidence-Based Health Education Programs. Health Education \& Behavior, 25, 545-563.

Bartholomew, L. K., Parcel, G. S., Kok, G., \& Gottlieb, N. H. (200I). Intervention Mapping. Designing theory- and evidence-based health promotion programs. New York: Mc Graw Hill.

Bartholomew, L. K., Parcel, G. S., Kok, G., \& Gottlieb, N. H. (2006). Planning health promotion programs; an Intervention Mapping approach. San Francisco, CA: Jossey-Bass.

Baxter, S. D., \& Thompson, W. O. (2002). Fourth-grade children's consumption of fruit and vegetable items available as part of school lunches is closely related to preferences. Journal of Nutrition Education and Behavior, 34, I66-I7I.

Bere, E., \& Klepp, K.-I. (2004). Correlates of fruit and vegetable intake among Norwegian schoolchildren: parental and self-reports. Public Health Nutrition, 7, 991-998.

Bere, E., Veierød, M. B., Bjelland, M., \& Klepp, K.-I. (2006a). Free school fruit sustained effect I year later. Health Education Research, 2, 268-275.

Bere, E., Veierød, M. B., Bjelland, M., \& Klepp, K.-I. (2006b). Outcome and process evaluation of a Norwegian school-randomized fruit and vegetable 
intervention: Fruit and Vegetables Make the Marks (FVMM). Health Education Research, 2I, 258-267.

Bere, E., Veierød, M. B., \& Klepp, K.-I. (2005). The Norwegian School Fruit Programme: evaluating paid vs. no-cost subscriptions. Preventive medicine, 4I, 463-470.

Bere, E., Veierød, M. B., Skare, Ø., \& Klepp, K. I. (2007). Free school fruit - sustained effect three years later. International Journal of Behavioral Nutrition and Physical Activity, 4.

Birch, L. L. (1980). Effect of peer models' food choices and eating behaviors on preschoolers' food preferences. Child Development, 5 I, 489-496.

Birch, L. L. (1990). Development of Food Acceptance Patterns. Developmental Psychology, 26, 515-519.

Birch, L. L. (1999). Development of food preferences. Annual Review of Nutrition, 19, 4I62.

Birch, L. L., \& Fisher, J. O. (1998). Development of Eating Behaviors Among Children and Adolescents. Pediatrics, I0I suppl., 539-549.

Birch, L. L., \& Sullivan, S. A. (I99I). Measuring children's food preferences. Journal of School Health, 6I, 2I2-2I4.

Blanchette, L., \& Brug, J. (2005). Determinants of fruit and vegetable consumption among 6-1 2 year old children and effective interventions to increase consumption. Journal of Human Nutrition and Dietetics, 18, 43 I-443.

Bland, J. M., \& Altman, D. G. (1997). Statistics notes: Cronbach's alpha. British Medical Journal, 3/4, 572.

Brody, G. H., \& Stoneman, Z. (I98I). Selective imitation of same-age, older and younger peer models. Child Development, 52, 7I7-720.

Brown, R., \& Ogden, J. (2004). Children's eating attitudes and behaviour: a study of the modelling and control theories of parental influence. Health Education Research, 19, 26I-27I.

Brug, J., de Vet, E., de Nooijer, J., \& Verplanken, B. (2006). Predicting Fruit Consumption: Cognitions, Intention and Habits. Journal of Nutrition Education and Behavior, 38, 73-8I. 
Brug, J., \& Oenema, A. (2005). Theory, evidence and Intervention Mapping to improve behavior nutrition and pshysical activity interventions. International Journal of Behavioral Nutrition and Physical Activity, 2.

Brug, J., Yngve, A., \& Klepp, K.-I. (2005). The Pro Children Study: Conceptualization, Baseline Results and Intervention Development of a European Effort to Promote Fruit and Vegetable Consumption in Schoolchildren. Annals of Nutrition \& Metabolism, 49, 209-2II.

Brussaard, J. H., Brandts, H. A. M., Erp-Baart, A. M. J., Hulshof, K. F. A. M., \& Kistemaker, C. (1999). Voedselconsumptie en voedingstoestand bij 8-jarige marokkaanse, Turkse en Nederlandse kinderen en hun moeders [Nutrition and nutritional state of 8-year old morrocon, turkish and dutch children and their mothers] (v099.1099). Zeist.

Buchner, F. L., Hoekstra, J., van den Berg, S. W., Wieleman, F., \& van Rossum, C. T. M. (2007). Kwantificeren van de gezondheidseffecten van voeding [Quantifying health effects of nutrition] (35008000I ). Bilthoven, The Netherlands: RIVM.

Burchett, H. (2003). Increasing fruit and vegetable consumption among British primary schoolchildren: a review. Health Education, 103, 99-109.

Burroughs, M., \& Terry, R. D. (1992). Parents' perspectives toward their children's eating behavior. Topics in Clinical Nutrition, 8, 45-52.

Centraal Bureau voor de Statistiek (CBS). (2005). Standaard voor etniciteit. Retrieved 23-03-2005, from the World Wide Web: http://www.cbs.nl/nl/cijfers/statline/index.htm

Cohen, J. (1988). Statistical power analysis for the behavioral sciences. Hillsdale, New York: Lawrence Earlbaum Associates.

Cole, T. J., Bellizi, M. C., Flegal, K. M., \& Dietz, W. H. (2000). Establishing a standard definition for child overweight and obesity worldwide: international survey. British Medical Journal, 320, 1240-1246.

Cooke, L. J., Wardle, J., Gibson, E. L., Sapochnik, M., Sheiham, A., \& Lawson, M. (2003). Demographic, familial and trait predictors of fruit an vegetable consumption by pre-school children. Public health Nutrition, 7, 295-302. 
Corwin, S., Sargent, R., Rheaume, C., \& Saunders, R. (1999). Dietary behaviors among fourth graders: A social cognitive theory study approach. American Journal of Health Behavior, 23, 182-197.

Davis, A., Baranowski, T., Resnicow, K., Baranowski, J., Doyle, C., Smith, M., Wang, D. T., Yaroch, A., \& Hebert, D. (2000). Gimme 5 fruit and vegetables for fun and health: process evaluation. Health Education \& Behavior, 27, I67-I76.

de Bourdeaudhuij, I., Klepp, K. I., Wind, M., Due, P., \& Brug, J. (2005). Reliability of a questionnaire to measure personal, social and environmental correlates of fruit and vegetable intake in I0-II year old children in 5 European countries. Public Health Nutrition, 8, 189-200.

de Bourdeaudhuij, I., Yngve, A., Te Velde, S. J., Knut-Inge, K., Rasmussen, M., Thorsdottir, I., Wolf, A., \& Brug, J. (2006). Personal, social and environmental correlates of vegetable intake in normal weight and overweight 9 to I3-year old boys. International Journal of Behavioral Nutrition and Physical Activity, 3.

Domel Baxter, S., \& Thompson, W. O. (2002). Fourth-Grade Children's Consumption of Fruit and Vegetable Items Available as Part of School Lunches Is Closely Related to Preferences. Journal of Nutrition Education and Behavior, 34, 166-17I.

Domel Baxter, S., Thompson, W. O., Davis, M., Baranowski, T., Leonard, S., \& Baranowski, J. (1996). Psychosocial predictors of fruit and vegetable consumption among elementary school children. Health Education Research, II, 299-308.

Donders-Engelen, M., van der Heijden, L., \& Hulshof, K. F. A. M. (2003). Maten, gewichten en codenummers. Wageningen: Landbouwuniversiteit Wageningen: Afdeling Humane Voeding

Edmonds, J., Baranowski, T., Baranowski, J., Cullen, K. W., \& Myres, D. (200I). Ecological and socio-economic Correlates of Fruit, Juice and Vegetable consumption among African-American boys. Preventive Medicine, 32, 476-48I.

Edmunds, L. D., \& Ziebland, S. (2002). Development and validation of the Day in the Life Questionnaire (DILQ) as a measure of fruit and vegetable questionnaire for 7-9 year olds. Health Education Research, 17, 21 I-220.

Eriksen, K., Haraldsdóttir, J., Pederson, R., \& Flyer, V. H. (2003). Effect of a fruit and vegetable subscription in Danish schools. Public Health Nutrition, 6, 57-63. 
Euridyce. (2005). Informatiedossier over het Nederlandse onderwijssysteem. [Information file on the Dutch education system]. Retrieved 23-03-2005, 2005, from the World Wide Web: http://www.minocw.nl/documenten/eurydice_nl.pdf

Ferme, L., \& McManamon, B. (2003). Role models for health: American Dietetic Association Foundation Survey Finds Parents Outrank All Others [website]. American Dietetic Association Foundation. Retrieved 03-12-2003, 2003, from the World Wide Web: http://www.eatright.org/Public/Media/PublicMedia_I6046.cfm

Fisher, J. O., Mitcell, D. C., Smicilas-Wright, H., \& Birch, L. L. (2002). Parental influences on young girls' fruit and vegetable, micronutrient, and fat intake. Journal of the American Dietetic Association, 102, 58-64.

Flanders, J. P. (1968). A review of research on imitative behavior. Psychological Bulletin, 69, 316-337.

Fleuren, M., Wiefferink, K., \& Paulussen, T. (2004). Determinants of innovation within health care organizations: Literature review and Delphi study. International Journal for Quality in Health Care, I6, 107-I23.

French, S. A., \& Stables, G. (2003). Environmental interventions to promote vegetable and fruit consumption among youth in school settings. Preventive Medicine, 37, 593-610.

French, S. A., \& Wechsler, H. (2004). School-based research and initiatives: fruit and vegetable environment, policy, and pricing workshop. Preventive Medicine, 39, SIOI-107.

Frobisher, C., \& Maxwell, S. M. (2003). The estimation of food portion sizes: a comparison between using descriptions of portion sizes and a photographic food atlas by children and adults. Journal of Human Nutrition and Dietetics, 16, $|8|-\mid 88$.

Gezondheidsraad [Health Council of the Netherlands]. (2002). Voedingsnormen energie, eiwitten, vetten en verteerbare koolhydraten [Dietary reference intakes: energy, proteins, fats and digestible carbohydrates]. Den Haag (in Dutch).

Gezondheidsraad [Health Council of the Netherlands]. (2006). Richtlijnen voor gezonde voeding [Guidelines for a Healthy Diet] (2006/2I). The Hague: Health Council of the Netherlands. 
Gibson, E. L., \& Wardle, J. (2003). Energy density predicts preferences for fruit and vegetables in 4-year-old children. Appetite, 4I, 97-98.

Gibson, E. L., Wardle, J., \& Watts, C. J. (1998). Fruit and Vegetable Consumption, Nutritional Knowledge and Beliefs in Mothers and Children. Appetite, 3 I, 205228.

Glasgow, R. E., Vogt, T. M., \& Boles, S. M. (1999). Evaluating the public health impact of health promotion interventions: the RE-AIM framework. American Journal of Public Health, 89, I322-I 327.

Golan, M., \& Crow, S. (2004). Parents are key players in the prevention and treatment of weight-related problems. Nutrition Reviews, 62, 39-50.

Gollwitzer, P. M. (1999). Strong effects of simple plans. American Psychologist, 54, 493503.

Gorts, C., \& Jonker, R. (200I). Gezondheid op school. Een inventariserend onderzoek naar schoolgezondheidsbeleid in Nederland. [Health at School. An Inventory of School Health Policy in the Netherlands.] Haarlem, the Netherlands: Rescon Research \& Consultancy.

Granner, M. L., Sargent, R. G., Calderon, K. S., Hussey, J. R., Evans, A. E., \& Watkins, K. W. (2004). Factors of fruit and vegetable intake by race, gender, and age among young adolescents. Journal of Nutrition Education Behavior, 36, I73-180.

Green, L. W., \& Kreuter, M. W. (1999). Health Promotion Planning: An Educational and Ecological Approach. (third ed.). Mountain View, California: Mayfield Publishing Co.

Griesbach, D., Inchley, J., \& Currie, C. (2002). More than words? The status and impact of smoking policies in Scottish schools. Health Promotion International, I 7, 3141.

Haraldsdóttir, J., Thórsdóttir, I., de Almeida, M. D. V., Maes, L., Pérez Rodrigo, C., Elmadfa, I., \& Frost Andersen, L. (2005). Validity and Reproducibility of a Precoded Questionnaire to Assess Fruit and Vegetable Intake in European IIto I2-Year-Old Schoolchildren. Annals of Nutrition \& Metabolism, 49, 22 I-227.

Harris, M. B., \& Baudin, H. (1972). Models and vegetable eating: The power of Popeye. Psychological Reports, 3I, 570. 
Hendy, H. M. (2002). Effectiveness of Trained Peer Models to Encourage Food Acceptance in Preschool Children. Appetite, 39, 217-225.

Hendy, H. M., \& Raudenbush, B. (2000). Effectiveness of teacher modeling to encourage food acceptance in preschool children. Appetite, 34, 6I-76.

Hinton, A. W. (1998). A social cognitive theory model to predict frequency of fruit and vegetable consumption among third-grade children. Birmingham School of Public Health, US, Alabama.

Hirasing, R. A., Fredriks, A. M., Buuren van, S., Verloove-Vanhorick, S. P., \& Wit, J. M. (200I). Toegenomen prevalentie van overgewicht en obesitas bij Nederlandse kinderen en signalering daarvan aan de hand van internationale normen en nieuwe referentiediagrammen [Increased prevalence of overweight and obesity among Dutch children and identification according to international standards and new refererence-diagrams]. Nederlands Tijdschrift voor de Geneeskunde, 145, I303-1308.

Hollander, A. E. M., Hoeymans, N., Melse, J. M., van Oers, J. A. M., \& Polder, J. J. (2006). Zorg voor gezondheid (27006I003). Bilthoven: RIVM.

Jago, R., Baranowski, T., \& Baranowski, J. (2007). Fruit and vegetable availability: a micro environmental mediating variable? Public health nutrition, 10, 681-689

Jansen, A., \& Tenney, N. (200I). Seeing mum drinking a 'light' product: Is social learning a stronger determinant of taste preference acquisition than caloric conditioning? European Journal of Clinical Nutrition, 55, 4I8-422.

Jansen, M. (2007). Mind the Gap: Collaboration between practice, policy and research in local public health. Universiteit Maastricht, Maastricht.

Jeffery, R. W. (2004). How can Health Behavior Theory be made more useful for intervention research? International Journal of Behavioral Nutrition and Physical Activity, I.

Johnson, S. L., \& Birch, L. L. (1994). Parents' and children's adiposity and eating style. Pediatrics, 94, 653-66I.

Kelder, S. H., Perry, C., Klepp, K.-I., \& Lytle, L. (1994). Longitudinal Tracking of Adolescent Smoking, Physical Activity, and Food Choice Behaviors. American Journal of Public Health, 84, I I 2 I- I I 26. 
Kidd, P. S., \& Parshall, M. B. (2000). Getting the Focus and the Group: Enhancing Analytic Rigor in Focus Group research. Qualitative Health Research, 10, 293308.

Klepp, K.-I., Pérez-Rodrigo, C., de Bourdeaudhuij, I., Due, P. P., Elmadfa, I., Haraldsdóttir, J., König, J., Sjöström, M., Thórsdóttir, I., Vaz de Almeida, M. D., Yngve, A., \& Brug, J. (2005). Promoting Fruit and Vegetable Consumption among European Schoolchildren: Rationale, Conceptualization and Design of the Pro Children Project. Annals of Nutrition \& Metabolism, 49, 212-220.

Knai, C., Pomerleau, J., Lock, K., \& McKee, M. (2006). Getting children to eat more fruit and vegetables: A systematic review. Preventive medicine, 42, 85-95.

Kok, G., Schaalma, H., Ruiter, R. A. C., \& van Empelen, P. (2004). Intervention Mapping: A protocol for Applying Health Psychology Theory to Prevention Programmes. Journal of health psychology, 9, 85-98.

Kratt, P., Reynolds, K., \& Shewchuk, R. (2000). The role of Availability as a Moderator of Family fruit and Vegetable Consumption. Health Education \& Behavior, 27, $47 \mid-482$.

Krebs-Smith, S. M., Heimendinger, J., Patterson, B. H., Subar, A. F., Kessler, R., \& Pivonka, E. (1995). Psychosocial Factors Associated with Fruit and Vegetable Consumption. American Journal of Health Promotion, 10, 98-104.

Kremers, S. P. J., Brug, J., de Vries, H., \& Engels, R. C. M. E. (2003). Parenting styles and adolescent fruit consumption. Appetite, 4I, 43-50.

Kristal, A. R., Beresford, S. A., \& Lazovich, D. (1994). Assessing change in dietintervention research. American Journal of Clinical Nutrition, 59, 185s-189s.

Leurs, M., Jansen, M., \& Ruiter, M. (2002). Coordinated School Health Program: het 'Gezonde School Model' van de toekomst? Tijdschrift voor Gezondheidswetenschappen, 80, 47I-473.

Licence, K. (2004). Promoting and protecting the health of children and young people Child: Care, Health and Development 30, 623-635.

Lien, N., Lytle, L. A., \& Klepp, K.-I. (200I). Stability in Consumption of Fruit, Vegetables and Sugary Foods in a Cohort from Age 14 to Age 21. Preventive Medicine, 33, 217-226. 
Lipsey, M. (1990). Design Sensitivity: Statistical power for experimental research. Newbury Park, CA: Sage Publications.

Livingstone, M. B. E., \& Robson, J. (2000). Measurement of dietary intake in children. Proceedings of the Nutrition Society, 59, 279-293.

Livingstone, M. B. E., Robson, J., \& Wallace, J. M. W. (2004). Issues in dietary intake assessment of children and adolescents. British Journal of Nutrition, 92, S2 I3S222.

Loo, R. (200I). A caveat on using single-item versus multiple-item scales. Journal of Managerial Psychology, 17, 68-75.

Lovato, C. Y., Sabiston, C. M., Hadd, V., Nykiforuk, C. I. J., \& Campbell, H. S. (2007). The impact of school smoking policies and student perceptions of enforcement on school smoking prevalence and location of smoking. Health Education Research, 22, 782 - 793.

Lowe, C. F., Horne, P., Tapper, K., Bowdery, M., \& Egerton, C. (2004). Effects of a peer modelling and rewards-based intervention to increase fruit and vegetable consumption in children. European Journal of Clinical Nutrition, 58, 510-522.

Lytle, L. A., Ward, J., Nader, P. R., Pedersen, S., \& Williston, B. J. (2003). Maintenance of a Health Promotion Program in Elementary Schools: Results from the Catch-on Study: Key Informant Interviews. Health Education \& Behavior, 30, 503.

McKinley, R. K., Manku-Scott, T., Hastings, A. M., French, D. P., \& Baker, R. (1997). Reliability and validity of a new measure of patient satisfaction with out of hours primary medical care in the united kingdom: development of a patient questionnaire. British Medical Journal, 3/4, 193.

McPherson, R. S., Hoelscher, D. M., Alexander, M., Scanlon, K. S., \& Serdula, M. K. (2000). Dietary assessment methods among school-aged children: Validity and Reliability. Preventive Medicine, 3I, SI I-S33.

Miller, M., \& Stafford, H. (2000). An intervention portfolio to promote fruit and vegetable consumption: Review of interventions. Melbourne: National Public Health Partnership.

Montano, D. E., Kasprzyk, D., \& Taplin, S. H. (1997). The theory of reasoned action and the theory of planned behavior. In K. Glanz \& F. M. Lewis \& B. K. Rimer 
(Eds.), Health behavior and health education (2 ed., Pp. 85-I I2). San Francisco: Jossey-Bass Inc.

Nicklas, T., Johnson, C. C., Myers, L., Farris, R. P., \& Cunningham, A. (1998). Outcomes of a high school program to increase fruit and vegetable consumption: Gimme 5. A fresh nutrition concept for students. Journal of School Health, 68, 248-263.

Nutbeam, D. (1996). Achieving 'best practice' in health promotion: Improving the fit between research and practice. Health Education Research, II, 3I7-326.

Nutrition and Physical Activity Branch. (2006). Healthy School Canteen Strategy Evaluation Report 2005. Sydney: NSW Department of Health.

Ouelette, J. A., \& Wood, W. (1998). Habit and Intention in Everyday Life:The Multiple Processes by which Past Behavior Predicts Future Behavior. Psychological Bulletin, I24, 54-74.

Paulussen, T., Kok, G., \& Schaalma, H. (1994). Antecedents to adoption of classroombased AIDS education in secondary schools. Health Education Research, 9, 485496.

Paulussen, T. G. W. (1994). Adoption and Implementation of AIDS Education in Dutch Secondary Schools. University of Maastricht, Maastricht.

Pérez-Rodrigo, C., Wind, M., Hildonen, C., Bjelland, M., Aranceta, J., Klepp, K.-I., \& Brug, J. (2005). The Pro Children Intervention: Applying the Intervention Mapping Protocol to Develop a School-based Fruit and Vegetable Promotion Programme. Annals of Nutrition \& Metabolism, 49, 267-277.

Perry, C. (2000). Preadolescent and adolescent influences on health. In B. D. Smedley \& S. L. Syme (Eds.), Promoting Health: Intervention Strategies from Social and Behavioral Research. Washington D.C.: National Academy Press.

Perry, C., Bishop, D., Taylor, G., Murray, D., Warren Mays, R., Dudovitz, B., Smyth, M., \& Story, M. (1998). Changing Fruit and Vegetable Consumption among Children: The 5-a-day Power Plus Program in St.Paul, Minnesota. American Journal of Public Health, 88, 603-609.

Peterson, R. A. (1994). A Meta-Analysis of Cronbach's Coefficient Alpha. Journal of Consumer Research, 21, 381-39I. 
Petty, R. E., \& Cacioppo, J. T. ( 1986). From Communication and persuasion: Central and peripheral routes to attitude change. New York: Springer-Verlag.

Pomerleau, J., Lock, K., Knai, C., \& McKee, M. (2005). Effectiveness of interventions and programmes promoting fruit and vegetable intake. Geneva, Switzerland: WHO.

Potvin, L., Haddad, S., \& Frohlich, K. L. (200I). Beyond process and outcome evaluation: a comprehensive approach for evaluating health promotion programmes. In I. Rootman \& M. Goodstadt \& B. Hyndman \& D. V. McQueen \& L. Potvin \& J. Springett \& E. Ziglio (Eds.), Evaluation in Health Promotion: principles and perspectives. Copenhagen: WHO Regional Publications, European Series;No.92.

Rasbash, J., Browne, W., \& Goldstein, H. (2000). A user's guide to MLwiN Version 2.I . London: Institute of Education, University of London.

Rasmussen, M., Krolner, R., Klepp, K.-I., Lytle, L., Brug, J., Bere, E., \& Due, P. (2006). Determinants of fruit and vegetable consumption among children and adolescents: a review of the literature. Part I: quantitative studies. International Journal of Behavioral Nutrition and Physical Activity, 3.

Resnicow, K., Davis, A., Smith, M., Lazarus-Yaroch, A., Baranowski, T., Baranowski, J., Doyle, C., \& Wang, D. T. (1998). How best to measure implementation of school health curricula: a comparison of three measures. Health Education Research, 13, 239-250.

Resnicow, K., Davis, M., Smith, M., Baranowski, T., Lin, L. S., Baranowski, J., Doyle, C., \& Wang, D. T. (1997). Social-Cognitive predictors of Fruit and Vegetable Intake in Children. Health Psychology, 16, 272-276.

Reubsaet, A., Reinaerts, E. B. M., Brug, J., van Hooff, J. P., \& van den Borne, H. W. (2004). Process evaluation of a school-based education program about organ donation and registration, and the intention for continuance. Health Education Research, 19, 720-729.

Reynolds, K., Franklin, F., Binkley, D., Raczynski, J., Harrington, K., Kirk, K., \& Person, S. (2000). Increasing the Fruit and Vegetable Consumption of Fourth-Graders: Results from the High 5 Project. Preventive Medicine, 30, 309-3I 9.

Reynolds, K., Franklin, F., Leviton, L. C., Maloy, J., Harrington, K. F., L.Yaroch, A., Person, S., \& Jester, P. (2000). Methods, Results, and Lessons Learned From 
Process Evaluation of the High 5 School-based Nutrition Intervention. Health Education \& Behavior, 27, 177-186.

Reynolds, K., Hinton, A. W., Shewchuk, R., \& Hickey, C. A. (1999). Social Cognitive Model of Fruit and Vegetable Consumption in Elementary School Children. Journal of Nutrition Education, 3I, 23-30.

Robinson, T. N., \& Sirard, J. R. (2005). Preventing childhood obesity: A solutionoriented research paradigm. American Journal of Preventive Medicine 28, $194-$ 201.

Rogers, E. M. (2002). Diffusion of preventive innovations. Addictive Behaviors, 27, 989 993.

Rogers, E. M. (2003). Diffusion of Innovations (5th ed.). New York: Free Press.

Rosenstock, I. (1974). Historical Origins of the Health Belief Model. Health Education Monographs, 2.

Rossi, P. H., Freeman, H. E., \& Lipsey, M. W. (1999). Evaluation : a systematic approach (6th ed.). Thousand Oaks, CA [etc.] Sage Publications.

Rychetnik, L., Frommer, M., Hawe, P., \& Shiell, A. (2002). Criteria for evaluating evidence on public health interventions. Journal of Epidemiology \& Community Health, 56, I19-127.

Sallis, J. F., \& Owen, N. (1997). Ecological models. In K. Glanz \& F. M. Lewis \& B. K. Rimer (Eds.), Health Behavior and Health Education: Theory, Research and Practice (2 ed., pp. 403-424). San Francisco: Jossey-Bass Inc.

Sandeno, C., Wolf, G., Drake, T., \& Reicks, M. (2000). Behavioral strategies to increase fruit and vegetable intake by fourth- to sixth-grade students. Journal of the American Dietetic Association, 100, 828-830.

Shrout, P. E., \& Bolger, N. (2002). Mediation in Experimental and Nonexperimental Studies: New Procedures and Recommendations. Psychological Methods, 7, 422-445.

Snijders, T. A. B., \& Bosker, R. J. (1999). Multilevel analyses. An introduction to basic and advanced multilevel modelling. London: Sage.

St Leger, L. (1999). The opportunities and effectiveness of the health promoting primary school in improving child health - a review of claims and evidence. Health Education Research, 14, 51-69. 
St Leger, L., \& Nutbeam, D. (1999). Evidence for effective health promotion in schools. In D. Boddy (Ed.), The Evidence of Health Promotion Effectiveness Shaping Public Health in a New Europe (Pp. I 10-122). Brussels: European Union.

Stokols, D. (1992). Establishing and Maintaining Healthy Environments: Toward a Social Ecology of Health Promotion. American Psychologist, 47, 6-22.

Story, M., Warren-Mays, R., Bishop, D. B., Perry, C. L., Taylor, G., Smyth, M., \& Gray, C. (2000). 5-a-day Power Plus: Evaluation of a Multicomponent Elementary School Program to Increase Fruit and Vegetable Consumption. Health Education and Behavior, 27, 187-200.

Tabachnick, B. G., \& Fidell, L. S. (1996). Using Multivariate Statistics (third ed.). Northridge: Harper Collins College Publishers.

Tak, N. I., te Velde, S. J., \& Brug, J. (2007). Ethnic differences in one-year follow-up effect of the Dutch Schoolgruiten Project - promoting fruit and vegetable consumption among primary schoolchildren. Public health nutrition, 10 I4971507.

Tak, N. I., te Velde, S. J., de Vries, J. H. M., \& Brug, J. (2006). Parent and child reports of fruit and vegetable intakes and related family environmental factors show low levels of agreement. Journal of Human Nutrition and Dietetics, 19, 275-285.

Thomson, C. A., Giuliano, A., Rock, C. L., Ritenbaugh, C., Flatt, S. W., Faerber, S., Newman, V., Caan, B., Graver, E., Hartz, V., Whitacre, R., Parker, F., Pierce, J. P., \& Marshall, J. R. (2003). Measuring Dietary Change in a Diet Intervention Trial: Comparing Food Frequency Questionnaire and Dietary Recalls. American Journal of Epidemiology, 157, 754-762.

Twisk, J. (2005). Applied Longitudinal Data Analysis for Epidemiology: A practical guide. Cambridge: Cambridge University Press.

van Assema, P., Brug, J., \& Lechner, L. (200I). Voedingsgedrag en de primaire preventie van kanker: de promotie van groente en fruit [Eating behavior and the primary prevention of cancer: Promotion of fruit and vegetables]. Tijdschrift Sociale Gezondheidszorg, 79, 346-355.

van Assema, P., Brug, J., Ronda, G., Steenhuis, I., \& Oenema, A. (2002). A short Dutch questionnaire to measure fruit ad vegetable intake: relative validity among adults and adolescents. Nutrition \& Health, 16, 85-106. 
van Assema, P., Glanz, K., Martens, M. K., \& Brug, J. (2007). Differences between parents'and adolescents'perceptions of family food rules and availability. Journal of Nutrition Education and Behavior, 39, 34-39.

van Buuren, S. (2004). Afkapwaarden van de 'body-mass index' voor ondergewicht van Nederlandse kinderen [Body Mass Index-standards regarding underweight for Dutch Children]. Nederlands Tijdschrift voor de Geneeskunde, I48, 1967-1972.

van Empelen, P., \& Kok, G. (2006). Condom use in steady and casual sexual relationships: Planning, preparation and willingness to take risks among adolescents. Psychology \& Health, 2I, I65-I8I.

van Zadellhoff, W. M., \& Snel, J. H. (2003). Achtergronden van groente- en fruitconsumptie in achterstandswijken in Arnhem en Tilburg [Insights into the fruit- and vegetable consumption in low SES neighbourhoods in Arnhem and Tilburg]. Den Haag: Voedingscentrum [Netherlands Nutrition Centre].

Vereecken, C. A., van Damme, W., \& Maes, L. (2005). Measuring attitudes, self-efficacy, and social and environmental influences on fruit and vegetable consumption of I I- and I2-year-old children: Reliability and Validity. Journal of the American Dietetic Association, 105, 257-26I.

Verplanken, B. (2006). Beyond frequency: Habit as a mental construct. British Journal of Social Psychology, 45, 639-656.

Verplanken, B., \& Aarts, H. (1999). Habit, Attitude and Planned Behavior: Is habit an empty Construct or an Interesting Case of Goal-directed Automaticity? European Review of Social Psychology, 10, $101-134$.

Verplanken, B., \& Faes, S. (1999). Good Intentions, Bad Habits, and effects of forming Implementation Intentions on Healthy Eating. European Journal of Social Psychology, 29, 59I-604.

Verplanken, B., \& Orbell, S. (2003). Reflections on Past Behavior: A Self-Report Index of Habit Strength. Journal of Applied Social Psychology, 33, I3। 3-1330.

Verplanken, B., \& Wood, W. (2006). Interventions to Break and Create Consumer Habits. Journal of Public Policy \& Marketing, 25, 90-I03. 
Voedingscentrum [Netherlands Nutrition Centre]. (2004). Schoolgruiten [Fruit and Vegetables at school campaign]. Retrieved 03-05, 2007, from the World Wide Web:

http://www.voedingscentrum.nl/voedingscentrum/Public/Statisch/English+sum mary/Fruit+and+vegetables+at+School+campaign.htm

Wanous, J. P., \& Reichers, A. E. (1996). Estimating the reliability of a single-item measure. Psychological Reports, 78, 631-634.

Wanous, J. P., Reichers, A. E., \& Hudy, M. J. (1997). Overall job satisfaction: How good are single-item measures? Journal of Applied Psychology, 82, 247-252.

Wardle, J., Cooke, L. J., Leigh Gibson, E., Sapochnik, M., Sheiham, A., \& Lawson, M. (2003). Increasing children's acceptance of vegetables: A randomized trial of parent-led exposure. Appetite, 40, 155-162.

Wardle, J., Herrera, Cooke, L. J., \& Gibson, E. L. (2003). Modifying children's food preferences: the effects of exposure and reward on acceptance of an unfamiliar vegetable. European Journal of Clinical Nutrition, 57, 34I-348.

Weber Cullen, K., Baranowski, T., Owens, E., Marsh, T., Rittenberry, L., \& deMoor, C. (2003). Availability, Accessibility, and Preferences for Fruit, 100\% Fruit Juice, and Vegetables Influence Children's Dietary Behavior. Health Education and Behavior, 30, 615-626.

Weber Cullen, K., Baranowski, T., Rittenberry, L., Cosart, C., Hebert, D., \& de Moor, C. (200I). Child-reported Family and Peer Influences on Fruit, Juice and Vegetable Consumption: Reliability and Validity of Measures. Health Education Research, 16, p.187-200.

Weber Cullen, K., Baranowski, T., Rittenberry, L., \& Olvera, N. (2000). Socialenvironmental influences on children's diets: results from focus groups with African-, Euro- and Mexican-American children and their parents. Health Education Research, 15, 581-590.

Weber Cullen, K., Bartholomew, L. K., Parcel, G. S., \& Kok, G. (1998). Intervention Mapping: Use of Theory and Data in the Development of a fruit and vegetable nutrition Program for Girl Scouts. Journal of Nutrition Education, 30, I88-195. 
Weber Cullen, K., Watson, K., Zakeri, I., \& Ralston, K. (2006). Exploring changes in middle-school student lunch consumption after local food service policy modifications. Public health nutrition, 9, 814-820.

Wells, J., Barlow, J., \& Stewart-Brown, S. (2003). A systematic review of universal approaches to mental health promotion in schools. Health Education, 103, $197-$ 220.

Wells, L., \& Nelson, M. (2005). The National School Fruit Scheme produces shortterm but no longer-term increases in fruit consumption in primary school children. British Journal of Nutrition, 93, 537-542.

WHO. (2003). Diet, Nutrition and the Prevention of Chronic Diseases (WHO Technical Report Series 916). Geneva: World Health Organization.

WHO. (2004). Global Strategy on Diet, Physical Activity and Health Geneva: World Health Organization.

Wind, M., Bobelijn, K., De Bourdeaudhuij, I., Klepp, K.-I., \& Brug, J. (2005). A

Qualitative Exploration of Determinants of Fruit and Vegetable Intake among I0- and II-Year-Old Schoolchildren in the Low Countries. Annals of Nutrition \& Metabolism, 49, 228-235.

Wind, M., de Bourdeaudhuij, I., te Velde, S. J., Sandvik, C., Due, P., Klepp, K. I., \& Brug, J. (2006). Correlates of fruit and vegetable consumption among I I-year-old Belgian-Flemish and Dutch schoolchildren. Journal of Nutrition Education and Behavior, 38, $21 \mathrm{I}-221$.

Wind, M., Te Velde, S. J., Hildonen, C., Bjelland, M., Perez-Rodrigo, C., Klepp, K. I., \& Brug, J. (2006). The development, implementation and evaluation of a school-based intervention to promote fruit and vegetable intake among 10-13 year old European schoolchildren [thesis]. Rotterdam: Erasmus MC.

Wind, M., Zadellhoff, v. W. M., Snel, J. H., Ham, v. d. E., \& Brug, J. (2004). Groente- en fruitconsumptie van basisschoolkinderen bevorderen. Voeding Nu, Maart, 2 I23.

Wood, W., Witt, M. G., \& Tam, L. (2005). Changing Circumstances, Disrupting Habits. Journal of Personality and Social Psychology, 88, 918-933.

Yngve, A., Wolf, A., Poortvliet, E., Elmadfa, I., Brug, J., Ehrenblad, B., Franchini, B., Haraldsdottir, J., Krolner, R., Maes, L., Perez-Rodrigo, C., Sjostrom, M., 
Thorsdottir, I., \& Klepp, K.-I. (2005). Fruit and Vegetable Intake in a Sample of II-Year-Old Children in 9 European Countries: The Pro Children CrossSectional Survey. Annals of Nutrition \& Metabolism, 49, 236-245.

Young, E. M., Fors, S. W., \& Hayes, D. M. (2004). Associations between perceived parent behaviors and middle school student fruit and vegetable consumption. Journal of Nutrition Education and Behavior, 36, 2-12.

Zaltman, G., \& Duncan, R. (1977). Strategies for planned change. New York: Wiley. 


\section{Summary \& Samenvatting}




\section{SUMMARY}

It is well-known that consuming sufficient amounts of fruit and vegetables (F\&V) is preventive for the development of several chronic diseases. Nevertheless, Dutch children, aged 4 tol 2 years, consume less F\&V than recommended. Steps must be taken to increase children's F\&V intake, especially since the adoption of a healthy lifestyle in childhood is associated with health and well-being in adulthood. Considering that dietary habits such as F\&V consumption have been shown to persist throughout life, attempts to increase children's F\&V consumption could be more efficient than interventions aimed at adults who developed a habit of their low consumption patterns.

The present dissertation describes the development and evaluation of two primary school-based interventions aimed at increasing children's F\&V consumption. The first part of this dissertation (Chapters I, 2, 3 and 4) describes the development of the interventions, based on literature, theory and the results of two determinant studies. The second part of this dissertation (Chapter 5, 6 and 7) focuses on the impact and process evaluation of the implementation of two programs. The dissertation concludes with a summary and an integration of the main findings, as well as a discussion of the methodological issues and implications for future research and practice.

In the first chapter the needs assessment and the development, implementation and evaluation of both interventions according to the IM protocol is described. The application of the protocol resulted in two school-based interventions aimed at making F\&V consumption habitual for children: (I) a free F\&V distribution program, and (2) a multi-component, age-specific program consisting of a classroom curriculum and parental involvement. During the IM process, a lack of relevant literature regarding determinants of F\&V consumption of young Dutch children was discovered. Therefore, two additional determinant studies were conducted among Dutch children aged 4 to 12 and their parents.

The results of the first determinant study, a qualitative study on the perceptions of Dutch children and their parents, are presented in Chapter 2. Group interviews were conducted with children $(n=104)$ and parents $(n=28)$ and a total of ten 
parents participated in an interview by telephone. Several factors that are likely to increase F\&V consumption of the participants were identified, such as preferences, modelling of F\&V consumption by teachers and parents and availability of F\&V in readyto-eat form at home and school. Although both children and parents favoured activities to promote F\&V at school, most parents were not willing to participate in these activities.

In addition to the qualitative study, the results of a quantitative cross-sectional survey among parents $(n=1739)$ of 4 to 12 year old children are presented in Chapter 3. The contributions of factors such as parental F\&V consumption, availability and accessibility of F\&V in the home, exposure to $F \& V$, and habit were studied in addition to more general psychosocial factors. The results showed that the models that included the additional factors explained both fruit and vegetable consumption better. Habit was identified as most influential correlate of F\&V consumption. Furthermore, it was demonstrated that the consumption of fruit and that of vegetables are clearly different behaviours, with different influencing factors for boys and girls and children of native and non-native background.

The last chapter of the first part of this dissertation (Chapter 4) deals with issues related to the measurement of F\&V consumption using either reporting by the children themselves or reporting by parents whereby parents act as a proxy. The results of a study comparing parental and child perceptions of children's F\&V intake and family-related factors $(n=37 \mathrm{I})$ indicated weak agreement for F\&V consumption but no differences in mean consumption of fruit at the group level. Regarding the familyenvironmental factors related to fruit consumption, significant differences were found between the perceptions of subjective norm, and the availability and accessibility of fruit. Perceptions of subjective norm, parental modelling and exposure regarding vegetable consumption were also viewed differently by the two groups. The familyenvironmental factors reported by the children were similarly associated with F\&V consumption compared to those reported by their respective parents. However, parents rated these factors more favourably than their children did.

In Chapter 5, the short-term effects of the intervention are presented. Multilevel analyses showed that both programs were equally effective in increasing children's fruit consumption with 0.2 portions per day. The free F\&V distribution increased 
vegetable intake among non-native children and the oldest children, and the multicomponent program among the oldest children and girls. The distribution also caused an increased consumption of $24 \mathrm{~h}$ fruit, juice and vegetable intake among the youngest and the oldest age groups, and the multi-component program among all children. It was concluded that although both interventions showed to be effective for different subgroups, the distribution program showed to be the more effective intervention, especially in increasing vegetable consumption.

The long term effects were measured one year after the termination of the interventions and are described in Chapter 6. The results showed that the effects of both interventions did not differ between the two follow-up measurements. Similar to the results described in Chapter 5, we found that both programs were equally effective in increasing children's fruit consumption over time. The distribution program also increased children's vegetable consumption over time, even after repeating the analyses using a pessimistic scenario. It was concluded that the distribution program could be considered most effective intervention.

Chapter 7 deals with the process evaluation. The implementation, evaluation and potential for adoption of the two interventions are described and compared. A total of 48 teachers who worked with either of these programs participated in this study. Results showed that compared to the F\&V distribution, the multi-component program was less fully implemented and that implementation of activities decreased over time. Both programs were evaluated favourably and about half of the teachers indicated that they were willing to use the program again in the following school year. Teachers who used the multi-component program experienced more social pressure to implement the program. They rated the program they had used as more complex than the teachers who used the distribution program. It was concluded that the free distribution program has the greatest potential for being adopted by school teachers.

This dissertation concludes with a general discussion in which the main findings are summarized and integrated. Methodological issues related to the research designs and data collection procedures, and implications for future research and practice are discussed. 


\section{SAMENVATTING}

Hoewel het bekend is dat het eten van voldoende groente en fruit allerlei chronische ziekten helpt voorkomen, consumeren Nederlandse kinderen in de leeftijd van 4 tot en met I 2 jaar minder G\&F dan aanbevolen. Het is daarom noodzakelijk stappen te ondernemen om de G\&F consumptie van deze kinderen te vergroten. Des te meer omdat een gezonde leefstijl tijdens de kindertijd geassocieerd is met gezondheid en welzijn als volwassene. Aangezien onderzoek heeft aangetoond dat voedingsgewoonten zoals de consumptie van G\&F meestal gedurende het hele leven aanhouden, is het efficiënter om te proberen de G\&F consumptie van kinderen te verhogen in plaats van interventies te richten op volwassenen die vaak al een gewoonte hebben gemaakte van hun lage G\&F consumptie.

In het eerste deel van het proefschrift (hoofdstuk I, 2, 3 en 4) wordt de ontwikkeling van twee interventies, gebaseerd op literatuur, theorie en de resultaten van twee determinanten studies, beschreven. Het tweede deel van dit proefschrift (hoofdstuk 5,6 en 7) is gericht op the impact- en procesevaluatie van deze interventies. Het proefschrift wordt afgesloten met een samenvatting en een integratie van de belangrijkste bevindingen, evenals een discussie van de methodologische beperkingen en implicaties voor toekomstig onderzoek en de praktijk.

In het eerste hoofdstuk worden de behoefteverkenning (needs assessment) en de ontwikkeling, implementatie en evaluatie van beide interventies beschreven aan de hand van het Intervention Mapping protocol (IM). Het toepassen van dit protocol heeft geresulteerd in twee interventies die gericht waren op het tot gewoontegedrag maken van G\&F consumptie, namelijk ( $I$ ) een gratis G\&F verstrekking op school, en (2) een leeftijdsspecifiek programma bestaande uit meerdere componenten, zoals een lesprogramma en betrokkenheid van de ouders. Tijdens het doorlopen van het IM proces werd er een lacune in relevante literatuur met betrekking tot determinanten van de G\&F consumptie van jonge Nederlandse kinderen vastgesteld. Daarom werden er twee additionele determinantenonderzoeken uitgevoerd onder Nederlandse kinderen in de leeftijd van $4 \mathrm{t} / \mathrm{m} 12$ jaar.

De resultaten van de eerste studie, een kwalitatief onderzoek naar de percepties van Nederlandse kinderen en hun ouders met betrekking tot G\&F, worden 
beschreven in hoofdstuk 2 .Voor deze studie werden groepsinterviews met kinderen $(n=104)$ en hun ouders $(n=28)$ uitgevoerd. Daarnaast namen tien ouders deel aan een telefonisch interview. Factoren die de G\&F consumptie van de deelnemers zouden kunnen verhogen werden geïdentificeerd. Voorbeelden hiervan zijn smaakvoorkeuren, modelling van G\&F consumptie door de leerkrachten en de ouders en hapklare beschikbaarheid van G\&F thuis en op school. Hoewel zowel kinderen als ouders voorstander waren van meer aandacht voor G\&F op school, bleken de meeste ouders niet bereid om deel te nemen aan dit soort activiteiten.

In aanvulling op de kwalitatieve studie, worden in hoofdstuk 3 de resultaten beschreven van een kwantitatief dwarsdoorsnede onderzoek onder ouders $(n=1739)$ van 4 t/m 12 jaar oude kinderen. Hierin werd de bijdrage van G\&F consumptie van de ouders, beschikbaarheid en toegankelijkheid van G\&F thuis, blootstelling aan G\&F en gewoontegedrag onderzocht, in aanvulling op de meer algemene psychosociale factoren. Uit de resultaten bleek dat de modellen mèt deze additionele factoren zowel de consumptie van groente als van fruit beter verklaarden. Gewoontegedrag werd geïdentificeerd als invloedrijkste factor m.b.t. de consumptie van G\&F. Ook werd aangetoond dat de consumptie van groente en de consumptie van fruit duidelijk twee verschillende gedragingen zijn met verschillende bijbehorende beïnvloedende factoren voor jongens en meisjes, autochtone en allochtone kinderen.

In het laatste hoofdstuk van het eerste deel van dit proefschrift (hoofdstuk 4) worden problemen bij het meten van G\&F consumptie bij kinderen behandeld, wanneer gebruik gemaakt wordt van de kinderen zelf of van de ouders als bron van rapportage. De resultaten van deze studie waarbij de perceptie van de G\&F consumptie van het kind en gezinsgerelateerde factoren tussen ouder en kind werden vergeleken, toonden dat er een lage overeenstemming tussen kind en ouder bestond wat betreft G\&F consumptie. Op groepsniveau werden er echter geen verschillen in de gemiddelde consumptie van fruit gevonden. Wat betreft de familiegerelateerde factoren ten aanzien van fruit consumptie, werden er verschillen in perceptie gevonden voor subjectieve norm en de beschikbaarheid en toegankelijkheid van fruit. Met betrekking tot de groente consumptie werden subjectieve norm, modelling door de ouders en blootstelling verschillend waargenomen door de twee groepen. De familiegerelateerde factoren die door de kinderen zelf werden gerapporteerd 
vertoonden dezelfde associaties met G\&F consumptie als de factoren gerapporteerd door de ouders. Desondanks beoordeelden de ouders deze factoren positiever dan hun kinderen. In hoofdstuk 5 worden de korte termijn effecten van de interventies gepresenteerd. De multilevel analyses toonden aan dat beide programma's in gelijke mate effectief waren in het verhogen van de fruit consumptie (ongeveer 0.2 porties per dag). Het gratis distributie programma bleek daarnaast ook de groenteconsumptie van allochtone kinderen en de oudste kinderen te verhogen, terwijl het multicomponenten programma dit deed voor de oudste kinderen en meisjes. Het distributieprogramma verhoogde ook de 24uurs groente, fruit and sapconsumptie van de jongste en de oudste leeftijdsgroep. Het multi-componenten programma deed dit voor alle kinderen. Geconcludeerd werd dat, hoewel beide interventies effectief bleken voor verschillende subgroepen, de distributie de meest effectieve interventie van de twee was in het bijzonder doordat door deze interventie ook de groenteconsumptie verhoogd werd.

Een jaar na het aflopen van beide interventies werden de effecten op de lange termijn gemeten. Deze worden beschreven in hoofdstuk 6. De resultaten lieten zien dat de effecten van beide interventies op de eerste nameting niet verschilden van de tweede nameting. Net zoals in hoofdstuk 5 vonden we dat beide programma's even effectief waren in het verhogen van de fruitconsumptie in de tijd. Door het distributieprogramma werd ook de groenteconsumptie op de lange termijn verhoogd. Zelfs wanneer de analyses werden herhaald met een pessimistisch scenario. Er werd geconcludeerd dat het distributieprogramma gezien moest worden als de beste interventie.

In hoofdstuk 7 wordt de procesevaluatie van het onderzoek beschreven. De implementatie, waardering en de kans dat de interventies zouden worden gebruikt werden vergeleken voor de twee interventies. In totaal namen 48 leerkrachten die gewerkt hadden met één van beide programma's deel aan de studie. Uit de resultaten bleek dat het multi-componenten programma minder volledig was geïmplementeerd dan het distributieprogramma. Verder bleek dat de activiteiten van het multicomponenten programma minder compleet werden uitgevoerd naarmate het programma langer liep. Beide programma's werden positief geëvalueerd en ongeveer de helft van de leerkrachten gaf aan dat zij bereid waren om het programma in het 
volgende schooljaar weer te gebruiken. Leerkrachten die gebruik hadden gemaakt van het multi-componenten programma ervoeren meer sociale druk om het programma uit te voeren. Daarnaast vonden zij het programma complexer om uit te voeren dan de leerkrachten het distributieprogramma vonden. Er werd geconcludeerd dat het distributieprogramma een grotere kans had om te worden gebruikt door de leerkrachten dan het multi-componenten programma. Dit proefschrift wordt afgesloten met een algemene discussie, waarin de belangrijkste resultaten worden samengevat en geïntegreerd. Methodologische beperkingen met betrekking tot het design van de studie en de methoden van dataverzameling worden besproken, evenals implicaties voor toekomstig onderzoek en toepassing in de praktijk. 


\section{Dankwoord, Curriculum Vitae \& Publication list}




\section{DANKWOORD}

Ho, ho... Stop maar met bladeren! Je hebt het gevonden. Het deel van mijn proefschrift dat waarschijnlijk het meest gelezen gaat worden: Het dankwoord.

"The spirit is there in everyone; it has to be discovered and brought to the light."

Met deze quote van Lord Baden Powell begin ik mijn proefschrift en hier wil ik ook graag mee afsluiten. Ik kan mijzelf namelijk ontzettend herkennen in wat deze man ergens begin 1900 al vaststelde. Ik wil aan het einde van dit proefschrift dan ook alle mensen bedanken die mij geholpen hebben de 'spirit' te ontdekken en meer uit mezelf te halen dan ik zelf ooit voor mogelijk gehouden had.

Jascha, jou wil ik graag al eerste bedanken. Een betere begeleidster als jij kan een beginnend wetenschapper zich niet wensen. Bedankt voor al je steun, motivatie en je kritische blik. Gedurende de vijf jaar dat we hebben samengewerkt is onze relatie veranderd van mentorschap naar vriendschap. $\mathrm{lk}$ hoop dat dit nog lang zo mag blijven. Nanne, ik heb onze gesprekken altijd als zeer waardevol beschouwd. Met zijn drieën om de tafel, ik met mijn lijstje met 'agendapunten' en vragen, en dan maar discussiëren. Meer dan eens stapte ik na een uur of twee geïnspireerd en met allerlei nieuwe onderzoeksideeën je kamer uit. Helaas had ik dan ook weer meer vragen dan aanvankelijk op mijn lijstje stonden. Nanne ontzettend bedankt voor je steun en begeleiding. Ik hoop dat we in de toekomst wegen kunnen vinden om onze samenwerking te continueren. Angelique, mijn begeleidster van de GGD, bedankt voor al je steun en hulp bij het uitvoeren van het praktische gedeelte. Ik denk nog met veel plezier aan alle autoritten, schoolbezoekjes en overleggen terug. Jij hebt me geleerd om de onderzoeksmogelijkheden in de praktijk te zien. Ik ben ontzettend blij dat jullie het in 2002 aandurfden om met een enthousiaste studente, die vooral erg veel zin had om interventies te ontwikkelen, een promotietraject in te laten gaan. Bedankt voor deze kans!

Voor het tot stand komen van de interventies hebben ontzettend veel mensen zich ingezet. De 'oude' Hartslagclub: Karin bedankt voor al je praktische hulp 
bij het selecteren van de scholen en het uitvoeren van de procesevaluatie. Vivian door jouw 'Vita \& Froet' ging het project leven. Je gaf de interventies een gezicht dat zowel de ouders als de kinderen aansprak. Dames, bedankt voor de gezellige uurtjes bij de GGD. Ook wil ik alle directieleden, leerkrachten, ouders en kinderen van De Zonnewijzer, Het Mozaïek, Het Ankertje-Kompas, St. Martinus, De Uitkijktoren, De Sjans en De Steenen Brug danken voor hun enthousiaste deelname. Een speciaal woord van dank gaat uit naar de mensen die bereid waren zitting te nemen in de contactgroep. Ook de deelnemende controlescholen te weten De Bongerd, De Flierefluit, De Springbeek, Maria, Onder de Wieken en St.Martinus (Venlo) wil ik hierbij van harte danken voor hun deelname. En natuurlijk wil ik Marga van de Schurenhof niet vergeten. Jij zorgde ervoor dat alle scholen hun groente en fruit hapklaar kregen aangeleverd en zelfs niet twee keer een appel per week. Ik wil niet weten hoeveel kilo's koolsalade jij hebt staan raspen voor het 'goede' doel. Dankzij jouw inzet is het project een groot succes geworden. Gerrit en Patries jullie muzikale genialiteit heeft geresulteerd in een heus projectlied voor de kleuters. Er zullen vast veel kleuters hebben staan 'wiebelen met hun kont', omdat groente en fruit gezond is.

Ook bij het uitvoeren van het onderzoek hebben veel mensen op de een of andere manier een belangrijke bijdrage geleverd. De medewerkers van het MEMIC wil ik bedanken voor het handmatig invoeren van alle data. Math Candell, bedankt voor je hulp bij het verkennen van de wereld van de multi-level analyse en het bekritiseren van mijn artikelen. Jij beheerst de kunst om zelfs de ingewikkelste statistiek begrijpelijk te maken! Rik bedankt voor je hulp bij het analyseren van de lange termijn effecten en Marja voor het leescommissieklaar maken van de manuscripten. Jullie hebben er mede voor gezorgd dat het proefschrift 'weg' was voordat Floor geboren werd.

In de afgelopen jaren heb ik heel wat collega's zien vertrekken en er ook een heleboel nieuwe voor teruggekregen. Ik wil jullie allemaal bedanken voor de gezellige jaren bij GVO. Ik heb de aio's altijd gezien als één grote zelfhulpgroep, waarbij je met al je frustraties terecht kon en altijd steun kon krijgen. Margien, Bilbo, Evelien, Emely, Rik, Astrid, Tamara, Froukje en de rest bedankt voor de talloze gezellige momenten!

En dan...mijn paranimfen: Froukje en Tamara. Woorden kunnen niet uitdrukken hoe fijn ik het vind dat jullie mij bij willen staan tijdens (waarschijnlijk) één 
van de meest stressvolle momenten van mijn leven. Ik hoop dat er nog veel hylarische 'weekendjes weg' zullen volgen, inclusief kapotte auto's en ingesneeuwde bungalows.

Tot slot ... Lieve vrienden en familie. "Hoe is het met de 'groente en het fruit'? ", is een vraag die ik de afgelopen jaren veelvuldig heb gehoord. Bedankt voor jullie oprechte interesse in mijn werk. Ik kan jullie nu meedelen dat het klaar is met de 'groente en het fruit'. Pap en mam als iemand ervoor gezorgd heeft dat ik het beste uit mezelf heb gehaald dan zijn jullie het wel. Dankjewel voor jullie vertrouwen. Ik hoop dat Floor later net zo blij is met Pat en mij als ik ben met jullie! Tenslotte Pat zonder jou was het nooit gelukt om dit boekje te schrijven. Niemand voelt mij zo goed aan als jij. Wat zijn wij een goed setje, hè! 


\section{CURRICULUM VITAE}

Eveline Bertie Mattie Reinaerts was born on October 18, 1977 in Heerlen, the Netherlands. After graduating from secondary school (VWO) at the Rombouts College in Brunssum, she studied Nursing at the Hogeschool Zuyd in Heerlen and graduated in 2000. She finished her study Health Sciences at the Universiteit Maastricht within the next two years, with a major in Health Education and Promotion. In January 2003, she started working as a PhD-student at the Department of Health Promotion and Health Education at the Faculty of Health Sciences of the Universiteit Maastricht on a project entitled: 'Two portion of fruit and 200 grams of vegetables! Naturally...'. The studies that were conducted as part of this project resulted in the present dissertation. From July till December 2007, she was engaged in teaching at the Department of Health Education and Health Promotion. Since January 2008, she is working as lecturer and researcher at the Academy Verloskunde Maastricht (AV-M). 


\section{PUBLICATION LIST}

Reinaerts, E., de Nooijer, J., van de Kar, A. and de Vries, N.K. (2006a), "Het meten van groente- en fruitconsumptie bij jonge kinderen (7-9 jaar): de DILQ-NL", Tijdschrift voor Jeugdgezondheidszorg, Vol. 6,

Reinaerts, E.B.M., de Nooijer, J., van de Kar, A. and de Vries, N.K. (2006b), "Development of a school-based intervention to promote fruit and vegetable consumption: Exploring perceptions among four-to-twelve year old children and their parents", Health Education, Vol. 106, No. 5, pp. 345-356.

Reinaerts, E., de Nooijer, J., Candel, M. and de Vries, N.K. (2007), "Explaining school children's fruit \& vegetable consumption: the contributions of availability, accessibility, exposure, parental consumption and habit in addition to psychosocial factors", Appetite, Vol. 48, pp. 248-258.

Reinaerts, E., de Nooijer, J. and de Vries, N.K. (2007), "Fruit and vegetable distribution program versus a multi-component program to increase F\&V consumption: which should be recommended for implementation?" Journal of School Health, Vol. 77, No.10, pp. 679-686.

Reinaerts, E.B.M., de Nooijer, J., Candel, M. and de Vries, N.K. (2007), "Increasing children's fruit and vegetable consumption: Distribution or multi-component programs?" Public Health Nutrition, Vol. 10, No.9, pp. 939-947.

Reinaerts, E., de Nooijer, J. and de Vries, N.K. (2007), " Parental versus child reporting of fruit \& vegetable consumption" International Journal of Behavioral Nutrition and Physical Activity, Vol.4, No.33.

Reinaerts, E. (2008), Groente- en fruitconsumptie kinderen omhoog door verstrekken of stimuleren?, Voeding $\mathrm{Nu}$, Vol. I0, No. I, pp. 32. 
Reinaerts, E., Crutzen, R., de Nooijer, J., Candel, M. and de Vries, N.K. (In Press), “Increasing fruit \& vegetable intake among children: comparing long-term effects of a free distribution and a multi component program" Health Education Research.

Reinaerts, E., de Nooijer, J. and de Vries, N.K. (In press), "The systematic development of two interventions aimed at increasing children's fruit and vegetable intake" Health Education.

Reubsaet, A., Reinaerts, E.B.M., Brug, J., van Hooff, J.P. and van den Borne, H.W. (2004), "Process evaluation of a school-based education program about organ donation and registration, and the intention for continuance", Health Education Research, Vol. 19, No. 6, pp. 720-729 
